\title{
Valutazioni imprenditoriali per la successione nell'impresa familiare
}

RICCARDO PASSERI

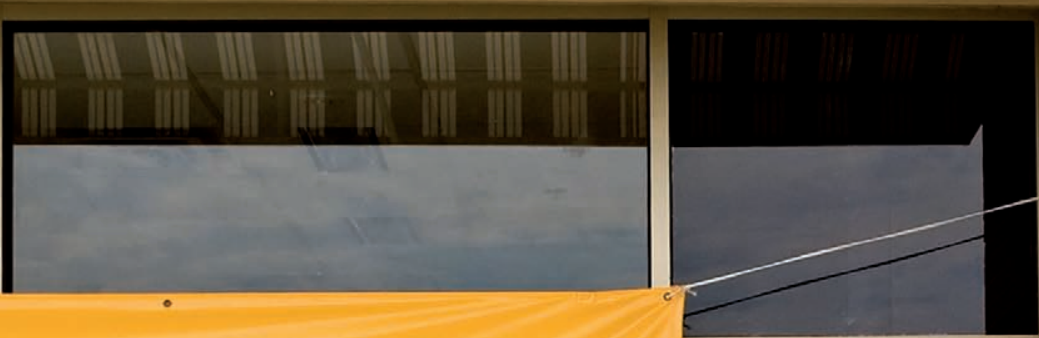

\section{Coming Soon!}
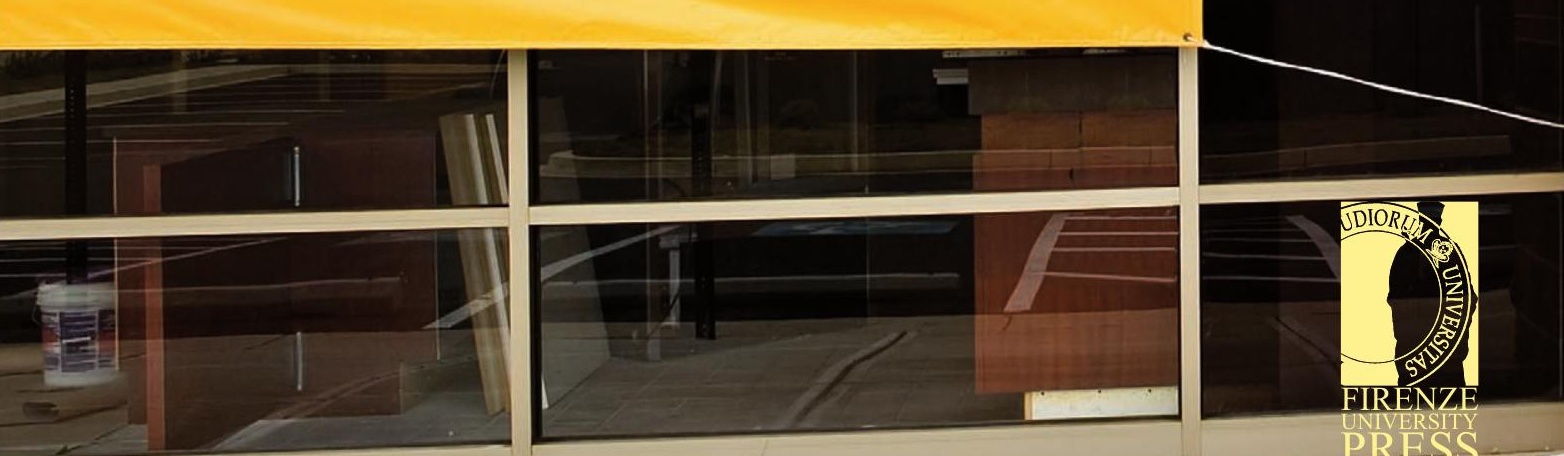
STRUMENTI

PER LA DIDATTICA E LA RICERCA 

Riccardo Passeri

\section{Valutazioni imprenditoriali per la successione nell'impresa familiare}

Firenze University Press 2007 
Valutazioni imprenditoriali per la successione nell'impresa familiare / Riccardo Passeri. - Firenze : Firenze University Press, 2007.

(Strumenti per la didattica e la ricerca)

http://digital.casalini.it/9788884537140

ISBN 978-88-8453-714-0 (online)

ISBN 978-88-8453-713-3 (print)

658.041 (ed. 20)

(C) 2007 Firenze University Press

Università degli Studi di Firenze

Firenze University Press

Borgo Albizi, 28, 50122 Firenze, Italy

http://www.fupress.com/

Printed in Italy 


\section{Indice}

$\begin{array}{ll}\text { Presentazione } & 7\end{array}$

$\begin{array}{ll}\text { INTRODUZIONE } & 9\end{array}$

Capitolo I

$\begin{array}{ll}\text { Il governo delle imprese familiari } & 11\end{array}$

Capitolo II

L'apertura della compagine sociale per lo sviluppo del capitalismo familiare

Capitolo III

La procedura successoria ed i suoi attori

Capitolo IV

La pianificazione della successione imprenditoriale 63

Capitolo V

Finanza straordinaria per la successione imprenditoriale 83

$\begin{array}{ll}\text { BIBLIOGRAFIA } & 101\end{array}$ 

Il fenomeno della successione imprenditoriale nell'impresa familiare risulta spesso problematico e complesso, richiede così di essere affrontato con adeguata pianificazione e conoscenza delle alternative strategiche-operative ideali a realizzarla. Dopo una ricognizione sugli aspetti relativi alla presa di coscienza dell'imprenditore, quindi alle sue valutazioni circa la necessità di programmare la propria successione, abbiamo delineato le fasi essenziali alla programmazione della stessa, fermandoci infine sulle possibili operazioni ritenute utili alla successione. Per ciascuna operazione poi si sono tracciate le principali caratteristiche, consapevoli che per ogni realtà aziendale è necessario modellare specifiche procedure.

Abbiamo rinunciato a risultanze empiriche maturate attraverso una specifica ricerca, perché le applicazioni concrete esaminate hanno evidenziato un'estrema flessibilità di correlazione fra iniziative di programmazione della successione e modalità operative seguite. Inoltre occorre ricordare che la natura giuridica di molte realtà aziendali familiari (società di persone), elude la possibilità di raccogliere dati ufficiali certi. Non per questo ce ne siamo astenuti, anzi stiamo realizzando un'indagine necessaria a mettere a fuoco una specifica metodologia che permetta di pervenire poi a risultati che confortino ed approfondiscano le idee esposte.

Per tale motivo la successione nell'impresa familiare è da noi presa in esame come evento modificativo dell'assetto imprenditoriale e non tanto come forma di trasferimento patrimoniale. Di conseguenza, solo in via subordinata potranno essere osservati alcuni aspetti inerenti ai rapporti giuridico-patrimoniali connessi all'evento in discorso.

È bene tener presente e ricordare che, nella successione imprenditoriale dell'impresa familiare, esistono due condizioni di partenza peculiari: 
8 Valutazioni imprenditoriali per la successione

- la coincidenza personale fra il soggetto proprietario e il soggetto imprenditore;

- l'avvenuta maturazione del/dei soggetto/i imprenditore/i in concomitanza e per il tramite della crescita quali-quantitativa del sistema aziendale con la conseguente determinazione di aspetti simbiotici.

Infine è normale che nell'impresa familiare i soci svolgano la propria opera in azienda, si tratti di mansioni operative o di funzioni imprenditoriali. Usualmente siamo innanzi a strutture del vertice a carattere unipersonale, costituite da soggetti di estrazione operativa, che hanno affinato le proprie capacità pur rimanendo sovente interessati maggiormente ad un'area funzionale specifica. Il soggetto imprenditore, in conseguenza di ciò e laddove gli sia stato reso possibile, ha finito per crescere insieme alla sua impresa e gli riesce difficile pensare di distaccarsene, proprio perché finisce per identificarsi nella sua creatura. Si intuisce, dato il tipo di legame, l'importanza del momento successorio per il futuro dell'impresa familiare e si giustifica altresì l'interesse dottrinale, in quanto l'imprenditore appare ancora una volta attore principale della scelta su chi debba proseguire nel continuo sviluppo della sua impresa. 
Affrontando il tema della successione imprenditoriale in un'ottica strategica, dobbiamo interrogarci sul fatto che tale evento possa essere o meno un'opportunità di sviluppo imprenditoriale, dal momento che circa 5 milioni di piccole e medie imprese (PMI) in Europa dovranno affrontare il passaggio generazionale nei prossimi anni.

Non vi è dubbio che il controllo della famiglia rende disponibili i capitali e le risorse indispensabili per lo star-up dell'impresa, ma quando nel corso della vita dell'impresa si preferisca il mantenimento del controllo proprietario alla crescita, allora il rischio connesso allo sviluppo o, peggio, la probabilità di entrare in crisi diventano minacce imminenti. Siccome, secondo stime UE, si prevede che circa 1,5 milioni di imprese scompariranno a causa di un'errata programmazione della successione imprenditoriale e al contempo occorre considerare che la probabilità di successo nel trasferimento dell'impresa all'interno della famiglia è sei volte maggiore rispetto all'entrata di nuovi soggetti, allora emerge con forza l'importanza del ruolo di un'adeguata pianificazione e conoscenza delle alternative strategiche ed operative ideali a realizzarla ${ }^{1}$.

È noto che le imprese a carattere e base familiare sono presenti, in modo rilevante, nei diversi contesti ed economie di tutto il mondo, prescindendo dalle tradizioni economiche e dai percorsi di sviluppo dei diversi Paesi. Un elemento che accomuna i diversi contesti è senza dubbio rappresentato dal fatto che il modello di impresa familiare, da un punto di vista dell'assetto proprietario, esprime il grande vantaggio di ridurre i conflitti di interesse nel governo dell'impresa. Infatti grazie alla coincidenza fra proprietà e governo, si riducono, o si eliminano del tutto, i conflitti fra gli scopi dei due assetti. Così ci si spiega come l'impresa familiare possa operare in contesti

${ }^{1}$ Dati Confindustria, settembre 2007. 
ad alta variabilità congiunturale, grazie alla capacità di mantenere performance alternate per periodi molto estesi, che trovano una giustificazione nell'orientamento al lungo termine proprio dell'assetto proprietario.

Infine non va taciuto che le imprese familiari riescono, in modo particolare, a creare e coltivare in maniera privilegiata i rapporti con i pubblici, soprattutto fornitori di risorse, sia finanziarie che operative, ma anche con il personale interno.

Tuttavia, spesso, il vantaggio sicuro sul fronte della performance si ottiene con il fondatore, in quanto le capacità imprenditoriali (strategica, organizzativa e politica) si assommano in una persona che si caratterizza per dedizione e possesso di abilità e competenze necessarie per operare nei vari contesti. Situazione, questa, che non è garantita nel momento in cui le stesse funzioni imprenditoriali siano divise fra più familiari, magari appartenenti a differenti generazioni. Ecco che allora emerge anche l'importanza di preparare i successori a saper svolgere le proprie funzioni con la stessa intensità con la quale il fondatore le espletava.

Il mondo dell'impresa familiare non si ferma alla esistenza nella realtà delle PMI dove è presente, in Italia, per il 95\%, ma delinea marcatamente anche quella della medio-grande impresa, con il 70\%. Allora, il fatto che solo il $24 \%$ delle imprese familiari italiane sopravviva al passaggio dalla prima alla seconda generazione imprenditoriale e un altro $10 \%$ si perda nel passaggio alla terza generazione, ci induce alla riflessione sul futuro di questo tipo di imprese e si riafferma con forza il ruolo di un'adeguata pianificazione e conoscenza delle alternative strategiche ed operative ideali a realizzare la successione imprenditoriale. 


\section{Il governo delle imprese familiari}

\section{Impresa familiare e successione imprenditoriale}

Le imprese familiari ${ }^{1}$ sono connotate dal coinvolgimento della famiglia proprietaria nell'impresa in tema di presenza diretta oltre che nell'as-

${ }^{1}$ È forse necessario chiarirsi che cosa si intenda per impresa familiare, in modo da potersi immaginare quali siano almeno i connotati ricorrenti individuati in letteratura. Si tratta normalmente di imprese di dimensioni ridotte ove i soggetti rappresentanti la proprietà svolgono spesso direttamente le fasi appartenenti ai processi operativi di ordine materiale, informativo o energetico.

«[P]er impresa familiare si intende l'impresa gestita direttamente dalla famiglia a livello imprenditoriale e/o direttivo. In questa configurazione l'impresa è un luogo della famiglia, anzi è spesso il luogo di ritrovo della famiglia per antonomasia. I fratelli e i cugini non coabitano sotto lo stesso tetto di casa, ma co-lavorano sotto lo stesso tetto di impresa. L'impresa diviene strumento dell'unità familiare» (C. Ciappei, La governance dell'impresa familiare, in A. Neri, A. Frangioni (a cura di), Successione imprenditoriale e continuità di impresa, ApiFinser, Livorno 2001).

«[S]i intende per familiare un'impresa in cui una o poche famiglie, collegate da vincoli di parentela, di affinità o di solide alleanze, detengono una quota del capitale di rischio sufficiente ad assicurare il controllo dell'impresa» (R.H. Coase, The nature of firm, «Economica», 4, 1937). «[Nell'impresa familiare:] - una o poche famiglie esercitano i poteri di governo, pur non detenendo la maggioranza assoluta del capitale di rischio. In tali casi, molto diffusi nelle imprese di grandi dimensioni, le famiglie proprietarie di una quota significativa del capitale di rischio, grazie ad accordi con altri soci minori, determinano con le decisioni prese nell'ambito familiare le scelte di sviluppo dell'impresa controllata;

- i membri della famiglia non sono presenti o non costituiscono la maggioranza negli organi di governo. In tali casi le famiglie proprietarie possono esercitare il proprio potere di condizionamento, ad esempio, per mezzo della nomina di amministratori di fiducia;

- nessun familiare è impegnato nella gestione dell'impresa. Anche in questi casi, come dimostrano molte imprese familiari di terza e quarta generazione, la famiglia può controllare l'impresa per mezzo della nomina dei direttori di fiducia;

- due o tre famiglie non collegate da legami di parentela, ma da solide alleanze, esercitano il controllo. Si pensi, ad esempio, al caso di due colleghi che fondano un'impresa lasciando la precedente occupazione» (S. Tomaselli, Longevità e sviluppo delle imprese familiari. Problemi, strategie e strutture di governo, Giuffrè, Milano 1996). 
setto proprietario, nel Consiglio di amministrazione (Cda) e nel gruppo dirigente.

In Italia si assiste ad un coinvolgimento delle famiglie proprietarie, soprattutto nelle organizzazioni delle PMI, che si sostanzia sia in apporto di capitale a titolo di rischio, che nell'implementazione di imprenditorialità e competenze manageriali e tecniche. Se osserviamo i dati emersi da una ricerca ${ }^{2}$ sulle caratteristiche principali delle imprese familiari, si nota che in Italia, rispetto agli Stati Uniti, si ha un maggiore numero medio di familiari coinvolti in azienda, rispettivamente di 3,1 rispetto a 1,8. Una prima spiegazione a questo fenomeno può essere ricondotta al fatto che l'investimento patrimoniale della famiglia nell'azienda italiana assume notevole rilevanza rispetto al patrimonio complessivo della famiglia. Risulta naturale che $\mathrm{i}$ familiari siano coinvolti spontaneamente, o tramite il capofamiglia, ad occuparsi dell'azienda. Inoltre la famiglia proprietaria italiana tende a voler conservare il controllo dell'impresa nel lungo termine. Infatti circa il $96 \%$ dei casi osservati nella predetta ricerca evidenzia che le imprese sono state fondate da avi e famiglie che sono attualmente proprietarie. Tale attaccamento della famiglia all'impresa, in Italia, sembra nascere sostanzialmente da motivi di ordine culturale che vedremo di seguito e che, a ben vedere, è confermato anche dal dato di raffronto fra Italia, Usa e Germania sulla rilevanza dei gruppi di imprese a proprietà familiare rispetto al totale, che evidenzia tra i primi 100, il numero rispettivamente di 42, 17 e $17^{3}$.

La cultura che lega le famiglie alle imprese di loro proprietà è composta da una serie di elementi fra cui un patrimonio di informazioni, di finalità e di valore costituito dal sapere, dalle capacità operative e dalle norme condivise sia alla famiglia che all'impresa. In particolare nella cultura familiare si ricomprende una serie di visioni del mondo, di credenze, di miti, di particolari linguaggi, di regole di ripartizione della ricchezza che si trasfondono direttamente nell'impresa, divenendo esperienze di mercato, gestione delle risorse critiche, tecniche di approvvigionamento, produzione, distribuzione ecc. ${ }^{4}$. Infatti, spesso, le migliori formule di successo imprenditoriale affondano le proprie radici in valori etico-sociali, quali la qualità della vita, la logica del servizio, il benessere sociale, la trasparenza e sincerità, l'importanza della conoscenza e dell'apprendimento, il rispetto della personalità altrui, l'autorealizzazione nel lavoro, insieme a valori economicomonetari, quali l'economicità, la parsimonia, l'efficienza e l'efficacia.

Quando poi si affronta l'argomento della successione nel governo delle imprese familiari, in Italia, i processi di ricambio generazionale, spesso, figurano come non pianificati a causa sia dell'atteggiamento imprenditoriale

\footnotetext{
${ }^{2}$ G. Corbetta, L. Gnan, D. Montemerlo, Indagine sulle piccole e medie imprese secondo il modello di indagine Mass Mutual, rapporto di ricerca, SDA Bocconi, Milano 1997

${ }^{3}$ D. Montemerlo, Il governo delle imprese familiari, Egea, Milano 2000.

${ }^{4}$ Ciappei, La governance dell'impresa familiare, cit.
} 
diffuso, caratterizzato da una bassa propensione alla definizione in via anticipata della propria uscita, sia da una scarsa formalizzazione delle modalità con cui realizzare il passaggio stesso, oltre che da una vaga conoscenza delle implicazioni giuridiche della successione.

La propensione verso l'incoraggiamento all'ingresso dei figli in azienda nasce principalmente dalla volontà di dare continuità all'impresa, mantenendo la tradizione avviata, ma tenendo conto anche del principio di base che il lavoro nell'impresa di famiglia rappresenta un'opportunità e consente di ottenere, oltre la crescita professionale, anche soddisfazioni economiche non facilmente disponibili sul mercato del lavoro. Si vede allora come alla base dell'atteggiamento dell'imprenditore nel coinvolgimento degli eredi si collochino anche ragioni personali piuttosto che aziendali e così si scopre che il fattore culturale, di cui si è detto, gioca un ruolo determinante nel processo successorio.

Occorre poi ricordare che, con il nuovo millennio, si è chiusa idealmente una fase del ciclo di vita delle imprese italiane (come abbiamo già visto in gran parte a base familiare) decollate negli anni Cinquanta-Sessanta, ovvero nel periodo del boom economico ${ }^{5}$.

Sappiamo $^{6}$ che spesso il successo di dette imprese familiari è stato connotato dalla creatività e dalla determinazione di una persona fisica. Tali connotati si esprimono particolarmente nella genialità personalistica della concezione della formula competitiva; nella sensibilità reattiva ai mutamenti di mercato e tecnologici; nella profonda conoscenza del prodotto; nella naturale propensione ad accettare rischi connessi a debolezza di struttura finanziaria; nella scelta di uno stile di governo con interventi diretti maggiormente alle decisioni operative ${ }^{7}$; nella convivenza delle due figure di imprenditore e di proprietario. Così caratterizzato, il nostro imprenditorefondatore trova effettiva difficoltà a configurare il suo successore. Laddove il problema venga affrontato sotto cogenza, occorrerà innanzitutto domandarsi se all'interno della famiglia imprenditrice esista o meno un soggetto che assommi, anche solo a livello potenziale, le doti e le caratteristiche ritenute indispensabili allo svolgimento delle funzioni imprenditoriali con riferimento specifico all'impresa da trasmettere.

È evidente intanto che la scelta del successore del vertice nell'ambito della famiglia che detiene il controllo societario lascerebbe inalterata l'identificazione proprietà-imprenditore. Inoltre ciò garantirebbe continuità della funzione di garanzia patrimoniale necessaria a conservare immutata l'affidabilità complessiva da parte di tutti i terzi dell'impresa (fornitori, sistema finanziario, clienti, ecc.). Tuttavia occorre stare attenti a non farsi condizio-

\footnotetext{
${ }^{5}$ L. De Rosa, Lo sviluppo economico dell'Italia dal dopoguerra a oggi, Laterza, Bari 1997.

${ }^{6}$ M. Bauer, Tra impresa e famiglia. Trasmissione e successione nelle piccole e medie imprese, NIS, Roma 1997.

${ }^{7}$ A. Di Vittorio, Evoluzione e funzione dell'impresa familiare, Giappichelli, Torino 2000.
} 
nare eccessivamente dalla continuità, vera o presunta, che si può ottenere attraverso il mantenimento dello stesso nome. Invece l'elemento che risulta senz'altro premiante è il talento imprenditoriale che non è un fattore necessariamente trasmissibile in linea genetica.

Se poi osserviamo che il $75 \%$ del tipo di imprese indicato all'inizio è controllato da persone fisiche e che nel 70\% della quota del capitale di comando è presente il fondatore o il suo diretto discendente, si capisce come, fisiologicamente, ad ogni passaggio generazionale la proprietà tenda a frammentarsi, con la conseguente perdita del controllo nella successione e dell'impresa ${ }^{8}$.

Può inoltre accadere che la famiglia si renda conto che i discendenti non hanno capacità imprenditoriali o non hanno la sufficiente capacità d'impegno personale nell'impresa - magari perché le dimensioni raggiunte dall'organismo sono eccessive per poter essere gestite con la preparazione tecnico-scientifica presente nei soggetti a disposizione -, sì che necessita colmare il gap culturale attraverso una acquisizione di nuova imprenditorialità. Naturalmente, in condizioni di urgenza, non si tratta di un processo facile, anche perché spesso i soggetti che sono chiamati ad esprimere il consenso sulla successione sono più di uno. Ne discende che sarebbe auspicabile attivare per tempo un vero e proprio processo di pianificazione successoria che, oltre a rendere possibile la creazione di credibili figure successorie, potrebbe contenere i rischi di contenzioso tra gli eredi ${ }^{9}$.

\section{Fattispecie successorie nell'impresa familiare}

Quando si parla di transizioni generazionali nell'impresa familiare, il riferimento principale riguarda la possibilità di trasmettere i connotati tipici dell'assetto proprietario, dell'assetto imprenditoriale e/o di entrambi. Potremo avere:

1. una successione familiare

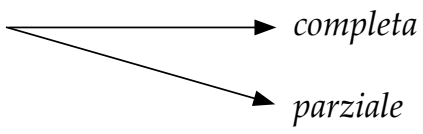

attuabile quest'ultima attraverso:

- una transizione familiare della proprietà senza quella dell'imprenditore;

\footnotetext{
${ }^{8}$ Cfr. Neri, Frangioni (a cura di), Successione imprenditoriale, cit.

${ }^{9}$ In letteratura si afferma (cfr. P. Jovenitti, Strategie mobiliari per la continuità e la successione dell'impresa, Egea, Milano 1998) che «si può sostenere che la pianificazione della successione assorbe l'effetto negativo del tempo, il quale procede inesorabilmente, provocando l'invecchiamento dell'imprenditore e conseguentemente la successione dei suoi beni, fra cui l'impresa familiare assume un peso determinante. Pianificando la sua successione, l'imprenditore 'gioca d'anticipo' e sostituisce ad uno scenario incerto una serie di decisioni e di soluzioni di concreta e immediata realizzazione».
} 
- una transizione familiare imprenditoriale senza transizione della proprietà;

- una transizione familiare imprenditoriale con transizione parziale della proprietà;

inoltre la successione familiare si presenta

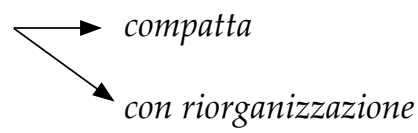

2. una successione non familiare

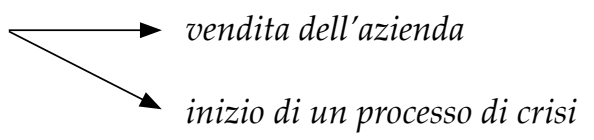

Dall'articolazione proposta si intuisce che processi di transizione scaturiscono quindi dall'esigenza di modificare gli obiettivi strategici dell'impresa, per rispondere prontamente ai cambiamenti dell'ambiente esterno. Essi, implicando un mutamento nella formula imprenditoriale, da un lato influenzano in modo notevole la distribuzione del potere e dall'altro pongono l'impresa di fronte ai rischi di continuità dell'autorevolezza dell'organo imprenditoriale. In queste situazioni, gioca un ruolo di primo piano la figura dell'imprenditore che sarà chiamato a mostrarsi capace di modificare il suo potere in modo da renderlo adeguato alle nuove esigenze; qualora ciò non fosse possibile, si innescherebbe un processo di transizione culminante nella sostituzione dell'imprenditore in carica a favore della nuova generazione. Infatti si potrebbero verificare situazioni in cui il precedente imprenditore non può essere sostituito a causa di assenza di eredi o per mancanza di volontà dello stesso a lasciare. In questi casi l'impresa sarà destinata verosimilmente a cadere in crisi profonde che potranno sfociare anche nel declino dell'impresa stessa ${ }^{10}$.

Indipendentemente dalle cause che ne hanno dato origine durante i passaggi generazionali, l'imprenditore, desideroso di perpetuare la dinastia da lui creata attraverso le generazioni future, esplica generalmente una forte volontà di trasmettere al proprio erede sia la proprietà che la direzione dell'impresa. Tuttavia potrebbero anche non verificarsi le condizioni necessarie per attuare una transizione completa, in quanto, come già notato, nella famiglia non si ritrova la figura di qualcuno in grado di sostituire l'imprenditore uscente. La famiglia potrebbe trovarsi davanti l'alternativa fra cedere le quote di capitale a terzi, pur continuando a mantenere il controllo, e/o assumere manager professionisti mantenendo il medesimo controllo.

I passaggi generazionali appaiono quindi strettamente legati ed influenzati sia dal rapporto intercorrente tra impresa e famiglia, sia da quello

${ }^{10}$ C.E. Schillaci, I processi di transizione del potere imprenditoriale nelle imprese familiari, Giappichelli, Torino 1990. 
tra famiglia e vertice aziendale. In altre parole la successione potrà avere come oggetto la trasmissione ereditaria delle sole quote azionarie e del diritto di proprietà, oppure potrà concludersi con la trasmissione del potere imprenditoriale ${ }^{11}$.

Riprendendo quanto detto all'inizio del paragrafo, potremmo concludere che la transizione generazionali possono assumere le configurazioni seguenti:

1. transizione familiare completa. Situazione ricorrente in tutti i casi dove la famiglia presenta al suo interno successori validi e competenti, disponibili e riconosciuti tali e quindi condivisi, che potrebbero assumere il comando dell'impresa. In questi casi la famiglia potrà eventualmente trovarsi ad affrontare 'solo' i problemi attinenti la formazione tecnica del successore e la gestione di eventuali conflitti scaturenti tra eredi in competizione;

2. transizione familiare della proprietà senza quella imprenditoriale. Tale situazione si riscontra nelle imprese familiari in cui non vi è la presenza di membri idonei ad assumere il governo della stessa. In seguito alla necessità di un ricambio, la famiglia opta per il mantenimento dell'intero pacchetto azionario nelle sue mani, ma delega le funzioni direttive a manager professionisti. Naturalmente la famiglia si potrebbe trovare di fronte a problemi scaturenti dalle diverse finalità del management e della proprietà;

3. transizione familiare imprenditoriale con transizione parziale della proprietà. Questa situazione è riscontrabile nelle imprese familiari in crescita, dove la famiglia decide, prima della successione, di cedere quote azionarie a terzi. La famiglia deterrebbe comunque la maggioranza relativa che le garantisce il controllo dell'impresa;

4. transizione non familiare sia della proprietà che del controllo. La famiglia, in assenza di eredi competenti, decide di mantenere solo una piccola parte del capitale di rischio nelle sue mani, mentre il rimanente viene ceduto a terzi, ai quali delega anche la direzione ${ }^{12}$.

Non va dimenticata la situazione particolare che si può venire a creare nel caso in cui nelle imprese familiari vi sia un intreccio di ruoli che a vario titolo rivestono i diversi familiari componenti l'assetto proprietario. Possono sussistere situazioni che creano ambiguità e potenziali tensioni fra i ruoli, ancor prima che fra le singole persone. Per correre in soccorso alla chiarezza dei rapporti e all'efficacia dell'operato del singolo e dell'effi-

\footnotetext{
${ }^{11} \mathrm{G}$. Stocchetti, L'utilizzo del sistema di controllo di gestione nel processo di successione generazionale in azienda, «Piccola Impresa», 2, 1998.

${ }_{12} \mathrm{M}$. Ciambotti, I processi di transizione imprenditoriale nelle imprese familiari di minore dimensione, «Piccola Impresa», 1, 1991.
} 
cienza complessiva, in tali situazioni potrebbe essere necessario ricorrere ad una divisione delle strutture operative pur in presenza della continuità soggettiva della proprietà, anche attraverso operazioni di scissione ${ }^{13}$, oppure cercando di costituire una capogruppo, finanziaria di famiglia.

Con la prima soluzione si interverrà sul sistema operativo cercando di dividere, se possibile, i processi operativi che possono corrispondere, idealmente, a competenze appartenenti a soggetti distinti. In tal modo, evidentemente, si separano i campi operativi evitando i possibili attriti, ma resta un momento di riunificazione personale, forse nell'organo amministrativo (per esempio: Cda), senz'altro nell'organo deliberante (Assemblea dei soci). In questa sede emergerà la figura con maggiore autorevolezza nell'esercizio della funzione armonizzatrice e costui sarà il vero imprenditore.

Con la seconda soluzione, la creazione di una holding, si consente di distinguere i ruoli e i meccanismi di funzionamento a livello di organismo e di proprietà oltre che nelle loro reciprocità. Ciò consentirebbe di: «creare due sedi distinte dove sono discussi rispettivamente i problemi di gestione della proprietà e quelli dell'impresa»; inoltre, la nuova struttura:

« $\bullet$ distingue gli interessi, talvolta in contrasto, degli azionisti da quelli dell'imprenditore membro della famiglia o manager;

- consente di nominare un unico rappresentante-portavoce della proprietà nell'impresa;

- riporta a livello di holding, quindi in una sede separata da quella operativa, i conflitti tra gli azionisti sulla gestione dell'impresa;

- contribuisce a distinguere e tenere separati i flussi finanziari di pertinenza della proprietà da quelli dell'impresa, poiché spesso vi è commistione tra la finanza della famiglia e quella dell'impresa $»^{14}$.

Osserviamo, invece, come accada spesso che i vertici delle imprese familiari siano progettati più in un'ottica di convenienza fiscale piuttosto che di suddivisione sulle competenze e sulle attitudini personali.

\section{Fasi del processo successorio}

Le principali fasi del processo di transizione generazionale, seguendo lo schema tracciato da McGiven ${ }^{15}$, si articolano su tre livelli.

La prima fase è caratterizzata dalla consapevolezza dell'imprenditore e dei dirigenti della necessità della transizione nel comando dell'azienda.

\footnotetext{
${ }^{13}$ R. Passeri, Valutazioni imprenditoriali in merito all'operazione di scissione con riferimento al caso italiano, Cedam, Padova 1995

${ }^{14}$ C. Demattè, G. Corbetta (a cura di), I processi di transizione delle imprese familiari, Mediocredito Lombardo, Milano 1993.

${ }^{15}$ P. McGiven, The dynamic of Management Decision, in «Management Decision», 1, 1978.
} 
In questo stadio si rende necessario discutere sul futuro dell'impresa, cercando di evidenziare i vantaggi e gli svantaggi circa il mantenimento del controllo nelle mani della famiglia e la possibilità di apertura del capitale a soci esterni o, nelle peggiori delle ipotesi, ad un'eventuale cessione della stessa.

Nella seconda fase, si rende necessario prendere una decisione circa l'individuazione del futuro successore. In questo contesto assume rilevanza la stesura di regole che permettano una più fluida selezione e successiva designazione del successore, nonché la stesura di piani in cui si delineino i percorsi formativi che l'erede dovrà espletare prima di entrare in azienda. Infine, la famiglia dovrà individuare il momento opportuno sia per comunicare ai dipendenti i cambiamenti in atto, sia per 'spodestare' l'imprenditore in carica. La seconda fase si conclude con l'entrata del nuovo imprenditore.

A questo punto inizia l'ultima fase in cui i problemi da risolvere sono per lo più legati all'affermazione del successore nella struttura aziendale. Egli sarà indotto a sviluppare un proprio stile di leadership con cui assicurarsi il consenso degli altri interlocutori, sia interni che esterni all'impresa; sviluppare appropriate capacità tecnico-direzionali sulla base dei nuovi bisogni dell'azienda ed apportare gli adeguati aggiustamenti in modo da rispondere alle mutate esigenze dell'ambiente esterno. Infine, risulta necessario curare le relazioni con gli altri dipendenti in modo da evitare eventuali conflitti futuri sull'andamento della gestione.

A questo punto del lavoro ci è sufficiente accennare il problema, che riprenderemo più estesamente nel capitolo terzo.

\section{Lo stadio del ciclo di vita dell'impresa nel processo successorio}

Tra le diverse variabili che possono in qualche modo influenzare o essere influenzate dal processo di successione, merita particolare attenzione lo stadio di sviluppo attraversato, in quel momento, dall'impresa familiare.

Il ciclo di vita dell'impresa si caratterizza per il susseguirsi di diverse fasi durante le quali la complessità della stessa, in termini di specializzazione funzionale, di ruoli e di procedure, tende ad incrementarsi. In conseguenza di ciò, poiché ogni fase richiede determinate capacità e conoscenze professionali, nel momento della successione l'attenzione si dovrà spostare sull'efficacia dell'evento stesso e sull'idoneità del successore; in altre parole diventerà di primaria importanza analizzare se il futuro imprenditore manifesti abilità tecniche-direzionali congrue con le reali esigenze dettate dallo stadio di sviluppo raggiunto dall'impresa.

Detto ciò, si può subito affermare che nella fase di avvio il fondatore tende a concentrare tutte le sue energie sull'aggregazione degli interessi interni ed esterni della famiglia, con lo scopo di attuare la crescita ed il successivo decollo dell'impresa. In tale stadio, quindi, l'evento successo- 
rio assume un ruolo di secondo piano, giacché il fondatore difficilmente riesce a prendere coscienza delle peculiarità della successione. La fase di sviluppo, in cui i meccanismi formali atti a gestire i processi di transizione appaiono più realistici, è rappresentata da quella in cui l'impresa inizia a espandere una struttura più professionalizzata ed inizia ad attuare una separazione tra famiglia ed impresa. Inoltre, poiché al crescere delle dimensioni, il numero dei familiari aumenta in modo notevole, la maggior rilevanza acquisita dalla continuità dell'impresa rende necessaria tutta una serie di interventi volti a mitigare l'effetto negativo di questi processi. In ogni caso, fra i vari stadi, pare che quello in cui la successione potrebbe divenire elemento propulsivo per sviluppi futuri sia rappresentato proprio dalla fase di declino. In questo stadio, infatti, l'impresa presenta forti bisogni di rinnovamento nel business idea onde evitare il suo fallimento. Come ha scritto P. Mastroberardino:

Il declino dell'impresa, o la seconda parte della fase di maturità, la cosiddetta maturità declinante, costituiscono i momenti in cui il fenomeno successorio, grazie all'introduzione di nuove energie, nuova linfa, competenze diverse, può essere la causa, l'origine di un rilancio dell'impresa, della rivitalizzazione, di un orientamento strategico ${ }^{16}$.

Purtroppo, però, non sempre l'imprenditore riesce ad individuare lo stadio di sviluppo in cui si trova l'azienda e ciò lo porta a non rendersi conto che è arrivato il momento di lasciare il comando; simili atteggiamenti, che prolungano l'attuazione del processo successorio, non fanno altro che danneggiare la continuità dell'impresa.

Il processo generazionale viene inoltre influenzato dal modo in cui l'imprenditore valuta il proprio ruolo in azienda, soprattutto se egli appartiene alla prima generazione. In questi casi, infatti, il fondatore si presenta come un uomo d'azione, con un forte bisogno sia di successo individuale, sia di operare in piena autonomia; spinto dall'impulso di concretizzare la propria idea o intuizione, è portato a fidarsi solo delle proprie capacità e a seguire tutto di persona. Egli si identifica completamente con l'impresa e, in genere, ritiene di essere l'unico in grado di dirigerla, in quanto è il solo a conoscere il business in tutta la sua complessità. Ciò lo porta a non accettare che il suo ruolo possa essere assunto da altri membri familiari, e ancor meno da persone esterne. In tali circostanze si crea una sorta di dipendenza dell'azienda nei confronti dell'imprenditore che, nel tempo, porta lo stesso a sottovalutare ogni tipo di successione. Come è stato scritto:

${ }^{16}$ P. Mastroberardino, Significato e ruolo dei clan familiari nel governo dell'impresa, Cedam, Padova 1996. 
È forse questa quasi inevitabile identificazione, che non può non ripercuotersi sulla maniera di affrontare i problemi di successione, che fa sì che, molto spesso, questi vengono affrontati in maniera intempestiva e inadeguata. Il passaggio dalla prima alla seconda generazione è, infatti, com’è noto, spesso testimone di crisi aziendali, molte volte irreversibili ${ }^{17}$.

\section{Di alcune situazioni e ostacoli che si creano fra imprenditore e possibili successori}

Abbiamo già sottolineato come la successione imprenditoriale non sia un processo di agevole governo, ma la situazione risulta ancora più insostenibile quando si iniziano a deteriorare i rapporti intercorrenti fra l'imprenditore ed i potenziali successori interni alla famiglia. In questi casi i possibili scenari che si possono delineare sono principalmente tre:

1. situazione conflittuale: in cui la generazione entrante mostra evidenti pretese di voler subentrare al ruolo dell'imprenditore nel minor tempo possibile. Il desiderio degli eredi è, ovviamente, ostacolato fortemente dall'imprenditore che, al contrario, non mostra nessuna intenzione a lasciare le redini dell'azienda. Da questi scontri possono nascere una serie di conflitti che porteranno verso lo slittamento della successione;

2. situazione di disagio: in questi casi, la generazione entrante si scontra con la figura di un imprenditore accentratore con forte riluttanza a lasciare il comando dell'impresa. Le conseguenze si ricollegano alla situazione precedente;

3. situazione consensuale: in cui la nuova generazione mostra un forte desiderio di collaborare all'interno dell'azienda di famiglia ed un forte interesse nel partecipare allo sviluppo della stessa. Se questi desideri si scontrano con un imprenditore disponibile al lavoro di squadra che accetta la collaborazione, allora all'interno dell'impresa si delinea un clima favorevole alla successione; nel caso contrario si ricade nelle situazioni precedenti ${ }^{18}$.

Le forme di 'resistenza' adottabili dall'imprenditore uscente si sostanziano, in primo luogo, in una designazione non tecnica del successore (selezione del successore per finalità diverse da quelle dirette a salvaguardare la continuità dell'impresa). Le resistenze possono manifestarsi non solo, e non necessariamente, al momento della selezione, ma anche durante le fasi

${ }^{17}$ Cfr. Allegra et al., Continuità e ricambio generazionale dell'impresa, Giuffré, Milano 1995.

${ }^{18} \mathrm{Cfr}$. G. Piantoni, La successione familiare in azienda. Continuità dell'impresa e ricambio generazionale, Etaslibri, Milano 1990; V. Bertella, La pianificazione del ricambio generazionale nell'impresa familiare, Cedam, Padova 1995. 
successive. L'imprenditore potrebbe ostacolare l'efficacia del passaggio, ad esempio: non concedendo abbastanza autonomia al successore; non fornendogli informazioni, conoscenze e collaborazione; alterando i flussi di comunicazione tra il successore e gli interlocutori esterni; ecc. ${ }^{19}$. Simili contesti, ovviamente, ostacolano la stesura di piani formali, rendendo la successione come un evento perturbante l'equilibrio dell'impresa. Per evitare di trovarsi nella situazione che vede la successione improvvisa e l'azienda inadeguata ad affrontarla, si rende necessario far capire all'imprenditore che essa deve sopravvivere anche senza di lui.

Accanto alle motivazioni personali dell'imprenditore a rifiutare o a rallentare il proprio ritiro dell'azienda, un altro fattore che potrebbe rendere non ottimale la successione è rappresentato dal significativo coinvolgimento della famiglia nella gestione e dal suo grado di controllo. Infatti anche in questo caso la famiglia potrebbe avanzare pretese ed aspettative in netto contrasto con la sopravvivenza e la continuità dell'impresa. È sufficiente pensare al fatto che, nella maggior parte dei casi, la famiglia tende a scegliere i successori al suo interno, indipendentemente dalle capacità e dalle conoscenze professionali dei membri; inoltre un'altra situazione ricorrente è quella che prevede atteggiamenti e trattamenti diversi, rispetto agli esterni, a favore dei familiari per quanto riguarda la carriera interna o le rispettive remunerazioni. Tutte queste situazioni avranno come effetto principale quello di inserire nelle posizioni di vertice persone di professionalità verosimilmente limitata; comportamento, questo, che andrà a deteriorare il clima organizzativo interno, creando situazioni instabili e dannose per la sopravvivenza dell'impresa.

Ulteriori ostacoli alla successione possono essere posti sia dallo stesso organico dell'impresa, sia dagli interlocutori esterni interessati alla stessa. Il primo caso indica quelle situazioni in cui le risorse umane, non riuscendo a riconoscere la leadership al successore poiché non ne condividono le idee, cercano di ostacolare il suo ruolo mediante azioni dirette (le forme estreme potrebbero arrivare ad essere anche il boicottaggio e l'astensione dal posto di lavoro), ed indirette (forme di non collaborazione, intralcio dei flussi informativi e comportamenti ambigui). Nel secondo caso, invece, le barriere scaturiscono dal fatto che gli interlocutori esterni, vedendo il passaggio generazionale come qualcosa capace di disgregare il clima ed i rapporti che avevano istaurato con la generazione uscente, tendono a limitare $\mathrm{o}$, addirittura, a estinguere ogni forma di interdipendenza con l'impresa.

A questo punto, possiamo asserire che il passaggio generazionale sarà perfettamente riuscito solo se il successore si mostrerà capace di capire l'ambiente in cui andrà ad operare, nonché se riuscirà preventivamente ad individuare i fattori che potrebbero ostacolare il suo subentro in azienda.

${ }^{19}$ Schillaci, I processi di transizione, cit. 
22 Valutazioni imprenditoriali per la successione

Solo se mostrerà tali capacità, lo stesso sarà in grado di implementare una serie di interventi mirati ad abbattere ogni barriera e che gli permetteranno la conquista della leadership. In caso contrario, il processo successorio si avvierà su un sentiero carico di conflitti che nel tempo potrebbero deteriorare la stessa impresa. 


\section{L'apertura della compagine sociale per lo sviluppo del capitalismo familiare}

\section{Sviluppo dell'impresa e capitalismo familiare}

Ricordiamo che anche nel nostro Paese il sistema finanziario ruota principalmente intorno al sistema bancario, con evidenti condizionamenti nella struttura del passivo delle imprese italiane. Sappiamo altresì che il sistema bancario italiano è molto diverso da quello di tipo anglosassone ${ }^{1}$ ove esiste una divisione molto netta fra banche commerciali, che esercitano il credito, e banche d'affari, che operano nel mercato dei capitali, rappresentando così l'anello di congiunzione tra risparmio e imprese.

Non vi è dubbio che il ruolo non marginale della centralizzazione del sistema bancario sia dovuto anche agli effetti indotti dalla crescita smisurata del debito pubblico. Negli anni Ottanta e Novanta il finanziamento della spesa pubblica ha creato un grave squilibrio nei mercati mobiliari, in quanto il Tesoro ha sottratto la stragrande maggioranza del risparmio all'economia produttiva convogliandola verso la finanza pubblica, anche attraverso titoli fino a pochi anni fa 'esenti'. Inoltre come ulteriore effetto si è avuto che l'inflazione ha raggiunto livelli notevoli e, di conseguenza, ciò ha indotto un aumento dei tassi di interesse e quindi del costo del capitale di debito. $\dot{E}$ evidente però che la condizione necessaria per lo sviluppo del mercato azionario sia quella di tassi di interesse non elevati, altrimenti il risparmio tende a indirizzarsi verso impieghi a reddito fisso, di fatto privi di rischio o a rischio limitato, e alternativi al capitale azionario.

Se poi pensiamo che il forte indebitamento dello Stato ha richiesto il raggiungimento di livelli di tassazione elevati, capiamo come le imprese abbiano preferito ricorrere al credito bancario, il cui costo (gli interessi pas-

${ }^{1}$ Cfr. L. Guatri, S. Vicari, Sistemi d'impresa e capitalismi a confronto. Creazione di valori in diversi contesti, Egea, Milano 1994. 
sivi) è deducibile dal reddito, piuttosto che raggiungere redditi più elevati e subire imposte come ILOR prima e IRAP poi, che rimangono indeducibili ai fini delle imposte dirette ${ }^{2}$. Il livello elevato di tassazione ha inoltre indotto le imprese a comprimere il reddito oltre il fisiologico, e ciò è assai poco conciliabile con il ricorso al mercato del credito, che presuppone la valutazione anche in base ai risultati netti. Ė noto che lo sviluppo del capitalismo finanziario moderno necessita di una forte riduzione del debito pubblico, della pressione fiscale e di una politica di privatizzazione del sistema bancario pubblico ${ }^{3}$.

In una situazione siffatta occorre chiedersi se il capitalismo familiare sia in grado di consentire o meno adeguati tassi di sviluppo. Per tentare di intuire la risposta è necessario distinguere due tipi di situazione $\mathrm{d}^{\prime}$ impresa: quella per la quale lo sviluppo è una scelta autonoma e l'altra, ove lo sviluppo è indotto dalla necessità di assumere dimensioni aziendali adeguate al mercato di riferimento.

Nel primo caso l'imprenditore persegue anche finalità di convenienza personale, mentre nel secondo la crescita è una condizione indispensabile per la sopravvivenza dell'impresa. Emerge così l'importanza del ruolo dell'autofinanziamento e delle capacità finanziarie del soggetto titolare per la composizione della struttura finanziaria dell'impresa. Tuttavia le imprese costrette dal mercato alla crescita, spesso anche oltre i confini nazionali, in realtà non dovrebbero intraprendere questa espansione solo se sono in grado di finanziare 'internamente' il processo di sviluppo attraverso l'autofinanziamento e il capitale di rischio. È necessario invece porsi l'interrogativo se sia corretto ricorrere a questo tipo di crescita o non sia più opportuna una crescita cosiddetta 'esterna', attraverso forme di aggregazione, più o meno coinvolgenti e vincolanti, con altre imprese, anche perché spesso accade che i tempi necessari per raggiungere dimensioni accettabili per il mercato siano troppo lunghi, dunque la via dello sviluppo relativamente più certo, risulta essere la concentrazione con altri operatori. Chiaramente la concentrazione dovrà essere possibile senza ulteriori necessità di ricorso al credito di terzi, perché altrimenti l'uso considerevole del debito bancario per finanziare, a questo punto la gestione corrente, può risultare fatale, in quanto al rischio insito in una struttura finanziaria che potrà risultare squilibrata, si aggiunge quello, sempre più latente, connesso ad un eventuale insuccesso dell'integrazione tra imprese.

Il ricorso ad un elevato indebitamento gioca invece in senso positivo per la tecnica del Leverage Buy-Out ${ }^{4}$, che consente di sfruttare in modo finanzia-

\footnotetext{
${ }^{2}$ Occorre comunque ricordare che, con l'introduzione dell'IRAP, gli interessi passivi risultano indeducibili ai fini di detta imposta.

${ }^{3}$ Si ricorda che il sistema bancario italiano è caratterizzato ancora da una forte presenza della 'mano pubblica'.

${ }^{4}$ Sull'argomento cfr. A. Paci, Assetti proprietari e governo d'impresa: il management buy-out, Tipografia pistoiese, Pistoia 1990.
} 
riamente, e spesso anche fiscalmente vantaggioso il meccanismo della leva finanziaria. Evidentemente, se anche questo meccanismo non fosse sufficiente all'impresa per finanziare la sua crescita, non rimane che ricorrere all'incremento del capitale proprio attraverso operazioni finanziarie di tipo straordinario, cioè sia attraverso l'ingresso di investitori istituzionali, che con il ricorso alla quotazione sul mercato borsistico. Ecco che allora l'impresa è indotta a passare, come abbiamo detto prima, da impresa familiare a impresa a controllo familiare, in quanto costretta dal mercato a crescere a ritmi superiori rispetto a quelli consentiti dal proprio finanziamento interno e del capitale di rischio.

In sintesi, l'impresa familiare ha davanti a sé un'alternativa:

- accettare la sfida e crescere finanziandosi sul mercato senza che ciò significhi la perdita del controllo familiare;

- continuare in maniera incerta rischiando la crisi durante le fasi recessive dell'economia.

In tale contesto il ricorso al capitale di rischio esterno di tipo finanziario

non solo consente all'impresa familiare di crescere in modo equilibrato e di diventare di conseguenza appetibile per manager capaci e ambiziosi, ma evita possibili cause di instabilità e disaffezione che possono condurre nel lungo termine solo a due probabili soluzioni finali: la crisi economico-finanziaria, che può portare l'impresa verso il fallimento o verso situazioni che di fatto costringono la famiglia a farsi da parte oppure, nella migliore della ipotesi, la vendita dell'impresa e la conseguente cessazione dell'esistenza del carattere familiare originario dell'impresa stessa ${ }^{5}$.

L'apertura della compagine sociale avviene, normalmente, in modo articolato. Si va dal capitale istituzionale proveniente da operatori quali i Fondi Pensione, i Fondi Chiusi, le Marchant Bank e il mercato azionario di Borsa, a privati - spesso amici o conoscenti dell'imprenditore - o altre imprese che non hanno come obiettivo quello del controllo, ma di saldare alleanze sinergiche. Se poi l'aumento del capitale avviene anche attraverso l'emissione di azioni prive del diritto di voto, si aumenta la possibilità della famiglia di controllare un gruppo di imprese ${ }^{6}$. Tutto ciò è ancora più sicuro qualora il pacchetto di controllo sia detenuto da una società che funge da holding capogruppo e che svolgerà, fra l'altro, la funzione non secondaria di tenere insieme le componenti della famiglia nei vari passaggi generazionali.

${ }^{5}$ Così A. Dessy, J. Vender (a cura di), Capitale di rischio e sviluppo dell'impresa, Egea, Milano 1996.

${ }^{6}$ Sull'argomento si vedano le importanti novità introdotte dalla riforma del diritto societario in tema di categorie di titoli rappresentativi del capitale. 
Certamente l'imprenditore non può non osservare le fondamentali regole di funzionamento di questo modello di governance, che potrebbe assumere una contrapposizione operativa anche al modello della public company. Tale contrapposizione alimenta una strategia finanziaria riguardante la creazione e soprattutto la diffusione del valore d'impresa e facilita il passaggio dall'impresa familiare all'impresa a controllo familiare.

Nell'ambito delle scelte relative all'assetto proprietario non possiamo tacere poi il ruolo delle risorse di capacità imprenditoriali. Infatti per lo sviluppo sono necessarie non solo le risorse finanziarie, ma anche e soprattutto le capacità; è necessario che l'impresa sappia esprimere un assetto imprenditoriale e un management in grado di risolvere le problematiche connesse con la crescita dimensionale. Tali risorse sono una criticità dei sistemi economici moderni e si assiste spesso a situazioni ove è il management che si sceglie l'impresa in cui operare dando vita ad un vero mercato contendibile, sempre più competitivo e di conseguenza più oneroso.

L'inserimento di manager in imprese medie di carattere familiare richiede all'assetto imprenditoriale una capacità di motivazione non solo di carattere economico, ma soprattutto inerente gli stimoli professionali che l'ambiente aziendale è in grado si assicurare. In tale contesto appare evidente che le risorse finanziarie necessarie allo sviluppo, soprattutto se effettuato attraverso acquisizioni, diventano un'importante leva per motivare il management, e una 'defamiliarizzazione' del capitale necessario alla crescita può condurre a significativi riflessi sulla capacità dell'impresa di dotarsi di un management efficiente.

A questo punto emerge la riflessione che se l'apertura della compagine societaria e il potenziale passaggio da un governo dell'impresa a livello familiare ad uno di tipo manageriale siano la condizione necessaria ad assicurare alle imprese che devono crescere i mezzi per farlo, allora è possibile chiedersi se l'impresa familiare, operante nei settori ove la crescita è una scelta obbligata, sia destinata all'estensione.

In realtà il ricorso al mercato finanziario non rappresenta la rinuncia al carattere familiare della gestione della proprietà dell'impresa. Il mercato finanziario consente invece la possibilità di collocare fuori dall'ambito familiare le azioni che non servono al controllo dell'impresa, le azioni di risparmio, azioni di altre società controllate o collegate con la capogruppo, dando così vita a veri e propri gruppi di imprese ${ }^{7}$, ognuna delle quali avrà vita autonoma sul mercato dei capitali.

\section{Le opportunità di apertura della compagine sociale}

Ogni impresa assume un proprio tipo di assetto societario, risultato della propria particolare evoluzione, che tende al raggiungimento dell'equi-

${ }^{7}$ Sull'economia dei gruppi, cfr. A. Zattoni, Economia e governo dei gruppi aziendali, Egea, Milano 2000. 
librio tra i diversi soggetti che ne fanno parte. È necessario ricordare che, pur nella unicità dell'impresa, le diverse modalità di corporate governance presentano delle caratteristiche di omogeneità che permettono di definire dei modelli ben identificabili ${ }^{8}$.

A seconda che prevalga una veste giuridica istituzionale o di aggregati di imprese, si avranno sistemi economici distinti che danno vita a diversi assetti istituzionali tipici e diverse modalità di governo societario. In Italia il modello di capitalismo che si è andato via via affermando ${ }^{9}$ occupa una posizione intermedia tra quello anglosassone, basato su un mercato finanziario efficiente e una proprietà azionaria molto diffusa, e quello renano, basato sulla supervisione delle imprese da parte di istituzioni finanziarie specializzate e in particolare da banche universali. Il connotato principale e definitore del modello italiano è principalmente la numerosità di PMI, perlopiù non quotate, ove si assiste ad una presenza costante dell'imprenditore, anche con compiti operativi, affiancato da staff dirigenziali solo a volte, prevalentemente nelle imprese di dimensioni di un certo livello. Inoltre il modello italiano si connota per un numero ridotto di grandi imprese, la cui proprietà è concentrata in poche mani, in prevalenza di matrice familiare, con una modesta presenza in borsa. Si ricorda inoltre la sostanziale assenza di public company di tipo anglosassone e il ruolo primario svolto dal sistema bancario come fornitore di capitali di debito a breve/medio termine. Normalmente tale sistema finanziario non si ingerisce nella gestione delle imprese.

Si hanno così almeno due tipi di imprese familiari: una di tipo tradizionale, monofamiliare o plurifamiliare di seconda generazione, un'altra di tipo allargato, con la presenza di più famiglie dello stesso ceppo o di ceppi diversi con soggetti proprietari, controllanti o meno.

Come ovunque, i potenziali investitori nelle imprese testé descritte sono sostanzialmente di due tipi e cioè gli azionisti 'industriali', più spinti nelle scelte di fondo da valutazioni in una prospettiva di controllo della combinazione prodotto-mercato-tecnologia, e gli azionisti 'finanziari', motivati principalmente da orizzonti remunerativi. Per entrambi l'impresa, intesa come investimento, ha senso se è in grado di creare e diffondere valore economico e ciò significa accrescere la dimensione del capitale economico ${ }^{10}$.

\footnotetext{
${ }^{8}$ Cfr. Guatri, Vicari, Sistemi d'impresa e capitalismi a confronto, cit.

${ }^{9}$ G. Corbetta, Le imprese familiari: caratteri originali, varietà e condizioni di sviluppo, Egea, Milano 1995.

${ }^{10}$ E noto come nelle imprese le scelte di politica finanziaria dipendano principalmente dalla fase del processo strategico (stabilità, risanamento, sviluppo) durante la quale sono assunte. Osserviamo inoltre il continuo fabbisogno di fondi resosi necessario per un'impresa che intraprenda una fase di sviluppo, stante l'obiettivo della creazione di valore economico che dovrebbe permeare le politiche aziendali; si capisce come assuma dunque importanza la formazione della struttura del passivo.

Il concetto di capitale economico si adatta meglio nella nostra realtà, data la quasi inesistenza delle public company e il numero ridotto di società quotate, rispetto al valore di mercato che finisce per realizzarsi quasi esclusivamente in caso di cessione dell'azienda.
} 
Per poter essere percepito e misurato dagli azionisti, il maggior valore che viene creato deve passare anche nel valore di mercato, cioè trasferirsi, 'diffondersi', nei prezzi dei titoli. Creazione e diffusione del valore ${ }^{11}$ sono momenti complementari proprio perché senza la diffusione del valore il processo rimane incompiuto. L'evento della diffusione interessa in modo particolare alcuni soggetti direttamente legati alla vita dell'impresa ed è agevolato dall'apertura della compagine societaria, soprattutto se può avvenire per tramite di un mercato mobiliare. Le conseguenze positive, infatti, si avvertirebbero sia per gli investitori finanziari, cioè per tutti coloro che hanno acquistato quote non con obiettivi di gestione, sia per l'imprenditore-proprietario, cioè per colui che partecipi in maniera attiva alla gestione dell'impresa. Solo quando il valore creato passa nel prezzo di mercato dei titoli, gli investitori finanziari hanno la possibilità di realizzare

È noto che per la massimizzazione del valore risulta importantissima la struttura finanziaria di un'impresa, in quanto quest'ultima può influenzare direttamente la ricchezza dell'azionista attraverso la politica dei dividendi, ma anche la crescita dell'autofinanziamento, la minimizzazione del rischio finanziario e del costo del capitale, nonché la garanzia di un'adeguata copertura finanziaria per favorire la stabilità dei risultati dell'impresa.

La struttura del passivo e le problematiche finanziarie relative alla crescita si modificano in funzione della fase di sviluppo dell'impresa. Se proviamo ad adottare uno schema classico di analisi, il ciclo di vita dell'impresa, possiamo osservare come, nelle diverse fasi di nascita (business idea - start-up - first stage), sviluppo (crescita accelerata - consolidamento dello sviluppo), maturità e declino, corrisponda un diverso contributo del cash flow all'equilibrio totale e, di conseguenza, diverse necessità cui corrispondono alternative di fonti finanziarie.

Si deve notare che, nella realtà del nostro Paese, da un po' di tempo, l'inasprirsi della concorrenza, l'incremento della pressione tributaria, il graduale attenuarsi del 'permissivismo fiscale' hanno contribuito ad una sensibile contrazione del tasso di autofinanziamento e, di contro, una lievitazione del fabbisogno finanziario esterno.

Nel ricorrere al capitale di credito, l'impresa a forte sviluppo presenta necessità precipue riguardanti l'analisi del rischio elevato e l'impossibilità di permettersi la commissione di errori nella composizione della struttura finanziaria, pena la distruzione di valore economico o peggio il fallimento. Ricordiamo che comunque, unitamente alla dimensione del capitale esterno, è necessario considerare anche l'elevato fabbisogno di capitale di rischio. Tuttavia, all'incirca dopo la fine dello stadio di sviluppo nel ciclo di vita dell'impresa, la possibilità di creare valore attraverso la leva del debito cresce direttamente con la maturità, attraverso il raggiungimento dei vantaggi connessi alle tipiche realtà costituite. Esiste in ogni caso un limite invalicabile all'indebitamento, anche per le realtà più mature, ed è rappresentato dall'impossibilità di non ricorrere a fonti esterne di capitale proprio senza cadere in una 'escalation di debito' che conduce irrimediabilmente ad un effetto leva negativo.

Tale situazione non potrà avere altro sbocco che il dissesto o il totale blocco dello sviluppo in una situazione di sopravvivenza ai margini della scena competitiva. L'eccessivo indebitamento limita non solo il tasso di crescita ma anche la capacità netta di autofinanziamento $\mathrm{e}$ tutte le leve competitive e finanziarie successivamente attivabili. Le successive operazioni di ristrutturazione si rileveranno spesso tardive e non potranno creare dal nulla tutto il valore che in precedenza tale tipo di crescita ha portato a perdere. Ne deriva la necessità di impiegare capitale qualitativamente idoneo ovviando al fenomeno del 'vincolo finanziario' di tipo competitivo e strutturale, intendendo con il primo alle condizioni di reperimento dei fondi, mentre il secondo riguarda la disponibilità degli stessi.

Compiuta tale premessa occorre riflettere sul 'se' e 'come' accedere al capitale a titolo di rischio e sulle implicazioni che ne derivano dal lato della corporate governance.

${ }^{11}$ Cfr. al riguardo L. Guatri, Creazione e diffusione del valore, Egea, Milano 1992. 
in modo completo il rendimento del proprio investimento. Così anche per l'imprenditore-proprietario il processo di diffusione diventa importante. Innanzitutto perché avere quotazioni elevate e crescenti significa migliorare l'immagine ed accrescere la fiducia; in secondo luogo un elevato valore di mercato del titolo azionario consente di ottimizzare il costo della raccolta del nuovo capitale, attraverso la possibilità di fissare elevati sovrapprezzi. Infine, la diffusione del valore assume importanza perché consente il contenimento del pay-out ratio (dividendo/utile netto), in quanto i capital gain rendono meno rilevante per gli azionisti la misura del dividendo, e permette la realizzazione del titolo, in qualsiasi momento, grazie all'apprezzamento giornaliero dello stesso da parte del mercato.

Occorre osservare che, nel caso di imprese di minori dimensioni, gli imprenditori detengono spesso l'intero capitale e non si pongono il problema delle relazioni con i soci di minoranza o con il mercato, elementi che, come abbiamo detto, sono potenzialmente interessati al processo di diffusione del valore. In altre parole ciò significa che i soci di minoranza sono interessati al valore di mercato dei titoli che essi detengono in portafoglio proprio perché il loro investimento è spesso di carattere meramente finanziario, più che di tipo industriale. Ma anche nel caso in cui l'imprenditore proprietario di maggioranza non sia intenzionato a cedere la propria impresa, il solo fatto che i prezzi di mercato riflettano il valore creato e siano elevati, significa direttamente maggior ricchezza in termini di patrimonio posseduto e immediatamente liquidabile.

L'apertura del capitale a terzi, soprattutto nell'impresa di tipo familiare, è tuttavia una scelta che va ponderata attentamente, alla quale occorre prepararsi per tempo. Si ricorda che ci sono accadimenti che possono rivelarsi fatali per la sopravvivenza dell'impresa, quali l'improvvisa indisponibilità dell'imprenditore, la mancanza degli eredi interessati a intraprendere l'attività, l'interesse della famiglia a portare alla guida della stessa eredi incapaci o poco preparati, l'esplosione di conflitti insanabili fra eredi e la mancanza di una pianificazione patrimoniale della successione. Se tutto ciò lo si collega alla sempre maggiore carenza di autofinanziamento delle imprese di piccola dimensione, appare evidente come, nell'affrontare i processi di sviluppo, risulti quanto mai necessario aumentare il peso e la qualità delle fonti esterne di finanziamento e delle risorse manageriali al fine di preparare puntualmente e per tempo l'apertura del capitale a terzi.

Riteniamo pertanto necessario ridurre il modello di capitalismo italiano ad una struttura proprietaria a carattere familiare della maggioranza delle PMI, vista l'impermeabilità fino ad oggi dimostrata dagli azionisti circa possibili aperture al capitale di terzi, ivi compreso il ricorso alla quotazio$\mathrm{ne}^{12}$. Se tuttavia l'allargamento della base societaria e la diversificazione

${ }^{12}$ Così Dessy, Vender (a cura di), Capitale di rischio, cit. 
delle fonti di finanziamento diventano sempre più una necessità improrogabile, non è difficile prevedere che nei prossimi anni si assisterà ad un passaggio dall'impresa familiare all'impresa a controllo familiare ${ }^{13}$. Se poi riflettiamo attentamente sulle necessità finanziarie maggiori che le imprese devono incontrare per adeguarsi a nuove regole della concorrenza, appare evidente come risulti necessario aumentare la componente finanziaria di natura esterna, così come la parte di risorse manageriali, proprio perché l'impresa come famiglia può non disporre di mezzi finanziari sufficienti alle esigenze di sviluppo.

Con il passaggio al controllo familiare si aprono così delle opportunità di finanziamento attraverso nuovi strumenti finanziari ${ }^{14}$ disponibili sul mercato e al tempo stesso si evitano in gran parte i problemi collegati alla mancata pianificazione successoria. Potranno entrare in scena operatori del private equity che avranno il compito di selezionare le imprese con maggiore potenziale di sviluppo, conferendo ad esse capitali e know-how strategico e finanziario, accelerando altresì il processo di sviluppo, anche se attraverso partecipazioni di minoranza ${ }^{15}$.

${ }^{13}$ Cfr. F. Perrini, Capitale di rischio e mercati per PMI. Metodologie e canali di accesso al capitale per lo sviluppo, Egea, Milano 1998.

${ }^{14} \mathrm{Si}$ veda a tale proposito la riforma del diritto societario introdotta il $1^{\circ}$ gennaio 2004 .

${ }_{15}$ È necessario specificare che una condizione, forse la principale, affinché possa essere raggiunta l'efficienza allocativa di cui si dice è senz'altro l'efficienza del Mercato finanziario in generale e della Borsa in particolare. Questo argomento, per quanto naturalmente complementare alla nostra trattazione, ci porterebbe senz'altro lontano dal nostro obiettivo principale. Si ricorda soltanto la riforma introdotta con il decreto legislativo 415/96, detto «Eurosim», oltre l'approvazione del Testo Unico della Finanza avvenuta il 20 febbraio 1997. 


\section{La procedura successoria ed i suoi attori}

\section{Gli attori e il processo della successione imprenditoriale}

Il problema successorio riteniamo debba essere affrontato con riferimento ai soggetti interessati e coinvolti nel fenomeno, proprio per introdurre le possibili soluzioni soddisfacenti per gli stessi. La ricerca di tale soddisfazione non potrà condurre certamente ad una soluzione di compromesso che possa inficiare l'equilibrio generale del sistema, in quanto obiettivo principale della successione imprenditoriale rimane comunque quello della sopravvivenza dell'impresa familiare ${ }^{1}$. La successione imprenditoriale è quindi occasione per la creazione di sinergie tra i diversi soggetti che ruotano intorno ad essa, i quali saranno chiamati ad essere portatori di comuni ideali riguardo al ruolo dell'impresa ed anche alla posizione che essi andranno a ricoprire al suo interno. Si potrà creare così una concordanza di obiettivi che faciliterà l'attuazione di un processo organizzato per fasi, con la finalità di garantire uno sviluppo e una continuità per l'impresa.

A questo fine è bene esaminare, in primo luogo, i fattori che possono spingere o contrastare la successione imprenditoriale, originati principalmente da atteggiamenti posti in essere dagli attori-chiave che operano nella stessa. Occorrerà indagare circa le motivazioni, i problemi e le aree di conflitto che inevitabilmente sorgono tra i vari componenti della famiglia ed anche tra gli esterni ad essa, al fine di capire come questi fattori possano essere utilizzati al meglio per la riuscita del cambio generazionale.

I principali attori-chiave che influenzano i processo di successione imprenditoriale possono essere ricondotti a:

\footnotetext{
${ }^{1}$ Cfr. Continuità e ricambio generazionale nell'impresa, cit.
} 
- l'imprenditore;

- il successore designato;

- i componenti della famiglia;

- i dipendenti dell'impresa.

Tutti questi soggetti influenzeranno la successione imprenditoriale e ne saranno influenzati, in maniera maggiore o minore, configurando la dimensione del successo o dell'insuccesso attraverso i propri comportamenti e le proprie decisioni. Vediamo quindi i ruoli di questi attori, in vista dell'individuazione delle fasi che compongono il processo di successione imprenditoriale.

L'imprenditore è il principale determinante del complesso meccanismo successorio. Sappiamo che è lui, attraverso la creatività delle sue idee, che ha dato vita all'impresa di famiglia; è lui che l'ha fatta progredire nel corso dei vari stadi del suo ciclo di vita; sarà ancora lui la figura principale che determinerà le sorti dopo il proprio ritiro dalla vita operativa. Avendo guidato l'impresa per lungo tempo, l'imprenditore conosce al meglio tutte le caratteristiche organizzative, le opportunità di sviluppo e la cultura che anima l'impresa familiare e diviene il selettore principe di quella che sarà la figura chiamata a sostituirlo, la quale dovrà possedere tutte le caratteristiche per rendere reali le ambizioni di continuità e di progresso dell'impresa.

Ricordiamo che altri elementi possono determinare il successo o l'insuccesso del processo, oltre la scelta del successore, e riguardano la migliore gestione dei rapporti famiglia-impresa, la propensione dell'imprenditore verso la successione, il suo grado di consapevolezza dell'evento in questione. Tanto più l'imprenditore avrà preso consapevolezza dell'evento e l'avrà saputo accettare, quanto più questo potrà avvenire con largo anticipo rispetto al momento del ricambio. Così sarà tanto meno difficile il passaggio delle consegne con un successore che verosimilmente avrà seguito un percorso di studi consono alla professione futura, forse avrà maturato esperienze in altre imprese, ma anche avrà prefigurato la futura struttura organizzativa e le opportunità di sviluppo dell'impresa.

Il successore, così operando, non solo si sentirà più sicuro nella guida aziendale, ma la sua figura risulterà probabilmente legittimata alla direzione anche da parte dei dipendenti e dei familiari, senza che essi creino attriti e discordie in seno all'impresa. L'imprenditore, da parte sua, sarà più sicuro nel lasciare in buone mani ciò che ha creato e nel vedere progredire la sua impresa.

Di contro, atteggiamenti imprenditoriali non infrequenti, di particolare attaccamento alla guida aziendale potranno determinare un pericoloso ritardo nella programmazione successoria $\mathrm{o}$, addirittura, una mancanza assoluta di pianificazione, la quale può compromettere totalmente il futuro e la continuità aziendale. 
Il ruolo del successore diviene altrettanto critico rispetto a quello imprenditoriale, anche perché da numerose ricerche risulta come vi sia, nella stragrande maggioranza delle aziende familiari, una preferenza alla successione in ambito familiare. Questo comporta che, molto spesso, l'erede in questione sia rappresentato dal figlio dell'imprenditore stesso, intorno al quale crescono solitamente numerose tensioni riguardanti:

- il fatto che egli potrebbe avere avuto aspirazioni differenti ed inoltre avere difficoltà a rapportarsi con la figura del padre;

- il fatto che qualche componente della famiglia, forse anche maggiormente portato al ruolo, potrebbe aver avuto aspirazioni in tal senso;

- la circostanza in cui i dipendenti dell'impresa tendano a considerare l'erede come il figlio dell'imprenditore e non come effettivo dirigente.

Il terzo attore-chiave nella successione imprenditoriale è dato dalla famiglia e dai suoi membri i quali, come già visto, nutrono delle aspettative sia nei confronti dell'impresa, sia nei confronti del successore designato (sia esso interno o esterno alla famiglia). Sappiamo come il rapporto famiglia-impresa necessiti di una figura mediatrice e come questa risulti impersonata, nella gran parte dei casi, dall'imprenditore medesimo, il quale presenterà abilità diplomatiche e presterà attenzione alle esigenze di entrambi gli istituti senza privilegiare né l'uno né l'altro. Le stesse doti saranno richieste ad un buon successore. Qualora il successore non possieda queste doti di mediatore, la situazione potrebbe esplodere in conflitti che si potrebbero ripercuotere sul clima dell'impresa.

La situazione maggiormente auspicabile sarebbe quella nella quale la famiglia fosse animata da principi guida saldi e considerati tali da ciascun membro, meglio ancora se sottoscritti in un documento denominato «Patto di famiglia ${ }^{2}$, con il quale i familiari stessi si impegnino moralmente al loro rispetto. Naturalmente si deve trattare di buoni principi guida, i cui valori ispiratori siano quelli dell'unità, del bene comune e dello sviluppo dell'impresa e dei lavoratori che vi operano. In caso contrario, nel quale cioè l'impresa sia formata da soggetti che operano seguendo regole di opportunismo, egoismo e reciproca sopraffazione, la mancanza di unità in seno alla famiglia si ripercuoterà negativamente sulla gestione aziendale $\mathrm{e}$, a lungo andare, potrebbe portare anche a crisi irreversibili.

Infine, gli altri soggetti in grado di influenzare in modo significativo il processo di successione imprenditoriale sono rappresentati dai lavoratori dell'impresa familiare. Essi, con la propria opera, consentono all'impresa di raggiungere traguardi operativi di volta in volta maggiori e risultano an-

${ }^{2}$ Cfr. par. 3 del capitolo quarto. 
che profondamente soggetti all'influsso di ricambio generazionale. Questi sono consapevoli che dalla successione, più o meno proficua, deriverà la stabilità futura dell'azienda e di conseguenza anche quella dei lavoratori che in essa operano. Oltre a ciò, dalla persona del futuro erede dipenderanno anche avanzamenti di carriera e licenziamenti che potrebbero mutare profondamente l'assetto operativo. Di contro, essi valuteranno l'erede designato mettendone a confronto la capacità con quelle del suo predecessore, formandosi opinioni che potrebbero facilitare o mettere in difficoltà l'operato del nuovo imprenditore.

Occorre poi ricordare che i valori dei lavoratori influenzano quelli dell'impresa, diventando parte della sua cultura. Infatti quando l'azienda familiare è di ridotte dimensioni, coloro che vi operano all'interno partecipano attivamente alla sua vita. Essi si sentiranno quindi coinvolti nel processo di successione e consapevoli che il cambiamento riguarderà anche loro, in quanto 'membri aggiunti' alla famiglia dell'imprenditore.

Dai comportamenti, dalle motivazioni, dalla cultura e dai valori di fondo che animano gli attori-chiave fin qui visti, dipenderà il successo o l'insuccesso del processo successorio. Una buona successione imprenditoriale necessita, infatti, di una pianificazione elaborata per tempo secondo principi da tutti condivisi. Eventuali contrasti e conflitti intestini che si sviluppino tra gli attori in questione, non faranno altro che ritardare il processo o far sì che esso venga ad attuarsi secondo schemi non congeniali al futuro dell'impresa, compromettendone così non solo lo sviluppo, ma anche la stessa sopravvivenza. Un imprenditore dotato di qualità e di esperienza dovrà gestire al meglio le parti in gioco, bilanciando le esigenze di ciascuno dei soggetti in causa, sempre però tenendo conto delle priorità dell'impresa familiare.

Vediamo ora come si sviluppa al meglio un processo di ricambio generazionale al vertice dell'azienda, il quale sia stato programmato per tempo, seguendo le esigenze proprie della società. Naturalmente con questo non si vuole ipotizzare una scelta che sia ottimale per qualunque azienda presa in considerazione, ma quella qui di seguito proposta è forse quella che più si attaglia alla maggior parte delle realtà presenti in Italia e maggiormente funzionale nel loro sviluppo.

Il processo di programmazione può essere articolato, nella grande maggioranza delle imprese, in tre distinte fasi. Ciascuna riveste una grande importanza ed è fondamentale per la riuscita complessiva. La standardizzazione qui riportata dei tre momenti in questione non deve però far pensare che questi si verifichino con regolarità, in quanto le variabili che influenzano la successione, e in particolare i delicati rapporti famiglia-impresa visti precedentemente, possono mutare l'intero percorso successorio e renderlo più o meno complesso. Una situazione media, nella quale l'impresa familiare non sia soggetta a particolari problemi, sarà così caratterizzata, mentre 
per situazioni più critiche bisognerà verificare caso per caso. Le tre fasi sopra menzionate si articoleranno quindi come descritto qui di seguito.

1. Il primo stadio ha luogo quando il responsabile dell'impresa, in accordo con gli altri membri del management aziendale, ravvisa l'esigenza di essere sostituito. In questa fase si comincerà a discutere del futuro dell'impresa, senza escludere la possibilità della sua cessione. Si tratta comunque di momenti difficili da gestire, nei quali i rapporti tendono ad inasprirsi, soprattutto quelli tra management e lavoratori, i quali si sentiranno minacciati dall'insicurezza che potrebbe venire a crearsi. Oltre a ciò, cominceranno a nascere le prime rivalità circa il nome del potenziale successore. Questo stadio deve quindi essere gestito con molta cura e non durare molto a lungo, viste le pressioni a cui sono sottoposti tutti gli attori coinvolti, che potrebbero sfociare in lotte destabilizzanti per l'impresa familiare.

2. La seconda fase riguarda la designazione del successore in grado di ricoprire il ruolo imprenditoriale e guidare l'impresa verso uno sviluppo futuro. Importante, in questo senso, diviene la sua formazione, che richiede anch'essa un'adeguata programmazione e i cui tempi serviranno anche a scandire il ritmo del disimpegno del dirigente in carica. La formazione non riguarderà soltanto le nozioni teoriche: è bene che queste siano corredate da un'esperienza fatta sul campo, che servirà a valutare le effettive capacità del futuro imprenditore ed a mettere in pratica quanto appreso nei suoi studi. Il successore è continuamente soggetto al giudizio del personale aziendale che paragonerà la sua opera con quella del suo predecessore ed il giudizio critico si trasformerà in aperta sfiducia se il primo non è all'altezza della situazione. In questo caso tutto il processo successorio tenderà a bloccarsi e si dovrà riprendere dalla prima fase.

3. La terza ed ultima fase è quella attinente all'atto formale di successione, con il quale si ha il completo ritiro del precedente imprenditore che lascia il campo alle nuove leve. Il successore è chiamato a dimostrare il possesso di effettive capacità per sviluppare al meglio l'impresa e farla crescere sia dimensionalmente che nelle singole performance, affrontando e contrastando tutte le eventuali barriere che si frappongono sul suo cammino verso tale scopo ${ }^{3}$.

Il processo di pianificazione della transizione imprenditoriale è fortemente influenzato e spesso ostacolato dall'incapacità dell'imprenditore di riconoscere il momento nel quale ritirarsi dalla gestione attiva della sua impresa. Tale momento viene reso ancora più complesso dal fatto che, se si

${ }^{3}$ Cfr. Piantoni, La successione familiare, cit.; Bertella, La pianificazione del ricambio generazionale, cit. 
escludono le cause relative a decessi prematuri o altre di tipo eccezionale, esso andrà a cadere nell'ultima fase della vita operativa di un imprenditore, che si colloca ormai frequentemente oltre i 70 anni.

Gli studi sulle fasi evolutive dell'uomo adulto chiariscono al meglio i problemi che si possono incontrare nel ritardare la programmazione successoria, con il prolungarsi della permanenza al potere della vecchia generazione e, di conseguenza, con una chiusura degli spazi riguardanti le giovani leve. Il permanere al potere in un periodo di 'tarda maturazione' dell'imprenditore costituisce una remora al cambiamento e all'innovazione. Egli infatti tenderà a mantenere le posizioni acquisite, alla ricerca di sicurezza, fattori che contrastano con l'evoluzione continua dei mercati, alla quale l'impresa familiare deve costantemente adeguarsi. In questa classe di età l'imprenditore è poco propenso a investire nuovo denaro, ad espandere l'impresa, a contrarre nuovi debiti e a reinvestire gli utili prodotti, mantenendo così l'azienda in una posizione di stallo per essa dannosa.

Per evitare questi pericoli è necessario che l'imprenditore abbia proceduto per tempo nell'attuare un adeguato meccanismo di pianificazione circa la propria successione, ricorrendo anche in certi casi, come abbiamo già detto, alla redazione di un Patto di famiglia. Questa programmazione dovrebbe avvenire, quindi, intorno alla fase di 'piena maturità' (45-55 anni), nella quale l'imprenditore è in possesso del giusto equilibrio tra propensione al rischio e salvaguardia delle posizioni raggiunte e degli equilibri creati, ed è inoltre ancora in grado di guidare i figli, sicuramente giovani, nella loro formazione.

L'evento successorio si caratterizza, quindi, per la sua alta criticità e per il fatto che esso deve essere gestito al meglio al fine di perdurare nella sua efficacia anche dopo l'avvenuto passaggio delle consegne. Una buona successione imprenditoriale (che cioè abbia le maggiori possibilità per concludersi positivamente) richiede una programmazione nel tempo, effettuata in modo non equivoco seguendo un apposito iter procedurale ${ }^{5}$. Una successione programmata per tempo consente, infatti, di affrontare l'evento in un momento nel quale l'imprenditore si trova ancora al meglio delle proprie capacità sia fisiche che psichiche, con le quali potrà guidare il futuro erede nel processo di apprendimento e nella successiva entrata nell'impresa di famiglia, consigliandolo sui problemi di gestione corrente e straordinaria.

In molti casi, invece, $\mathrm{i}$ tempi per attuare il processo di pianificazione slittano progressivamente a causa della mancanza di volontà da parte del fondatore. La successione diventerà così un fatto improvviso e non valutato con attenzione e si potranno inoltre manifestare da parte degli eredi inadeguatezze nella gestione dell'impresa, che non avevano avuto modo

${ }^{4}$ Per un'analisi più dettagliata cfr. par. 3 del capitolo quarto.

${ }^{5}$ Cfr. Bertella, La pianificazione del ricambio generazionale, cit. 
di evidenziarsi quando l'ormai ex imprenditore era ancora in carica ed alle quali più difficilmente potrà porsi rimedio.

Altro requisito da tenere in debita considerazione, vista la sua importanza, è quello relativo alla chiarezza con la quale deve svolgersi l'intero processo successorio. Il fondatore dovrà, di conseguenza, uscire di scena senza creare equivoci nel successore e negli altri membri aziendali circa il suo nuovo ruolo. Questo non significa necessariamente che l'ex imprenditore debba abbandonare totalmente l'impresa, ma è buona regola che egli non partecipi alla sua gestione attiva, in modo tale da non provocare interferenze che potrebbero mettere in dubbio la sua volontà di lasciare la posizione guida che prima deteneva.

È buona regola poi che il fenomeno successorio venga analizzato e vissuto dai familiari attraverso una partecipazione diretta allo stesso. Questa partecipazione potrà avvenire attraverso l'elaborazione di un apposito "piano successorio», cioè un insieme di regole, da tutti condivise, alle quali fare ricorso al momento del passaggio generazionale e solitamente inserite all'interno di un più ampio documento denominato «Patto di famiglia». Questo documento deve porsi l'obiettivo di esplicitare con chiarezza le regole per la scelta dei candidati al ruolo in questione, le modalità con le quali dovrà avvenire il loro processo di formazione ed inoltre le fasi operative con le quali avverrà materialmente il passaggio delle consegne. Parte di queste regole dovrebbero essere messe a conoscenza del personale dell'impresa, il quale avrà così la possibilità di prendere coscienza dei cambiamenti in atto nella distribuzione del potere aziendale.

Un processo di programmazione valido serve inoltre a stabilire delle regole anche sul piano familiare. Mentre, infatti, l'impresa è comunque un istituto che nella gestione della sua attività si avvale di tecniche e procedure note a tutti i componenti, così non è per la famiglia dell'imprenditore. Non esistono regole per la gestione dei rapporti tra consanguinei e per questo uno schema di riferimento servirà a prevenire contrasti e diverbi che potrebbero sorgere proprio per questa mancanza di schemi precostituiti. Per questo motivo le problematiche attinenti i potenziali candidati al ruolo imprenditoriale devono essere risolte definendo dei percorsi da seguire sotto il profilo:

- della scelta dei successori alla guida dell'impresa;

- delle modalità di distribuzione degli altri ruoli-chiave tra i familiari

- della pianificazione della formazione e della carriera di ciascun aspirante al ruolo imprenditoriale.

Con riferimento alla scelta del candidato alla sostituzione dell'imprenditore, occorre dire che non tutti i familiari debbono essere presi in considerazione in questo senso, ma soltanto quelli dotati di effettive capacità e di una volontà a subentrare nella posizione di guida. Come abbiamo visto, 
poi, il costume vuole, in determinati casi, privilegiare alcune componenti del clan familiare (maschi, figli maggiori, ecc.).

Spesso, a causa dei difficili rapporti che possono sussistere in ambito familiare, soprattutto per una scelta così sentita, il processo di pianificazione successoria è gestito e guidato attraverso l'ausilio di consulenti esterni, che consentono all'imprenditore di prendere coscienza dei problemi dell'impresa e delle sue prospettive di sviluppo future e individuando, di conseguenza, il candidato ideale per raggiungerle. Il contributo degli intermediari è apprezzabile sia con riguardo alla risoluzione dei contrasti intrafamiliari che possono sussistere, facendo prendere coscienza a ciascuno che il bene comune viene prima delle ambizioni del singolo, sia nel gestire al meglio i problemi più tecnici di tipo organizzativo e legale che la successione inevitabilmente comporta.

In conclusione potremo affermare che la successione imprenditoriale, per svilupparsi al meglio, necessita di una serie di contributi da parte di una molteplicità di attori che vengono in essa coinvolti e che debbono venire indirizzati su binari tracciati con largo anticipo, in modo tale da pervenire al risultato voluto, che poi non è altro che il migliore sviluppo del binomio impresa-famiglia.

\section{Le fasi operative della successione imprenditoriale}

Dopo aver accennato nel paragrafo 1 del presente capitolo quali siano

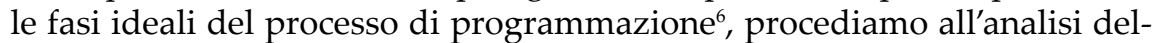
le fasi operative della successione imprenditoriale che qui rappresentiamo sinteticamente.

- acquisizione della consapevolezza della successione da parte dell'imprenditore;

- ricerca della figura dell'imprenditore all'interno della famiglia;

- ruolo del successore in relazione al regime teleologico;

- grado di trasparenza delle caratteristiche che dovrà avere l'imprenditore;

- modalità di ingresso del successore;

- comportamenti attuati dal nuovo imprenditore;

- valutazioni imprenditoriali del neo-imprenditore;

- ostacoli attuativi al processo successorio;

- forme di reazioni al cambiamento.

${ }^{6}$ Le ricordiamo in:

- consapevolezza dell'imprenditore;

- designazione del successore;

- ritiro dell'imprenditore e subingresso del nuovo imprenditore. 
Pianificare la successione nell'impresa familiare implica, innanzitutto, che l'imprenditore acquisisca la consapevolezza di dovere un giorno, in modo ragionato o istintivamente, lasciare l'impresa senza che questo costituisca un fatto traumatico ${ }^{7}$. Tale consapevolezza dovrebbe maturare con largo anticipo rispetto al momento nel quale si ritenga più opportuno operare la successione, in modo tale che la stessa possa venire programmata al meglio. L'autoconvincimento è però difficile da raggiungere proprio per le caratteristiche tipiche dell'imprenditorialità familiare, che vuole un imprenditore accentratore e profondamente in simbiosi con la realtà che governa. Per queste ed altre motivazioni, l'imprenditore tenderà sempre a rimandare il problema, non considerando i rischi che potrebbe correre, così facendo, la sua impresa.

Le difficoltà insite nel programmare il proprio ritiro nascono da alcune reazioni psicologiche dell'imprenditore, come ad esempio, il sentirsi indispensabile, il bisogno di dimostrare ancora le proprie capacità e competenze, la mancanza di fiducia nei confronti del successore ${ }^{8}$, ecc. Queste difficoltà tendono spesso a sfociare in conflitti tra padre e figlio oppure tra i fratelli candidati alla successione, e sono ascrivibili anche all'insicurezza regnante nell'impresa fino a quando non vengano rese chiare le decisioni dell'imprenditore uscente.

Se invece l'imprenditore inizia a riflettere sul problema per tempo, la consapevolezza della successione potrà maturare per diverse motivazioni, fra cui:

1. la progressiva inadeguatezza dell'imprenditore rispetto alle variazioni delle sue funzioni impostegli dai mutamenti del marcato;

2. una prospettiva futura diversa delle proprie funzioni espressa da terzi attori influenti, che faranno così comprendere all'imprenditore l'inadeguatezza al proprio ruolo;

3. la spinta, sempre maggiore, da parte di soggetti diversi nell'acquisire il ruolo in questione;

4. la volontà di ritiro determinata da motivazioni differenti da quelle sopra esposte, non ultimi gli imprevisti di vario tipo.

A parte l'ultimo caso, nel quale la successione arriva come un evento imprevisto dovuto alla morte o ad impedimenti dell'imprenditore, negli altri si assiste ad atteggiamenti che vanno dal totale rifiuto del ritiro alla piena consapevolezza dello stesso. Ogni volta che vi sia piena consapevolezza di dover lasciare il governo dell'impresa, l'imprenditore ravvisa in prima persona la necessità della sua successione ed accetta con lo spirito volto soprattutto a governare il processo di successione, di programma-

Cfr. Schillaci, I processi di transizione, cit.

${ }^{8}$ Cfr. Ciambotti, I processi di transizione imprenditoriale, cit. 
re con il management i passi necessari per il suo migliore svolgimento. All'estremo opposto, a volte, l'imprenditore non ravvisa la necessità del passaggio delle consegne e non l'accetta, intendendo rimanere saldamente ancorato al ruolo che svolge. In quest'ultimo caso, se il management aziendale è di avviso contrario rispetto al pensiero dell'imprenditore in carica, potranno facilmente nascere conflitti e rivalità dannosi per l'impresa e la sua gestione.

Da quanto esposto finora, risulta chiaro come la maggior o minore consapevolezza nell'affrontare la successione imprenditoriale incida in modo determinante sullo svolgimento del processo stesso, creando o meno situazioni di conflitto.

Il diverso grado con il quale può essere avvertita la consapevolezza della successione deriva non soltanto dall'imprenditore in prima persona, ma anche dall'insieme di soggetti che operano nell'impresa familiare e che possono convincere quest'ultimo al ritiro, facendogli comprendere le problematiche alle quali si potrebbe andare incontro nel caso contrario.

Dal lato dell'imprenditore, la consapevolezza all'abbandono del ruolo è legata a specifiche caratteristiche quali, per esempio, l'età avanzata; un imprenditore molto giovane tende, infatti, a non porsi il problema. Tuttavia l'età è solo uno dei fattori da prendere in considerazione nell'affrontare la presa di coscienza con riferimento al ricambio generazionale. Incideranno su questa anche gli obiettivi personali dell'imprenditore, i suoi valori, il suo stile di direzione, i metodi con cui governa e dirige l'impresa, ecc. Molto importanti sono poi la competenza e la professionalità dell'imprenditore, fattori questi in grado di incidere sulla capacità di comprendere il problema, percepirlo con correttezza e valutare l'insieme di comportamenti che sarebbero necessari per porvi rimedio.

Da quanto visto, risulta importante per l'esercizio efficace della funzione imprenditoriale, il saper affrontare con chiarezza e competenza il problema del ricambio generazionale. Qualora poi l'imprenditore non riesca, in modo autonomo, a ravvisare il problema successorio, come abbiamo accennato in precedenza, la consapevolezza di ciò può essere sviluppata dagli altri soggetti coinvolti nella gestione dell'impresa. In questo caso diviene di fondamentale importanza la professionalità, la sincerità e la correttezza degli attori in questione. Al loro aumentare, cresce anche l'attendibilità della critica nei confronti delle scelte operate dall'imprenditore e quindi sulla sua adeguatezza al ruolo. La necessità del ricambio può essere fatta sentire da questi soggetti nei casi in cui si ravvisi l'inadeguatezza della direzione gestionale rispetto ai nuovi compiti ed alle nuove opportunità che il mercato offre. Qualora, infatti, queste opportunità non vengano sfruttate, si creerà un clima di generale malumore interno all'impresa, che non farà altro che sfociare in un declino se non si provvede ad una brusca svolta determinata, ad esempio un ricambio al vertice. Naturalmente, gli attori della gestione non potranno far altro che rendere cosciente l'imprenditore della situazio- 
ne nella quale versa la sua impresa, ma la decisione di abbandonare il ruolo spetterà in definitiva solo a quest'ultimo.

Si vede quindi come la prima fase della successione dovrebbe essere caratterizzata da un imprenditore in grado di:

- percepire i rischi e le opportunità alle quali va incontro;

- concepire razionalmente il passaggio generazionale come un momento critico di cambiamento da gestire con anticipo e non da ritardare nel tempo;

- facilitare la successione determinando un clima di consenso tra tutti gli attori coinvolti nella stessa.

Sulla base di questi presupposti si potrà passare con serenità a gestire la successiva fase del ricambio generazionale.

Presa consapevolezza della opportunità successoria, si giunge al momento di affrontarla. La domanda da porsi, a questo stadio, è quella se esista in famiglia (o in impresa) un imprenditore a livello potenziale, in grado di esprimere le proprie capacità dopo aver attraversato un adeguato processo formativo. Specialmente nelle PMI è di fondamentale importanza l'esistenza di un erede in grado di continuare l'attività dopo il ritiro della figura guida precedente, proprio perché spesso le vicenda della società sono intimamente legate a quelle del suo uomo-guida, ed è auspicabile (per la maggior parte delle imprese) che questo soggetto sia rintracciabile internamente alla famiglia che detiene il controllo. A questo proposito si possono individuare quattro diversi percorsi che un potenziale erede potrà affrontare per dimostrare e sviluppare le sue capacità?:

- avviare una nuova iniziativa imprenditoriale o acquisire una nuova azienda che risponda appieno alle sue vocazioni imprenditoriali. Questa è la soluzione che meglio di tutte consente di mettere alla prova le effettive capacità gestionali dell'erede, il quale viene messo in condizione di operare al meglio seguendo le sue aspirazioni e dimostrando di valere, indipendentemente dal cognome che porta, meritando sul campo il rispetto e la fiducia dei suoi collaboratori;

- affidargli, nella stessa impresa di famiglia, lo sviluppo di un nuovo business, di una nuova area territoriale, così da affrontare autonomamente la realtà imprenditoriale, comunque supportato da una struttura ed organizzazione già affermati sul mercato. Anche qui, se l'erede dimostrerà le proprie capacità direzionali, acquisirà rispetto tra i suoi collaboratori ed il ricambio generazionale diverrà meno traumatico;

\footnotetext{
${ }^{9}$ Cfr. Di Vittorio, Evoluzione e funzione dell'impresa familiare, cit.
} 
- effettuare esperienze esterne che gli permettano di sviluppare le proprie capacità, anche in business diversi rispetto a quelli gestiti dall'impresa di famiglia, in modo da comprendere al meglio le difficoltà del ruolo in questione e valutare con calma, e non 'sulla pelle dell'impresa', l'effettiva attitudine a ricoprire incarichi così importanti;

- effettuare esperienze interne all'impresa, entrando in essa come assistente dell'imprenditore o di qualche altro manager importante. È la soluzione più scomoda, in quanto non consente di apprezzare a pieno le capacità imprenditoriali dell'erede, il quale si trova in una posizione ambigua tra ruolo proprietario e dipendente.

Ereditare il ruolo imprenditoriale significa quindi passare un doppio esame, in quanto il successore deve essere in grado:

- di dimostrare le proprie conoscenza e competenze, le quali dovranno essere addirittura superiori a quelle del suo predecessore, in quanto egli si troverà ad operare in uno scenario competitivo sicuramente più ampio e quindi più difficile da gestire;

- di riuscire ad ottenere il rispetto dei suoi collaboratori (familiari e non), attraverso i meriti acquisiti 'sul campo', in quanto potranno essere frequenti i paragoni tra il suo operato e quello del predecessore; in tal senso è buona norma che il 'bilancio' abbia sempre ad essere in positivo.

La scelta del successore diviene poi ancora più difficoltosa se si ha a che fare con una famiglia giunta al secondo o al terzo passaggio generazionale, perché diviene ancora più sentita e sarà più difficile affrontare i contrasti per l'acquisizione del ruolo in esame. Le rivalità, se mal gestite, potrebbero portare addirittura alla vendita o alla rovina dell'impresa e perciò diviene fondamentale la figura dell'imprenditore competente e capace di gestire le rivalità, trasformandole magari anche in occasioni di sviluppo per l'impresa. Se non è presente una figura di questo tipo è necessario far fronte alla questione attraverso l'ausilio di esperti esterni.

È bene tener presente, comunque, che la scelta del successore non è conveniente ricada obbligatoriamente su un membro interno alla famiglia (anche se questa è la soluzione adottata e preferita nella grande maggioranza dei casi). Qualora nessuno degli eredi presenti le caratteristiche ideali al fine di guidare con successo il futuro aziendale, la scelta dovrà ricadere su candidati esterni, i quali, possedendo le necessarie capacità, potranno guidare con profitto l'azienda e garantirle una sana continuità. Anche questa soluzione richiede però un periodo di formazione per il successore, che gli garantisca la migliore comprensione delle problematiche che si troverà ad affrontare al momento del suo insediamento e nel futuro. 
Come nei processi dinastici, tuttavia, la tendenza dei genitori è però quella di favorire comunque i figli, indipendentemente dalle capacità che essi dimostrino (o non dimostrino) di possedere. Per questo, una delle vie adottate è quella di fissare a priori delle regole imparziali che servano a rendere la scelta del successore maggiormente oggettiva e volta a privilegiare, in primo luogo, il bene e la continuità dell'impresa. Le regole devono essere approvate con l'accordo di tutti ed inserite in un apposito documento (il già ricordato «Patto di famiglia») ${ }^{10}$. Tra queste regole possiamo ricordare la necessità di un titolo di studio minimo, l'aver svolto un'esperienza esterna di una certa durata, ecc. Queste norme fungono quindi da griglia di selezione dei potenziali candidati, in quanto solo i più motivati e capaci potranno superare gli 'ostacoli' che esse pongono e quindi aspirare al ruolo imprenditoriale.

Da quanto visto fin qui, possiamo affermare che, l'identificazione del successore 'ideale' dovrà tener conto di tre importanti fattori ${ }^{11}$ :

1. la fonte di designazione;

2. la provenienza interna o esterna alla famiglia o all'impresa;

3. le capacità richieste al successore.

\section{La fonte di designazione}

La fonte di designazione è rappresentata dal soggetto che dovrà scegliere il successore al ruolo imprenditoriale ed è, solitamente, incarnata da parte dell'imprenditore stesso. Questi valuterà attentamente tutti i possibili candidati, al fine di trovare la persona più idonea a perseguire le finalità dell'impresa ed il suo sviluppo futuro. Naturalmente tutto ciò non potrà venire totalmente svincolato da quelli che sono il pensiero, il complesso di valori, le esperienze e le conoscenze proprie del valutatore, le quali di conseguenza influenzeranno comunque la scelta.

Le influenze potranno arrivare fino a punte massime qualora l'imprenditore uscente attui uno dei seguenti comportamenti:

- l'imprenditore è molto legato al proprio ruolo e, di conseguenza, non vuole abbandonarlo, perciò mette in pratica azioni volte a dimostrare la propria indispensabilità in seno all'impresa. Una di queste azioni potrebbe essere proprio quella relativa alla scelta di un candidato non idoneo alla successione, il quale, con le sue azioni, dimostri la tesi dell'impresa inseparabile dalla figura che precedentemente la guidava. Questo comportamento nasconde, in certi casi, anche la

${ }^{10}$ Cfr. par. 3 del capitolo quarto.

${ }^{11}$ Cfr. Di Vittorio, Evoluzione e funzione dell'impresa familiare, cit. 
speranza di veder operare una sorta di transizione contraria, cioè un fallimento della nuova generazione che spinga l'ormai ex imprenditore a tornare sui suoi passi e riprendere così in mano le redini della sua azienda. Si assisterà, in questo caso, ad un ritorno dalla seconda alla prima generazione;

- l'imprenditore vuole che l'impresa che ha creato (o comunque governato per lungo tempo), continui ad operare secondo quei meccanismi, ampiamente rodati, messi a punto durante la sua gestione, senza che avvengano modifiche sostanziali nelle quali egli non riconoscerebbe la propria 'creatura'. La volontà del dirigente uscente, sarà quindi quella di trovare un successore che lo rispecchi nei comportamenti, una sorta di 'clone'. Avendo questa convinzione, egli tenderà, nel processo di scelta del successore, ad eliminare a priori tutti quei soggetti che dimostrino di voler attuare comportamenti gestionali di tipo innovatore o dissenziente, i quali, in certi casi, potrebbero invece rappresentare l'alternativa più idonea a creare uno sviluppo durevole per l'impresa familiare. Trovare una figura che rispecchi completamente il modo di operare dell'imprenditore uscente può rivelarsi dannoso per l'azienda, la quale rappresenta una realtà in continua evoluzione, per cui è importante cercare elementi dotati del necessario grado di flessibilità e non persone legate al passato (anche qualora questo sia stato positivo);

- un caso molto simile al precedente è quello in cui l'imprenditore tende a selezionare una figura non dotata della necessaria fermezza per essere totalmente indipendente nel ruolo che è chiamato a ricoprire. In questa situazione, egli sarà formalmente indipendente, ma di fatto dominato dalla figura dell'ex dirigente, il quale potrà nelle retrovie guidare i comportamenti dell'attuale leader, senza però essere in primo piano. Il processo di transizione in questo caso è puramente di tipo formale, non esistendo i requisiti di una sua sostanzialità.

I tre casi sopra visti rappresentano le realtà più comuni nelle quali il processo di transizione avviene in maniera non corretta e questa alterazione è dovuta in primo luogo al soggetto che compie la scelta fondamentale del successore. Formalmente l'imprenditore procede ad un ricambio generazionale, ma nella sostanza egli fa di tutto per impedire che esso avvenga, non comprendendo che così facendo compie soltanto atti a danno della propria impresa.

Per evitare questi pericoli, occorre che la scelta dell'erede designato sia attuata in modo maggiormente oggettivo. Potranno perciò interagire con l'imprenditore altri soggetti, nella figura di consulenti, i quali avranno il compito fondamentale di guidare la scelta verso i giusti candidati e di far comprendere al leader uscente le potenzialità di questi ultimi, ben sapendo comunque che la decisione finale spetterà solo a lui. 


\section{Provenienza interna o esterna alla famiglia o all'impresa}

La scelta del successore potrà avvenire tra soggetti che fanno parte della famiglia del fondatore o esterni alla stessa, o anche tra soggetti interni o estranei all'impresa di riferimento.

Il desiderio maggiore, nella gran parte delle imprese familiari, è quello che il successore venga scelto tra i membri della famiglia d'origine del fondatore. La decisione finale in merito, come visto, spetterà all'imprenditore, il quale, sulla base delle proprie convinzioni, valori ed obiettivi, ed eventualmente supportato da intermediari esterni o interni, selezionerà i candidati alla successione, che potranno essere soggetti interni alla famiglia, oppure anche esterni ad essa. Molta influenza, in questo senso, avranno i rapporti famiglia-impresa: maggiore sarà il coinvolgimento della prima nella seconda, maggiore sarà di conseguenza la possibilità che il successore ne faccia parte. Qualora ciò avvenga, sarà importante tenere in considerazione la situazione che la famiglia attraversa: una fase caratterizzata da conflitti, gelosie, interessi diversi comporterà un passaggio generazionale di tipo traumatico, con continue liti e dispute per i posti di controllo.

La scelta di un successore interno alla famiglia porta quindi con sé un possibile insieme di problemi che si possono così riassumere:

- il primo è quello relativo ai rapporti padre-figlio. Questi potrebbero essere caratterizzati da un senso di sudditanza psicologica dell'erede nei confronti del genitore $\mathrm{o}$, al contrario, da un totale rifiuto delle sue idee e delle sue scelte; tutti comportamenti questi che sfociano in diverbi e contrasti tra le due generazioni che provocheranno sicuramente ripercussioni all'interno dell'impresa;

- un secondo tipo di problemi è dato dalle più comuni forme di rivalità e conflitti che si creano in seno alla famiglia. Se, infatti, gli aspiranti successori sono più d'uno, ed inoltre non sono state formulate norme e regole attinenti alla sua scelta, la selezione in questione diverrà 'terreno di battaglia' e farà esplodere tensioni sopite, provocando di conseguenza ostilità ed attriti in seno all'impresa;

- un problema ben più grave si ha qualora il candidato scelto a succedere nel ruolo di guida aziendale dimostri di non possedere i requisiti idonei a ricoprire tale difficile posizione. In questo caso, se sono stati privilegiati soggetti esclusivamente in quanto membri della famiglia, si potranno avere anche qui tensioni interne all'impresa. Così facendo si è infatti preferito attuare una scelta sulla base di motivazioni personali, rispetto ad una preferenza basata su logiche economiche e di sviluppo dell'impresa. Non sempre però accade che gli eredi si dimostrino inadeguati rispetto al ruolo da ricoprire, anzi è facile il contrario, visti gli stimoli che essi subiscono da una famiglia da tempo immersa nel mondo degli affari. Proprio questo clima di 
imprenditorialità che si respira in famiglia potrebbe però essere uno stimolo per i giovani eredi a non venire inseriti nella realtà aziendale di famiglia, ma provar da soli ad intraprendere un nuovo cammino nel campo imprenditoriale;

- ultimo problema che si può incontrare, in conseguenza alla scelta di un successore interno alla famiglia, è quello relativo ai rapporti con gli altri collaboratori dell'impresa. Essi potrebbero sentirsi frustrati e delusi dal mancato riconoscimento dei propri meriti, che si esprime nell'impossibilità di aspirare alla posizione dirigenziale qualora la scelta debba ricadere sempre su consanguinei dell'imprenditore. Tutto ciò potrà avere l'effetto negativo di un abbandono dell'impresa da parte di questi soggetti che, non vedendo riconosciuti i propri meriti e sforzi, tendono a ricercare soddisfazioni in altri ambiti, producendo così una perdita non solo umana per l'impresa, ma anche di tipo culturale e professionale.

Questi problemi dovranno essere risolti a monte da parte dell'imprenditore uscente, il quale, qualora voglia comunque privilegiare i candidati interni alla famiglia, dovrà renderli almeno competitivi con le figure professionali presenti all'esterno, legittimandoli di conseguenza anche agli occhi dei dipendenti. Questo potrà avvenire facilmente attraverso la scelta, internamente alla famiglia, dei soli eredi che possiedano le qualità giuste e la volontà per aspirare al ruolo. Avvenuto ciò, si procederà con l'attuare, nei confronti di questi ultimi, un adeguato processo di formazione che faccia loro acquisire le competenze necessarie per subentrare nella posizione vacante. Tutto ciò legittimerà l'erede allo svolgimento del proprio compito e lo preparerà ad affrontare gli ostacoli (anche di inserimento) che incontrerà lungo il suo percorso.

Nel caso in cui il successore sia invece una persona esterna alla famiglia, si possono avere due casi distinti:

1. il successore è esterno alla famiglia, ma interno all'impresa;

2. il successore è esterno alla famiglia e anche all'impresa.

Nella prima ipotesi, un successore esterno alla famiglia potrà essere nominato: qualora manchino, in seno ad essa, i potenziali candidati; qualora vi siano potenziali eredi in famiglia, ma questi vogliano svolgere attività diverse; nei casi in cui gli eredi familiari siano inadeguati; qualora infine vi siano troppi conflitti interni al clan familiare circa le scelte del candidato e si preferisca perciò adottare una scelta che non privilegi nessuna parte, puntando su professionalità esterne.

Questo tipo di successione è meno problematico dei precedenti, ma solo se è condiviso da tutti i membri della famiglia. Se, infatti, alcuni eredi del 
fondatore si sentissero privati di un ruolo ad essi spettante, si potrebbe pervenire a contrasti volti ad intralciare e ritardare il ricambio generazionale, con ripercussioni inevitabili sullo sviluppo e la redditività aziendale. Se invece questi contrasti vengono risolti, o non sussistono affatto, la scelta di un candidato esterno avrà il privilegio di poter contare su una riconosciuta competenza e capacità del successore, senza sospetti di favoritismi e, di conseguenza, anche i collaboratori d'impresa saranno maggiormente portati allo svolgimento ottimale della loro attività, per poter un giorno aspirare al ruolo in questione.

Il caso in cui il candidato alla successione sia esterno tanto alla famiglia quanto all'impresa è molto più raro dei precedenti. La scelta di questo tipo di figura si avrà qualora non esistano potenziali eredi familiari e nemmeno idonei collaboratori d'impresa. Sarà una scelta difficile, in quanto l'entrata di un esterno (soprattutto in posizione dirigenziale) è quasi sempre vista come una minaccia da parte di coloro che operano in un'azienda. Dal canto suo, il nuovo imprenditore avrà sicuramente maggiori difficoltà di ambientamento rispetto ai candidati interni. Tale via è però spesso scelta da imprenditori che vogliono dare una svolta rispetto al passato, ricercando nuove condizioni di sviluppo e gestionali.

\section{Le capacità richieste al successore}

Nella scelta del successore è importante valutare le capacità possedute da ciascuno dei candidati al ruolo in questione. L'erede designato dovrà infatti possedere una serie di caratteristiche che gli consentano di operare al meglio nell'impresa e che si adattino alle esigenze di questa, sia per quanto riguarda il presente sia, soprattutto, per ciò che attiene il futuro. Il successore 'ideale' è quindi colui il quale riesce a portare a termine il ricambio generazionale senza che si creino rilevanti ritardi ed inefficienze, ed inoltre riesce a gestire nel migliore dei modi il futuro dell'impresa familiare, comprendendo le sue possibilità di sviluppo.

L'erede, per gestire al meglio il ricambio generazionale avrà necessità di possedere la capacità di comprendere i bisogni attuali dell'organizzazione, di contrastare le problematiche che possono accompagnare il passaggio delle consegne ed infine, saper sviluppare un clima di consenso intorno a sé. Per poi sviluppare l'impresa familiare e portarla a nuovi livelli di gestione, egli necessita delle capacità di essere in grado di definire lo stato al quale l'azienda potrà realisticamente ambire in futuro, di mediare le caratteristiche necessarie al raggiungimento di tali obiettivi, con quelle attuali dell'impresa; dovrà essere in grado di 'leggere' attentamente e con razionalità la situazione attraversata dal sistema aziendale e di impostare di conseguenza la gestione direzionale ed operativa, in modo tale da ottenere $\mathrm{i}$ migliori risultati.

La scelta ricadrebbe su un soggetto dotato, se non di tutti, della gran 
parte di questi requisiti, i quali per una migliore comprensione, possono essere a loro volta raggruppati in tre macro-categorie ${ }^{12}$ :

1. capacità di apprendimento;

2. capacità di identificazione;

3. capacità di ruolo.

Queste tre capacità sono tra loro collegate e predisposte in modo sequenziale, nel senso che sono l'una propedeutica all'altra: l'imprenditore dovrà, infatti, prima apprendere le nozioni che applicherà in seguito, si dovrà identificare nella realtà nella quale opera e comprendere il ruolo che è chiamato a svolgere (cfr. fig. 3.1).

Figura 3.1. Le capacità di cui necessita il successore

$\begin{array}{ccccc}\text { Capacità di } & \rightarrow & \text { Capacità di } & \rightarrow & \text { Capacità di } \\ \text { apprendimento } & \leftarrow & \text { identificazione } & \leftarrow & \text { ruolo }\end{array}$

Fonte: C.E. Schillaci, I processi di transizione del potere imprenditoriale nelle imprese familiari, Giappichelli, Torino 1990, p. 91.

Le capacità di apprendimento richieste ad un valido successore riguardano la comprensione dei meccanismi di funzionamento specifici della realtà nella quale si opera, intendendo con essa sia la situazione specifica dell'impresa familiare sia quella più globale dell'impresa di riferimento. Oltre a ciò, l'erede è chiamato a percepire, con largo anticipo, eventuali segnali di mutamento di dette condizioni, al fine di adeguarvisi con prontezza e in modo da non venire colto impreparato.

La capacità di apprendimento può essere migliorata solo dallo stesso (vecchio) imprenditore che può agire sui fattori che la determinano, e più in particolare:

- il tempo. Un buon apprendimento (acquisizione di conoscenza) non potrà essere realizzato se il ricambio generazionale avviene in modo improvviso e inaspettato, senza programmazione successoria;

- la motivazione. È forse un pre-requisito del successore, sul quale l'imprenditore esercita un'azione di stimolo costante tesa ad orientare l'apprendimento;

- la conoscenza dei risultati. Conoscere quelli che sono i vantaggi dell'apprendimento aiuta l'erede ad indirizzare i propri sforzi verso di essi e ad essere maggiormente stimolato in tal senso. 
La seconda capacità che dovrebbe possedere un valido candidato al ruolo imprenditoriale, riguarda l'attitudine ad identificarsi con l'impresa. L'azienda infatti è una realtà storica, che si è evoluta nel tempo, dotata di una serie di caratteristiche che derivano direttamente dai soggetti che operano in essa o che vi hanno operato in passato. Compito del potenziale erede sarà quello di far propria questa serie di elementi e di amalgamarsi il più possibile al contesto in questione, in modo tale da divenirne parte integrante.

La 'capacità di identificazione' è quindi l'attitudine dell'erede ad accettare e farsi accettare all'interno dell'impresa di famiglia, comprendere i valori di fondo che la animano, fare, di conseguenza, propria la missione perseguita e comprendere al meglio le modalità di gestione utilizzate in passato dal proprio predecessore al fine di modificarne in parte il contenuto, in modo tale da renderlo maggiormente consono alle mutate condizioni che il mercato impone. Per questi motivi, identificarsi con l'impresa non significa mantenere inalterate le condizioni che le hanno permesso di operare fino a quel momento, ma, qualora il neo-imprenditore apporti sostanziali modifiche all'assetto strutturale e operativo, occorre tener conto che le modifiche stesse siano parte integrante della realtà aziendale. In altre parole significa che egli ha compreso le necessità fisiologiche della società ed ha proceduto ad assecondarle, dimostrando con ciò di essere inserito nelle problematiche gestionali.

Il processo di identificazione con l'impresa familiare risulta influenzato da una serie di fattori:

1. dalla condivisione degli obiettivi aziendali con gli altri soggetti che già operano nell'impresa;

2. dalle modalità con le quali il neo-imprenditore vede soddisfatti i propri bisogni attraverso il raggiungimento degli obiettivi suddetti;

3. dalla frequenza dei contatti con il resto della compagine aziendale, in quanto maggiore sarà il tempo impiegato a stretto contatto con i propri collaboratori, maggiore sarà la cementificazione delle relazioni e più alta sarà la sensazione di appartenenza ad una 'famiglia aziendale';

4. dal prestigio che l'imprenditore ritiene di assumere operando nella realtà aziendale in questione; il prestigio sarà direttamente proporzionale alla posizione ricoperta dall'azienda, alla sua visibilità sociale, ecc.;

5. dalla mancanza di concorrenza con altri soggetti per il ruolo imprenditoriale, in quanto essere l'unico potenziale candidato sarà una maggiore fonte di stimolo all'operare ed al divenire parte di un gruppo.

Il ruolo che il successore è chiamato a svolgere si differenzia poi a seconda del diverso regime teleologico ${ }^{13}$ presente nell'impresa che è chiama-

${ }_{13}$ Sull'argomento cfr. C. Vallini, Fondamenti di governo e di direzione d'impresa, Giappichelli, Torino 1990. 
to a governare. In questo senso si possono distinguere quattro tipologie di eredi che possono divenire 'confermatori', 'riorientatori', 'rivitalizzatori' o 'trasformatori' della realtà aziendale loro attribuita in gestione. Sarà, infatti, differente la strategia direzionale da adottare qualora l'impresa debba soltanto essere rivitalizzata, oppure si trovi in uno stato di scompenso tale da rendersi necessaria una più radicale trasformazione.

Se l'impresa si trova già in un buono stato di salute ed opera a condizioni favorevoli che le possono garantire ancora per un certo lasso di tempo uno sviluppo costante, occorrerà una figura di imprenditore che 'confermi' le strategie positive messe in pratica dal suo predecessore. Compito del successore sarà quindi quello di capire, al meglio, la formula imprenditoriale adottata dal precedente gestore d'impresa e far propri i punti di forza che ne hanno garantito il successo. La strategia precedente ha, infatti, dimostrato di essere valida nel tempo e di potersi ben adattare ai mutamenti ambientali ed interni. Comprenderne i valori vincenti significherà non solo partire avvantaggiati nella gestione futura, ma sfruttare i vantaggi insiti in tale formula imprenditoriale per modificare l'impresa e renderla ancora più al passo con i rinnovati obiettivi strategici. L'errore più grave che può commettere il neo-imprenditore che si trovi ad operare in questa favorevole situazione è quello di adagiarsi sulle posizioni raggiunte, le quali se ancora ottimali in quel momento per la prosecuzione della vita aziendale, ben presto, si potrebbero rivelare anche obsolete. Occorre, quindi, dare nuova linfa alle strategie, migliorandole costantemente in modo da essere sempre pronti ad affrontare le inevitabili problematiche aziendali derivanti da mutamenti del mercato nel quale si opera.

Diverse sono le capacità richieste ad un successore che si trovi a dover operare in un'impresa che necessiti di un 'riorientamento'. Questo potrà derivare da una errata gestione passata o da mutamenti esterni che non sono stati ben compresi ed assecondati dal predecessore. Il neo-imprenditore sarà chiamato quindi a riformulare una nuova strategia gestionale che sia maggiormente coerente con gli sviluppi del mercato e le condizioni operative interne. Il successore verificherà poi se intervenire solo sulle linee di gestione non più al passo con i tempi e non su quelle che hanno, comunque, permesso all'impresa di continuare fino ad oggi proficuamente le sue attività. L'errore di maggior portata in questo senso sarebbe quello di voler cambiare tutto e subito, non prendendo in considerazione i valori più radicati che, se confermati, possono ancora essere dotati di una loro validità.

In altri casi, si rende necessario un imprenditore che abbia le caratteristiche di 'rivitalizzatore' aziendale. Il suo ruolo consisterebbe nel ridare fiducia all'impresa, nel ricostituire una solida struttura dirigenziale, nel ridare coerenza alle scelte strategiche di fondo. Si tratta, infatti, di una situazione nella quale l'impresa si trova ad uscire da un periodo caratterizzato da conflitti interni, da tensioni, da inadeguatezze dell'imprenditore precedente e necessita, quindi, di una sorta di check-up volto a comprendere ciò 
che è necessario per risollevarla e farla nuovamente divenire protagonista nel settore nel quale opera.

La trasformazione, infine, è l'intervento più radicale che si richiede qualora l'impresa non sia più in grado di procedere nelle condizioni precedenti. Si tratta di una situazione nella quale il neo-imprenditore è chiamato a dimostrare non solo le capacità di riorganizzazione operativa e strategica, ma anche di modifica della cultura e dei valori di fondo dei soggetti che operano in azienda. Occorre perciò organizzare attività rieducative, oltre a modificare strutture e processi; interventi questi molto lunghi e difficoltosi, ma che si rendono necessari per la sopravvivenza dell'intera azienda familiare.

Tutte le caratteristiche che dovrà avere il neo-imprenditore non sono sempre connaturate e palesate nei potenziali candidati al ruolo imprenditoriale. Nella situazione in cui i candidati abbiano connaturate le caratteristiche richieste per il ruolo di imprenditore, si tratterà di far emergere detti requisiti sia attraverso un percorso di studi, sia con la maturazione di esperienze empiriche. Risulta evidente che questi ultimi interventi saranno ancora più importanti e necessari se il/i candidato/i al ruolo imprenditoriale non ha connaturate le caratteristiche innanzi evidenziate.

La formazione imprenditoriale riguarda principalmente il bagaglio di esperienze che il candidato è necessariamente chiamato ad assumere e che si rifletteranno sull'esito delle problematiche che egli incontrerà lungo tutto il suo percorso gestionale. Così gli ostacoli potranno essere affrontati e superati più o meno agevolmente, a seconda che si siano incontrati in passato o che si disponga di sufficienti conoscenze maturate sul campo.

Ricordiamo però che l'apprendimento del ruolo necessita comunque di studi teorici maturati, che possono riguardare i più diversi campi applicativi, e che, comunque, permettano al successore di formarsi una cultura minima indispensabile per poter proficuamente affrontare il mondo che lo circonda senza eccessivi dubbi, titubanze o, addirittura, complessi d'inferiorità. Questo percorso culturale potrà fermarsi a studi superiori, oppure procedere in campo universitario. In quest'ultimo caso la scelta della facoltà può diventare importante e, per il futuro imprenditore, si dovrà tenere conto anche dell'ambito nel quale vorrà operare in futuro, senza comunque trascurare gli interessi personali del candidato. Infatti solo studiando argomenti che rientrano, o si ritiene che debbano rientrare, nei suoi interessi, il futuro imprenditore potrà procedere proficuamente nel suo percorso di maturazione intellettuale ed entrare successivamente nell'impresa familiare conscio dei suoi mezzi e delle nozioni che, finalmente, potrà mettere in pratica.

In un adeguato processo di formazione, risulta di grande importanza maturare un'esperienza esterna all'impresa familiare. Questo momento, di fatto, diviene il fulcro di tutto il processo e a volte può essere anche una scelta obbligata per permettere al successore di dimostrare il suo va- 
lore, legittimando ulteriormente il suo ingresso nel ruolo imprenditoriale, una volta terminato il percorso formativo ${ }^{14}$. Spesso il problema non è tanto se fare o meno un'esperienza esterna, ma come affrontarla nel migliore dei modi.

Sono molteplici le motivazioni che spingono l'imprenditore uscente a propendere per un'esperienza esterna attuabile da parte del successore. Alcuni ritengono che questa sia opportuna al fine di acquisire nuove conoscenze ed una maggiore professionalità. Altri ritengono utile l'esperienza in relazione alla comprensione maggiore delle problematiche $\mathrm{d}^{\prime} \mathrm{im}$ presa, che si potrà acquisire soltanto operando direttamente sul campo. Altri ancora pensano che l'erede, che comunque dovrà operare sotto un superiore, impari ad obbedire meglio all'imprenditore ed accetti così passivamente le decisioni da lui prese (si tratta in questo caso di imprenditori, solitamente, restii a lasciare la propria posizione). Frequentemente, poi, il leader uscente si augura che l'erede possa acquisire un po' di tutto quanto esaminato finora.

Una soluzione efficace, potrebbe essere quella di un'esperienza esterna, maturata dall'erede, presso un concorrente dell'impresa familiare. Questa consentirebbe al successore, di conoscere meglio la realtà del settore nel quale in futuro si troverà ad operare e comunque permetterà al successore stesso di confrontare un diverso modo di governare un'impresa che opera nello stesso settore della propria. Si capisce come, in pratica, ciò sia molto difficile da attuarsi perché, in primo luogo, difficilmente un imprenditore concorrente accetterebbe nella propria azienda un figlio o un familiare di un'impresa in competizione con la sua. Riteniamo poi che, qualora comunque lo accettasse, probabilmente gli rivelerebbe solo la minima parte dei meccanismi organizzativi ed operativi, per non parlare di quelli strategici, proprio per non fornirgli della conoscenza che, in futuro, potrebbe tradursi in vantaggio competitivo.

Le difficoltà operative o l'impossibilità di questa scelta non sono da ritenersi sempre un aspetto negativo, in quanto un successore che abbia assunto esperienze e know-how presso un concorrente sarà portato a riprodurre in azienda le conoscenze così acquisite. In questo modo, egli, al momento dell'ingresso nell'impresa di famiglia, si troverà a conoscere solo le regole di gestione viste precedentemente presso il concorrente e quindi a rimetterle in pratica in una nuova realtà, la quale potrebbe non essere consona a queste. I punti di forza di un'impresa non è detto, infatti, che siano anche quelli di un'altra e così vale anche per le regole di gestione che tendono proprio a far risaltare tali punti di forza. Il neo-imprenditore dovrebbe, in questo caso, essere in grado di riconoscere quelle che sono

\footnotetext{
${ }^{14}$ Abbiamo parlato di 'scelta obbligata', in quanto Piantoni, nella sua opera, mette in evidenza come questa maturazione esterna risulti importante per il $91 \%$ degli imprenditori familiari. Cfr. Piantoni, La successione familiare, cit.
} 
le norme operative utilmente collocabili nella formula imprenditoriale applicata all'impresa familiare e quelle invece che risultino intrasferibili, in quanto caratteristiche proprie di un'unica società e perciò inimitabili con profitto in un altro contesto.

Una soluzione maggiormente attuabile, e forse con più proficui risultati, è quella di far operare l'erede presso un'impresa in settori affini, per questo non direttamente concorrente, oppure presso un importante fornitore o un cliente privilegiato. Con questa esperienza, il futuro imprenditore riuscirà a comprendere una realtà nuova, ma comunque attinente la propria filiera produttiva e potrà fare esperienze significative. Il successore potrà poi comprendere le strutture dei costi, arricchire la propria comprensione del mercato, valutare nuove tecnologie, sviluppare rapporti umani che potrebbero rivelarsi proficui per il futuro.

Potrebbe addirittura essere utile alla formazione del successore la maturazione della propria esperienza esterna in un contesto imprenditoriale completamente estraneo all'azienda familiare. Si dovranno preferire, naturalmente, le aziende dotate di caratteristiche vincenti in assoluto, per esempio, negli ambiti della gestione del cambiamento tecnologico, dell'abilità nel cogliere le sfumature nei gusti del pubblico, della gestione dei servizi, ecc. L'erede, in queste imprese, dovrà operare nell'area/e funzionale/i che, per l'impresa familiare, probabilmente risulterà/anno critica/che nel futuro.

Per operare in tal senso, occorre però antecedentemente attuare un'analisi sull'azienda familiare, al fine di comprendere quelle che saranno le sue aree critiche di successo per il futuro. Si incroceranno poi queste aree con le corrispondenti funzioni dell'impresa 'esterna' (cfr. fig. 3.2).

Figura 3.2. Aree di successo e funzioni aziendali

\begin{tabular}{ll}
\hline Punti critici dell'impresa di famiglia & $\begin{array}{l}\text { Aree funzionali in cui svolgere una } \\
\text { preliminare esperienza di lavoro }\end{array}$ \\
\hline Tecnologia & Ricerca e sviluppo \\
Network & Organizzazione \\
Decentramento & Produzione \\
Internazionalizzazione & Marketing \\
Attenzione al cliente & Vendite \\
\hline
\end{tabular}

Fonte: G. Piantoni, La successione familiare in azienda. Continuità dell'impresa e ricambio generazionale, Etaslibri, Milano 1990.

Una volta deciso dove far svolgere all'erede l'esperienza esterna, occorre stabilirne la durata. Questa non è definibile a priori e valida per tutte le imprese. Molto dipende infatti dagli obiettivi che ci si prefigge di ottenere 
attraverso questo percorso formativo, dall'età del successore e dalla situazione nella quale versa $\mathrm{l}^{\prime}$ impresa familiare ${ }^{15}$. Il rischio che si corre maggiormente, in caso di durata breve dell'esperienza, è quello di far credere al successore di aver acquisito in tempo record capacità che egli invece non possiede; in virtù di ciò, si sentirà autorizzato a compiere in futuro scelte poco ponderate. Tuttavia il fattore di maggiore importanza nella formazione dei futuri imprenditori, non è tanto il luogo in cui si matura l'esperienza esterna (per quanto, come visto, rilevante), o la durata della stessa, ma riguarda le capacità del formatore. Se questi è un soggetto capace, un leader abile, di esperienza e con doti umane e professionali, è molto probabile che l'erede abbia acquisito buona conoscenza.

Dopo aver educato per lungo tempo il successore, avergli fatto acquisire le necessarie attitudini per gestire l'impresa familiare, averlo dotato delle qualità e delle competenze necessarie al ruolo in questione, arriva il momento tanto atteso dell'ingresso nell'impresa. Ancora però non sono terminati gli interrogativi e le problematiche, che in questo caso faranno riferimento alle modalità più opportune per operare tale ricambio con il minor trauma possibile per tutti i soggetti coinvolti. La via che il successore può seguire per il suo definitivo ingresso nell'azienda di famiglia, potrà essere 'diretta', 'mediata' o 'per affiancamento'16.

Il primo caso è quello che si discosta maggiormente dalla pianificazione successoria fin qui descritta. In esso, infatti, il ricambio generazionale avviene in modo non programmato, senza che l'erede abbia percorso tutte le tappe del processo di formazione. Questo tipo d'ingresso in azienda avviene, solitamente, qualora vi sia una scomparsa improvvisa dell'imprenditore in carica, che crea una esigenza immediata di copertura del suo ruolo. La soluzione in questione presenta delle incertezze, in quanto il neo-imprenditore potrebbe essere un soggetto capace e competente, dotato delle necessarie professionalità, ma potrebbe anche trattarsi di una persona totalmente estranea alla vita aziendale (che magari è chiamata a ricoprire il ruolo solo in quanto membro della famiglia proprietaria), o che non abbia mai ricoperto ruoli direzionali. In quest'ultimo caso, soprattutto, il futuro dell'impresa familiare sarà molto incerto e solo se l'imprenditore avrà autentiche potenziali capacità imprenditoriali nascoste, l'impresa potrà sopravvivere, altrimenti il declino diverrà inevitabile. La tensione del momento successorio, poi, potrebbe far capitolare anche $\mathrm{i}$ soggetti più capaci, e si dovrebbe, in questo caso, ricorrere ad un nuovo ricambio al vertice.

\footnotetext{
${ }^{15}$ Si può però affermare, in senso generale, che una valida esperienza esterna debba durare non meno di un anno, in quanto per entrare a pieno nei meccanismo dell'impresa ospitante, per comprenderne a fondo le problematiche e per inserirsi in settori completamente sconosciuti, è necessario un certo lasso di tempo, che solitamente non è inferiore a dodici mesi.

${ }^{16}$ Cfr. Schillaci, I processi di transizione, cit.
} 
La via 'mediata' è invece quella da noi indicata nel corso di questo capitolo. Il potenziale successore viene istruito al ruolo che sarà chiamato a svolgere, attraverso un apposito iter formativo che prevede sia studi di tipo teorico che esperienze pratiche da attuarsi in imprese esterne a quella familiare. Questo permetterà all'erede di sviluppare le proprie capacità ed acquisire nuove professionalità. Come abbiamo visto, un percorso di questo tipo è ottimale sia per l'impresa, sia per il candidato. Egli potrà, infatti, sviluppare progressivamente le sue capacità e maturare con il tempo, fino a raggiungere il momento del ricambio in uno stato di preparazione tale che ogni tensione risulti esclusa e vi sia anzi, da parte dell'erede, una volontà ad iniziare il proprio ruolo, al fine di dimostrare quanto appreso nel lungo iter formativo. Anche per l'azienda, l'erede così formatosi risulta essere maggiormente accettato, in quanto il suo ingresso non è più improvviso, ma preparato attraverso un adeguato percorso di carriera.

Il percorso di inserimento 'per affiancamento', consiste nell'accostare, per un determinato arco di tempo, la figura dell'imprenditore a quella del suo successore. Con questa via l'obiettivo che si vuole ottenere è quello di una sorta di osmosi tra la vecchia e la nuova generazione, in modo tale che ognuna comprenda le posizioni dell'altra e si possa così realizzare una proficua combinazione di esperienze e di idee, il tutto per migliorare il futuro dell'impresa familiare. Così il ricambio generazionale diverrà anche meno traumatico, in quanto i soggetti che operano in azienda avranno tutto il tempo per abituarsi e vedere all'opera il nuovo imprenditore e, progressivamente, l'idea del passaggio delle consegne sarà fatta propria da tutti. Un processo di ingresso in azienda così strutturato ha l'indubbio vantaggio del confronto anticipato con le problematiche successorie, viste in un'ottica di continuità generazionale, anche se presenta comunque degli obiettivi non sempre positivi.

Accade in molti casi che il potere attribuito al successore sia solo apparente. Diviene, infatti, molto difficoltoso, da parte dell'imprenditore uscente, staccarsi progressivamente dal ruolo dirigenziale, fino a quel momento occupato in modo autonomo. Le difficoltà aumentano qualora poi vi siano divergenze di opinione tra i due soggetti circa le modalità di gestione dell'azienda, differenze queste molto spesso riguardanti i valori di fondo, gli obiettivi ed i comportamenti da tenere con gli altri membri aziendali e derivanti in gran parte dai diversi punti di vista che necessariamente sussistono tra i soggetti appartenenti a due diverse generazioni. Tutto ciò può condizionare negativamente il risultato di tale affiancamento e comportare, per il successore, delle difficoltà future nella gestione.

La scelta della modalità con la quale affrontare l'inserimento del successore in azienda dipende da una serie di fattori, quali le esigenze dell'imprenditore uscente, le capacità del successore, le necessità dell'impresa, ecc. Per esempio, all'aumentare della capacità del successore, diverrà sempre meno necessaria una forma di inserimento di tipo mediato. 
Una grande importanza assume invece il momento nel quale operare il ricambio generazionale. Naturalmente, il momento ottimale deve essere reputato tale quando coincidano le esigenze di uscita dell'imprenditore e quelle di subentro del successore. Questo però è molto difficile da valutare (e, soprattutto, è ancor più raro che i due momenti coincidano), perciò l'unico criterio che si può seguire è quello relativo allo stato di salute dell'impresa familiare.

La sostituzione dell'imprenditore dovrebbe avvenire in un momento nel quale l'azienda si trovi in un buon stato di salute. Il ricambio generazionale operato in condizioni di difficoltà o di crisi dell'impresa può risolversi in scelte affrettate, con soggetti non adeguatamente motivati oppure impreparati al ruolo che dovranno ricoprire, che perseguono obiettivi orientati a giudizi di tipo personale, molto probabilmente non opportuni per l'azienda. Se lo stato di crisi fosse dovuto, principalmente, a conflitti interni alla società, alle insoddisfazioni personali di alcuni membri dell'azienda o ad una improvvisa necessità di sostituzione dell'imprenditore, non sarebbe improbabile una situazione di tensione, con la conseguente assunzione di scelte irrazionali.

Una situazione di stabilità dell'impresa, invece, comporta anche un insediamento meno traumatico del successore, il quale non dovrà affrontare ulteriori problematiche rispetto a quelle già complesse, relative al ricambio generazionale stesso.

Dopo aver visto quelle che sono le varie vie che il successore può seguire nell'ingresso in impresa, ed il momento migliore per attuare questo ricambio, occorre ora indagare i comportamenti che l'erede terrà una volta subentrato nel ruolo imprenditoriale.

I comportamenti che possono essere attuati dal nuovo imprenditore possono essere di tre tipi:

1. di replica;

2. di intervento;

3. di contrapposizione.

Riguardo alle strategie del primo tipo, va detto che queste attengono a comportamenti del successore che ricalcano, quasi in modo totale, le modalità di gestione del suo predecessore. Si tratta quindi di un atteggiamento passivo che denota una mancanza di creatività nell'erede, il quale altrimenti avrebbe proposto ed attuato soluzioni nuove, volte a rinnovare alcuni metodi di gestione, al fine di sfruttare al meglio le diverse opportunità che il mercato offre. In alcuni casi, però molto rari, la scelta di tipo passivo può essere quella più idonea alla situazione dell'impresa familiare e per questo un imprenditore che la adotti può essere ritenuto, a ragione, maggiormente competente rispetto ad un innovatore. Si tratta di casi - come detto: rari - in cui l'ambiente sociale nel quale opera l'impresa non ha subito rile- 
vanti mutamenti nel corso degli anni e perciò è ancora auspicabile operare secondo una strategia consolidata e profittevole. La strategia passiva crea molti meno problemi nella gestione del ricambio al vertice, ma limita, o non fa emergere del tutto, quelle che sono le capacità del successore, creando perciò eventuali problematiche nella gestione futura.

Comportamenti di 'intervento' o di 'contrapposizione' si caratterizzano invece per essere totalmente l'opposto di una strategia passiva. Con essi, il neo-imprenditore tende a far valere le proprie idee in ambito aziendale e quindi a valutare in chiave critica la gestione passata, individuando ciò che andrà corretto per renderla maggiormente al passo con i mutamenti ambientali. Gli svantaggi riguardano un maggior impatto traumatico dell'evento successorio sull'impresa, ma in cambio si potrà avere il futuro vantaggio di un'impresa competitiva, probabilmente innovatrice.

Da quanto fin qui detto, la scelta del miglior comportamento da tenersi al momento dell'ingresso in impresa dipende direttamente dalla mentalità del successore, dalle sua capacità e dal particolare momento che l'impresa attraversa. Qualora il neo-imprenditore che abbia fatto il suo ingresso in azienda non tenga comportamenti di tipo passivo, egli sarà chiamato ad una serie di valutazioni sulla struttura, sull'organizzazione e sulle modalità di gestione della realtà che comincerà a governare. Egli dovrà quindi conoscere l'assetto dell'impresa, identificare i problemi che in essa potrebbero sussistere, mettere a punto le strategie per la loro soluzione ed infine attuarle per raggiungere così gli obiettivi che si è posto.

Questi momenti, a differenza delle fasi che hanno caratterizzato precedentemente tutto il processo di successione imprenditoriale, vengono gestiti autonomamente da parte del successore stesso. Anche in questo caso, però, queste attività non sono standardizzabili, ma si differenziano da impresa a impresa e solo l'erede potrà dare la sequenzialità più idonea ai comportamenti in questione.

Il processo di cambiamento gestionale ed organizzativo deve però essere graduale nel tempo; il successore non dovrà quindi subito porsi in netto contrasto con le strategie elaborate dal suo predecessore, ma elaborare i mutamenti in modo costante e accettabile, in modo tale da rendere, progressivamente, l'impresa idonea ai nuovi traguardi da raggiungere. Il neo-imprenditore, nelle fasi immediatamente successive al suo ingresso in azienda, è chiamato in primo luogo a rendersi conto dell'ambiente nel quale si troverà ad operare, acquisendo informazioni utili per la migliore comprensione delle sue problematiche interne ed esterne. Questa prima fase di indagini, consentirà al successore di comprendere tutti i dettagli circa gli aspetti più complessi della realtà aziendale e, con ciò, di avere anche una visione migliore del ruolo che è chiamato a svolgere al suo interno. Inoltre, visionando i potenziali problemi che l'impresa dovrà affrontare, potrà con anticipo elaborare le soluzioni più idonee ad affrontarli, oppure i mutamenti strutturali, organizzativi e gestionali che potranno permettere all'azienda di 'aggirarli'. 
I problemi attuali o prospettici dell'azienda possono essere indagati soltanto attraverso un complesso lavoro di raccolta ed elaborazione di notizie ed informazioni, che permetteranno all'erede di valutare la realtà che sarà chiamato a dirigere, al fine di migliorarla. La complessità di questa operazione dipenderà, a sua volta, da una serie di fattori quali la trasparenza aziendale, le doti del neo-imprenditore e l'esistenza di un clima di collaborazione interno all'impresa nei confronti di quest'ultimo.

L'imprenditore avrà innanzi due principali tipologie di problemi. I primi sono quelli che l'impresa avrebbe dovuto comunque affrontare, indipendentemente dall'avvenuto processo di successione, al fine di garantirsi la sua continuità e gli sviluppi futuri. I secondi sono invece direttamente dipendenti dalla successione imprenditoriale appena affrontata e sono volti a reagire agli ostacoli post-successione.

Le problematiche che meritano una più solerte attenzione sono quelle del primo tipo, le quali riguarderanno principalmente questioni di carattere organizzativo attinenti alle risorse umane. Occorrerà, in questo caso, prima di operare i cambiamenti necessari, valutare la capacità di risposta a tali modifiche da parte di tutti i soggetti che operano in impresa, per comprendere, di conseguenza, i costi ed i benefici dell'operare in tal senso. La propensione al cambiamento del successore e degli altri componenti dell'impresa sono quindi fondamentali nel valutare le strategie di gestioni future.

Compresi i benefici che i cambiamenti in questione apporteranno all'impresa familiare ed ai soggetti in essa coinvolti, occorrerà scegliere la via migliore per metterli in pratica. Questa potrà derivare da un atteggiamento unidirezionale da parte del neo-imprenditore, il quale deciderà in proprio ogni questione, oppure si potrà avere, da parte di quest'ultimo, un atteggiamento di apertura che servirà a far comprendere anche agli altri operatori aziendali i benefici dei cambiamenti che si vorranno porre in essere, in modo tale da coinvolgerli maggiormente e contribuire ad una comprensione reciproca che servirà a lenire le tensioni che il processo di successione e qualunque altra forma di cambiamento rispetto al passato portano con sé.

Gli ostacoli che possono rendere difficoltoso il processo di successione imprenditoriale ed il successivo ingresso dell'erede nell'impresa familiare sono molteplici e dipendono da una serie di fattori riferibili, in primo luogo, alla continuità dei caratteri del successore rispetto all'imprenditore che lo ha preceduto. Successivamente dipenderanno anche dalla capacità dell'impresa di adattarsi ai mutamenti che necessariamente verranno ad attuarsi. Infine, alcuni ostacoli potranno dipendere anche dal grado di comunicazione esistente tra i vari soggetti operanti in azienda, tutti interessati al fenomeno successorio.

Le barriere che l'erede può incontrare nel suo percorso di insediamento nell'impresa familiare potranno dipendere direttamente dal suo prede- 
cessore. Abbiamo già visto come l'imprenditore uscente possa ostacolare in vari modi l'entrata dell'erede, proprio per la difficoltà che incontra nel distaccarsi dalla propria 'creatura'. Uno di questi modi riguarda il tentativo di rendersi insostituibile e di voler affermare le proprie idee anche in futuro. Questo tipo di miopia può arrivare perfino alla scelta di soggetti deputati alla successione non competenti, rinforzando così, nei confronti degli interni e degli esterni, la convinzione della sua insostituibilità. Nei momenti successivi all'insediamento il 'sostituendo' potrebbe ostacolare anche il processo di formazione dell'erede, non lasciandogli abbastanza autonomia per esprimere le proprie potenzialità, non concedendogli informazioni, conoscenze e collaborazione al fine di entrare maggiormente in contatto con la realtà d'impresa e al fine di porlo in cattiva luce con i vari membri della famiglia o con gli altri interlocutori esterni. Scelte, queste, evidentemente pericolose che soprattutto possono rivelarsi molto dannose per l'impresa e, nei casi più gravi, portare addirittura al dissolvimento della stessa.

Un altro gruppo di soggetti che può dar adito a comportamenti tesi ad ostacolare il successore, nel processo d'ingresso, è rappresentato dalle risorse umane che prestano la loro attività all'interno dell'impresa. Gli ostacoli posti in essere saranno tanto maggiori quanto più ampi saranno gli interventi riorganizzativi promossi dall'erede. I dipendenti e i collaboratori dell'impresa, infatti, soprattutto quando il neo-imprenditore tenderà ad attuare processi di 'svecchiamento' e ricambio generazionale, si sentiranno minacciati e, di conseguenza, reagiranno con interventi volti a preservare la propria posizione. Lo stesso potrà accadere nel caso in cui il processo di sostituzione derivi da un periodo di 'lotte intestine' volte a far prevalere un candidato nei confronti di altri. Qualora ciò avvenga, il successore designato si troverà a far fronte alle fazioni contrarie alla sua scelta al momento della selezione, le quali faranno di tutto per ostacolare la sua futura attività.

Come abbiamo visto i comportamenti volti a contrastare l'imprenditore possono assumere diverse forme che vanno, nei casi fin qui esaminati, dalla resistenza passiva, attraverso informazioni non trasparenti fornite al management, alla bassa collaborazione allo sviluppo dell'impresa, fino ad arrivare a vere e proprie forme di boicottaggio. Anche la famiglia e i portatori di capitale di rischio potrebbero svolgere attività ostacolanti il successore. Questo accade, solitamente, quando l'imprenditore non è persona gradita alla famiglia, oppure ad una parte della stessa. Si possono inoltre notare comportamenti simili qualora il neo-imprenditore sia una persona esterna alla famiglia e venga da questa accolto con una sorta di diffidenza circa il suo futuro operato. Le barriere alla buona riuscita gestionale del successore diverranno tanto più rilevanti quanto maggiore sarà l'influenza della famiglia sull'impresa. Quando poi questa detenga la gran parte del capitale di rischio, le sarà molto facile, attraverso la partecipazione 
maggioritaria agli organi di governo, ostacolare ogni decisione presa dal neo-imprenditore ${ }^{17}$.

Infine, anche gli altri stakeholder aziendali, come fornitori, clienti e finanziatori possono divenire un'altra fonte di problemi per il nuovo dirigente. Tutti questi soggetti, potrebbero venire in parte penalizzati dal ricambio generazionale e attuare, di conseguenza, comportamenti ostruzionistici. I fornitori o i clienti, ad esempio, qualora ritengano la successione causa di mutamenti del clima collaborativo instaurato con il precedente imprenditore, potrebbero decidere di concludere qualsiasi rapporto di collaborazione, con effetti, in certi casi, destabilizzanti per l'impresa familiare, in quanto il successo di questa si può basare anche sulla continuità dei rapporti collaborativi esterni. Compito dell'imprenditore entrante, in questi casi, sarà quello di far percepire la sua volontà di rafforzare i rapporti con questi interlocutori aziendali, proponendosi con una strategia che non sia di tipo conflittuale, ma neanche troppo innovativa, cercando di perseguire obiettivi di continuità ed armonia nei rapporti con i vari stakeholder.

I comportamenti che si manifestano in ostacoli, da chiunque attuati, rappresentano, evidentemente, una forma di resistenza al cambiamento in quanto tale. Anche qualora il mutamento in questione non risulti pregiudizievole a chi lo subisce, questi sarà comunque portato inerzialmente ad un suo rifiuto, proprio perché c'è il timore di subire una variazione nelle posizioni duramente conquistate. C'è dunque una volontà a mantenere ciò che si ha, valutando ogni tipo di variazione come una pericolosa incognita.

Accanto a queste forme di resistenza al cambiamento in quanto tale, ve ne sono di più specifiche che possono riguardare l'accettazione completa del successore, la comprensione dello stesso, una idealizzazione dei comportamenti del predecessore e, infine, una resistenza all'azione da parte dei collaboratori d'impresa. La forma di resistenza riguarda, quindi, l'accettazione completa del successore, il quale può essere visto come una fonte di minaccia, da parte di alcuni soggetti dell'impresa. Essi potrebbero vedere in pericolo lo stato dei rapporti di forza raggiunto con la precedente gestione, perciò tenderanno ad ostacolare in qualsiasi modo il successore.

Per quanto attiene la comprensione del successore, anche qui potrebbero nascere problemi relativi al non intendimento, o alla mancanza di condivisione, circa gli obiettivi e le azioni che l'erede vuole mettere in atto. Questo avviene, nella gran parte dei casi, perché il neo-imprenditore può non attuare forme di interrelazione diretta con i propri collaboratori. I soggetti che operano in impresa potrebbero poi aver troppo idealizzato le azioni poste in essere dall'imprenditore uscente e, in questi casi, diverrà

${ }^{17}$ Ci sarebbe da chiedersi perché allora sia stato scelto un soggetto che, di fatto, non è voluto dalla proprietà. Spesso accade che sia proprio l'imprenditore uscente a designarlo, senza alcun contributo del resto della famiglia. 
molto difficile per il successore, compiere delle azioni senza che queste non vengano giudicate e, vista la posizione di cui ormai gode il predecessore, valutate negativamente.

L'imprenditore entrante, dal canto suo, se ha svolto in modo proficuo la fase relativa all'analisi dell'ambiente nel quale si troverà ad operare, sarà anche in grado di riconoscere i soggetti a lui alleati da quelli contrari. Conoscendo ciò, potrà valutare con profitto gli ostacoli che si troverà ad affrontare nel futuro e, di conseguenza, adotterà le contromisure più opportune.

Gli ostacoli non sono però sempre un fenomeno da combattere, in quanto, in molti casi, possono risultare un segnale d'allarme circa i comportamenti da tenere da parte dell'imprenditore, il quale soltanto attraverso l'opposizione dei soggetti che collaborano in azienda potrà riconoscere un proprio eventuale errore e, di conseguenza, correggere le proprie linee d'azione. Gli appoggi incondizionati all'operato di quest'ultimo possono non essere, infatti, utili al bene dell'impresa. Atteggiamenti di giudizio critico (qualora questo non diventi eccessivo e ripetitivo) possono invece diventare profittevoli per la continuità aziendale.

Al fine di raggiungere questo clima collaborativo ed evitare gli ostacoli successori, si può anche far ricorso a dei validi strumenti non mobiliari che, certe volte, prevengono addirittura la nascita di tali problematiche. Questi strumenti saranno analizzati all'interno del prossimo capitolo. 



\section{La pianificazione della successione imprenditoriale}

\section{II sistema dualistico}

Normalmente i rapporti fra soci sono regolati dallo statuto della società ma, con la riforma del diritto societario del 2003, hanno assunto piena disciplina anche dai patti parasociali, oltre ad essere disciplinati anche da un nuovo modello di governo che è appunto il sistema dualistico ${ }^{1}$.

Nello statuto e nei patti parasociali si focalizzano e si regolamentano alcuni momenti fondamentali della vita dell'impresa, quali ad esempio i meccanismi di formazione della volontà dei soci, con particolare riferimento alle operazioni di natura straordinaria, i principi base della gestione operativa, i termini e modalità di trasferimento delle partecipazioni o quote, le regole di composizione delle eventuali liti fra soci.

Il modello dualistico è stato recepito in Italia da alcuni schemi di governance appartenenti ad altre realtà europee, quali la Germania e la Francia, e prevede che alcune opzioni devolute normalmente all'assemblea ordinaria dei soci siano appannaggio di un organo di tipo professionale, il Consiglio di sorveglianza, costituito da soggetti indipendenti. A questo spetta l'approvazione del bilancio e la nomina dei componenti il Consiglio di gestione, ovverosia gli amministratori stessi. All'Assemblea rimangono deliberare sulla terminazione dell'oggetto sociale, delle operazioni modificative dello statuto e la nomina del Consiglio di sorveglianza.

Per l'impresa familiare il sistema dualistico appare adatto a mediare fra gli interessi, spesso contrapposti, dei soci-eredi che hanno una naturale propensione a continuare nel governo dell'impresa e di coloro che tale 'vocazione' non la coltivano, ma che vogliono rimanere soci. Allora si vede

\footnotetext{
${ }^{1}$ Sull'argomento cfr. «L'imprenditore. Piccola Industria. Confindustria», numero speciale su
} Passaggio generazionale per la continuità dell'impresa, settembre 2007. 
come nel Consiglio di sorveglianza o di gestione potrebbero trovare collocazione gli eredi 'vocati' al governo dell'impresa, mentre gli altri membri della famiglia potrebbero rimane soci e controllare l'operato del management partecipando all' Assemblea degli azionisti. Ma è soprattutto in fase pre-successoria che il sistema dualistico espleta la sua massima funzione. Infatti il fondatore e gli amministratori 'anziani' potrebbero far parte del Consiglio di sorveglianza e governare l'impresa, mentre i soci-eredi 'vocati' andrebbero nel Consiglio di gestione; in tal modo si darebbe vita a un periodo di 'sperimentazione gestionale' che sarebbe utile sia per coloro che dovranno dimostrare di essere in grado di governare l'impresa, sia per coloro che in futuro non governeranno l'impresa, ma saranno rassicurati dalla sperimentazione dell'operato altrui.

\section{II supporto personale}

Come abbiamo visto fino ad ora, la successione imprenditoriale evidenzia una tale complessità da richiedere il contributo di soggetti caratterizzati da competenze specialistiche, al fine di orientarsi in un così articolato fenomeno. Questa necessità risulta ancor più esaltata dal fatto che tale processo viene a svolgersi all'interno di un'impresa di tipo familiare, connotata da rapporti delicati, sentimenti e meccanismi psicologici caratterizzanti i soggetti che appartengono alla medesima famiglia. Proprio per questo motivo, l'intervento di persone esterne ad essa, accettate ed in grado di analizzare con più obiettività il fenomeno, potranno proporre soluzioni ritenute più opportune senza correre il rischio di ingenerare il sospetto di favorire alcuno.

L'imprenditore può quindi avvalersi della consulenza di figure esterne all'impresa ed alla famiglia, ma fondamentali soprattutto nella delicata fase della presa di coscienza dell'esistenza di un problema successorio. Queste sono persone che, per vari motivi, hanno un'assidua frequentazione dell'impresa e della famiglia, si trovano nelle condizioni ottimali per valutare al meglio le problematiche e le situazioni conflittuali che possono sorgere in seguito a queste e, sulla base della fiducia di cui godono, proporre le soluzioni che ritengono più idonee al caso specifico ${ }^{2}$.

Gli attori in grado di offrire un contributo alla successione imprenditoriale in questo senso sono molteplici e diversi tra loro, e gli interventi esterni sono tra loro eterogenei e possono avvenire nei modi più diversificati. A tal proposito è di rilevanza un'analisi delle principali figure di intermediari che, analizzando le varie situazioni, attribuiranno all'impresa la soluzione ritenuta più idonea in ambito successorio. Le principali, in questo senso, sono descritte qui di seguito ${ }^{3}$.

${ }^{2}$ Cfr. Bertella, La pianificazione del ricambio generazionale, cit.

${ }^{3} \mathrm{Si}$ segue la graduazione decrescente di prossimità alla famiglia. 
1. Consulenti-confidenti di famiglia: sono figure professionali che tradizionalmente assistono la famiglia in operazioni di natura economica, finanziaria o patrimoniale. Possono essere rappresentati da commercialisti di fiducia, avvocati amici di famiglia, notai, o professionisti specifici (un civilista o un penalista, ad esempio), che avendo in passato contribuito a risolvere alcune problematiche, vengono chiamati in causa per un parere ad ogni evenienza. Di solito, queste persone frequentano abitualmente la famiglia, della quale, quindi, conoscono i più importanti risvolti umani. La loro attività ha carattere di riservatezza e si svolge attraverso una visione poco invasiva. Essi svolgono principalmente la loro attività senza invadere il campo dell'imprenditore, ma aiutandolo a prendere le decisioni migliori in modo autonomo. Proprio per questo motivo, la loro collaborazione all'interno dell'impresa è solitamente prolungata nel tempo e si instaura con l'imprenditore uscente un rapporto che va oltre la sfera professionale.

2. Consulenti in gestione aziendale: mentre i consulenti di famiglia sono intermediari che focalizzano la loro attenzione prevalentemente sui problemi della famiglia, i consulenti di gestione aziendale hanno maggiori riguardi per le problematiche proprie dell'impresa. L'obiettivo finale della loro attività è quello di garantire una continuità all'azienda di famiglia e questa può essere raggiunta soltanto attraverso la risoluzione delle problematiche successorie.

3. Lo specialista in materia successoria: è una figura di intermediario nata recentemente, proprio per la rilevanza che ha assunto nella totalità delle impresa la tematica successoria. Si tratta di un professionista con competenze principalmente nel campo giuridico e aziendale, capace soprattutto di comprendere la situazione nella quale versa l'impresa ed il rapporto di questa con la famiglia di origine, al fine di scegliere la soluzione migliore per impostare la pianificazione della successione imprenditoriale. Le competenze professionali di questo intermediario non sono quindi riferite solo all'ambito specialistico nel quale opera, ma comprendono anche una serie di conoscenze che gli permetteranno di intuire subito la necessità del ricorso a determinate altre specialità; non sempre questa interdisciplinarietà fa parte del suo bagaglio culturale e perciò egli dovrà avere rapporti anche con specialisti in altri settori (consulenti di famiglia o aziendali, ad esempio), la cui consulenza è di fondamentale importanza per risolvere la gran parte dei problemi successori.

4. Professionisti in vari campi: si tratta di un insieme di figure di tipo eterogeneo ma complementari per competenza distintiva, che vanno dal notaio al commercialista, dal penalista al sociologo, dallo psicologo all'aziendalista, dallo specialista di settore allo psichiatra, ecc. Sono figure portatrici di competenze diverse ed utili in alcuni mo- 
menti critici del processo di successione imprenditoriale. È molto raro che tutte queste fattispecie di intermediari intervengano insieme all'interno di un unico ricambio generazionale, ma è però importante, qualora emergano dei problemi in tale sede, che lo specialista in materia successoria o il contract manager (figura che vedremo in dettaglio all'interno del terzo paragrafo), individuino la causa del 'malanno' e provvedano di conseguenza a contattare lo specialista più abile a curarlo o vi provvedano essi stessi.

5. Banche: le problematiche, soprattutto quelle da un punto di vista finanziario, all'interno della successione imprenditoriale, possono essere risolte solo attraverso il contributo fondamentale dell'intermediario bancario. In relazione poi ai prelievi e ai versamenti, le banche sono le prime a valutare eventuali preoccupanti evoluzioni nel processo del ricambio generazionale.

6. Persone di riferimento per i figli: questa è una classe di intermediari non molto presa in considerazione dagli esperti di successione imprenditoriale, ma di rilevante importanza per la stessa. Ci riferiamo a quelle persone che hanno svolto un ruolo importante nella formazione, a vari livelli, dei figli dell'imprenditore. L'educazione ricevuta dai futuri imprenditori diviene parte integrante di quella che sarà la cultura dell'impresa e, perciò, influenzerà positivamente o negativamente il futuro della stessa. Gli educatori sono molteplici, se si pensa anche alla moltitudine di soggetti con i quali il futuro erede di famiglia si trova a confrontarsi nel corso della sua esistenza.

7. Amici e colleghi dell'imprenditore: queste figure di intermediari (anche se non si può parlare di persone che facciano questo per mestiere) divengono molto utili per l'imprenditore, il quale, avendo con loro un rapporto di reciproca confidenza, cerca di superare il problema successorio attraverso i loro consigli, tanto più quando essi l'abbiano già affrontato proficuamente in passato. Diviene però, come abbiamo già notato precedentemente, molto pericoloso seguire la medesima strada impostata da altri per la loro impresa, in quanto le aziende familiari si distinguono tra loro per una molteplicità di variabili che vanno ad influenzare direttamente il processo successorio rendendolo mutabile, nelle sue condizioni di sviluppo, da impresa ad impresa.

8. Associazioni di categoria: questo tipo di intermediario è sempre molto presente nell'ambito del sostegno alle imprese nel momento della successione imprenditoriale. Anche se queste associazioni non hanno una competenza specifica in tale campo, si adoperano al fine di aiutare le aziende in difficoltà, per garantirne così la sopravviven$\mathrm{za}$, la quale diviene fondamentale anche per quella dell'associazione stessa. La forza di ogni di ogni associazione dipende, infatti, dalla longevità delle imprese che ne fanno parte, e questa viene garantita attraverso validi processi di successione imprenditoriale. 
Il ruolo svolto da queste ultime categorie di attori non può apparire secondario e casuale rispetto a quello svolto da esperti: 1'imprenditore, prima di rivolgersi ad esperti specializzati nella successione imprenditoriale, spesso comprensibilmente, chiede consiglio alle persone a lui più vicine e con le quali ha un rapporto di maggiore fiducia, allo scopo di comprendere e prendere coscienza delle problematiche reali che egli dovrà affrontare. L'opinione, presumibilmente sincera, delle persone vicine permette all'imprenditore di comprendere l'effettiva necessità del ricorso a specialisti esterni ed infine di indirizzarsi verso la figura professionale più opportuna in tal senso. Queste figure professionali danno quindi un apporto tra loro diverso al processo di successione imprenditoriale. Si può dire che all'interno di questa pianificazione essi ricoprano quattro distinti ruolit:

1. di sensibilizzazione al problema;

2. di consiglio e di sostegno;

3. di proposta di soluzioni innovative;

4. di consolidamento delle decisioni prese.

Il primo di questi compiti viene svolto qualora l'imprenditore non percepisca in maniera autonoma la necessità di attuare un meccanismo di pianificazione della propria successione. Per gestire questa situazione e le problematiche che ne seguiranno intervengono in molti casi le associazioni di categoria, le quali, essendo in contatto con un numero rilevante di imprese della medesima specie, hanno la possibilità di coagulare un gran numero di esperienze ed organizzare interventi di formazione e di sensibilizzazione al problema in questione.

Il secondo ruolo, di consiglio e di sostegno, può essere adeguatamente svolto anch'esso da persone esterne alla famiglia, come per esempio le persone di riferimento oppure la banca. È un incarico di grande rilevanza, in quanto non è necessario solo mettere l'imprenditore a conoscenza del problema successorio, ma occorre anche costantemente stimolare la sua attività nei suoi confronti. Questi professionisti, proprio per la loro estraneità alla famiglia, sono in grado proficuamente di far riflettere il dirigente con la dovuta calma, senza che questi possa essere indirizzato ad una decisione che tenga conto dei profitti personali dell'erede, invece che del bene dell'impresa, come probabilmente avverrebbe se l'intermediario fosse un soggetto interno all'azienda o, ancor peggio l'erede designato alla successione.

Presa coscienza della necessità di attuare una pianificazione del passaggio delle consegne, occorre contattare i professionisti idonei a prospettare le soluzioni più in linea con l'impresa di riferimento. Questo è il compito svolto da coloro che definiscono proposte innovative, rappresentati da

${ }^{4}$ Cfr. Bertella, La pianificazione del ricambio generazionale, cit. 
esperti vari e dai consulenti in gestione aziendale. Questi, dopo aver analizzato la situazione dell'impresa, valuteranno la proposta più idonea per definire con chiarezza i passi da compiere per il raggiungimento, meno traumatico possibile, del traguardo del ricambio generazionale.

La scelta del professionista reputato adatto andrà a condizionare l'intero futuro dell'azienda di famiglia e perciò è necessario che l'imprenditore rispetti alcune regole per la sua nomina. Come abbiamo già visto, è necessario che egli prenda coscienza delle problematiche che affliggono la sua impresa, con riguardo all'ambito successorio, per scegliere così la figura di intermediario che meglio si adatta alla loro risoluzione. La fase successiva riguarderà la ricerca di referenze per i soggetti in questione, rilasciate da altre imprese che si sono avvalse in passato della loro collaborazione. Bisognerà indagare sulle modalità di gestione dei problemi, sull'approccio al rapporto famiglia-impresa adottato da ciascuno di essi ed, infine, sui risultati ottenuti nello svolgimento dei precedenti incarichi. Ottenuta così una rosa di candidati idonea a supportare il ricambio generazionale, la scelta definitiva del professionista avviene, solitamente, attraverso colloqui personali con gli stessi, in modo da ottenere un quadro completo anche della loro personalità.

Come abbiamo fin qui visto, i compiti che possono svolgere gli 'intermediari' al fine di avvantaggiare il processo di successione imprenditoriale sono molteplici. Accanto a quelli finora visti ve ne sono di più specifici. Questi riguardano:

1. la risoluzione dei conflitti che possono sorgere tra familiari;

2. la programmazione ed il supporto nell'inserimento delle giovani leve nella posizione imprenditoriale;

3. il supporto nella stesura del Patto di famiglia.

Le tensioni tra familiari, come visto precedentemente, possono rappresentare una costante nel processo di ricambio generazionale. L'aiuto che può dare un intermediario esterno alla famiglia sarà quello di ridurre queste incomprensioni, facilitando così una meno traumatica sostituzione dell'imprenditore. Le forme di intervento sono molteplici e possono avere riguardo a: mantenere aperti canali di comunicazione tra le parti; far comprendere ai familiari il punto di vista più profittevole per la continuità aziendale; ecc. Questi interventi avvengono quasi sempre in via posticipata, quando il problema è già emerso; difficile diventa, infatti, la comprensione dello stesso in via preventiva, in quanto l'intermediario, essendo una persona esterna, non è così intensamente immerso nelle questioni familiari.

Da quanto fin qui detto possiamo valutare le caratteristiche richieste ad un professionista, e cioè: la capacità di catturare la stima ed il rispetto di tutti i familiari, i quali, altrimenti, ben difficilmente lo seguirebbero nelle sue decisioni; disporre di tempo rilevante al fine di ascoltare e comprenderne 
le parti in causa; essere autonomo rispetto a tutti gli attori coinvolti nel processo di successione imprenditoriale; avere una buona cultura aziendale; essere flessibile ai segnali di cambiamento, non fossilizzandosi in decisioni prese; essere capace di risolvere anche i problemi più complessi.

Spesso il soggetto chiamato a risolvere i conflitti tra familiari viene anche nominato come tutore nell'attuazione dei processi di formazione e selezione delle nuove generazioni. Ultima funzione è quella di supporto nella stesura del Patto di famiglia, documento questo importantissimo per il futuro dell'impresa e, soprattutto, per evitare tensioni tra i familiari presenti nella stessa.

\section{II «Patto di famiglia»}

Introdotto in Italia con la L. 55 del 14 febbraio $2006^{5}$, il «Patto di famiglia» è lo strumento attraverso il quale la famiglia proprietaria di un'impresa definisce, formalizza e rende trasferibile alle future generazioni dell'impresa il proprio orientamento strategico di fondo, indicando il campo (o i campi) di attività nel quale l'impresa è impegnata nel presente ed intende impegnarsi nel futuro, le ragioni fondamentali del proprio impegno nell'impresa familiare, la filosofia comportamentale ed organizzativa alla quale la famiglia intende ispirarsi nel controllo e nella gestione dell'impresa familiare $^{6}$.

È importante che siano definite e rese certe una serie di regole che riguarderanno anche i principali problemi attinenti alla successione alla guida dell'impresa, alla scelta del successore ed alle modalità del suo insediamento in azienda. Andranno, a questo proposito, stabiliti anche una serie di contenuti attinenti alla regolamentazione dei rapporti con gli altri membri della famiglia e le modalità con le quali dovrà essere attuato il passaggio delle consegne tra l'imprenditore ed il suo successore. Gli scopi, i contenuti e l'articolazione del Patto di famiglia, non sono poi così lontani da quelli che, più comunemente, possono essere riscontrati con riguardo allo statuto di qualsiasi società. Tuttavia non si devono confondere i due documenti, i quali hanno tra loro lati in comune, ma anche molteplici differenze: il Patto di famiglia è di utilizzo esclusivo delle imprese con carattere di familiarità, come dice la parola stessa, mentre l'altro regola i rapporti fra qualsiasi tipo di socio. Lo statuto regola, in base alla legge, il funzionamento della società ed è sottoscritto da tutti i soci, mentre il Patto di famiglia regola il rapporto della famiglia con l'impresa, è sottoscritto dai componenti della famiglia, tra i quali, presumibilmente, alcuni sono soci e/o amministratori (dipendenti o collaboratori dell'impresa stessa), altri sono al di fuori della stessa.

\footnotetext{
${ }^{5}$ Si accoglie così l'invito rivolto nel 1994 dalla Commissione Europea agli Stati membri di introdurre deroghe ai divieti di patti successori.

${ }^{6}$ Cfr. Tomaselli, Longevità e sviluppo delle imprese familiari, cit.
} 
Un'altra importante differenziazione tra i due documenti riguarda il fatto che, mentre lo statuto della società dà solitamente una previsione di quelli che saranno i diritti dei vari soci, senza fare alcun riferimento ai loro obblighi (soprattutto morali) nei confronti dell'impresa ${ }^{7}$, il Patto di famiglia, invece, attraverso l'individuazione dei valori imprenditoriali di cui la famiglia intende farsi portatrice, le modalità di gestione dell'azienda, le caratteristiche dell'impegno proprio dei familiari e le loro attese nei confronti dell'impresa, offre importanti indicazioni su quelli che saranno gli obblighi dei familiari coinvolti nell'attività d'impresa. Tutto ciò non farà altro che incentivare il senso di responsabilità delle giovani generazioni, le quali si troveranno un giorno a gestire un'impresa che sarà loro 'lasciata' sulla base di regole da tutti approvate e condivise, al fine di preservare la continuità dell'azienda a beneficio proprio delle future generazioni.

Visto in questo senso, il Patto di famiglia diviene un documento di pari importanza dello statuto della società, in quanto svolge una funzione di supporto e di trasparenza degli ideali propri della famiglia, i quali vengono messi a conoscenza sia dei lavoratori dell'impresa, sia dei vari stakeholder aziendali. Questa trasparenza porterà questi soggetti ad operare o meno con l'istituzione familiare, a seconda che condividano o non condividano la missione aziendale ed i valori che la ispirano.

Naturalmente, il Patto di famiglia non deve essere un'entità statica ed immutabile, ma anzi dovrà essere rivisto periodicamente al fine di adeguarlo alle mutate condizioni ambientali e di settore nel quale opera l'impresa; inoltre i valori, le indicazioni e le scelte della famiglia proprietaria dovranno essere anche adeguate sulla base delle esigenze e delle nuove competenze di cui è portatrice la nuova generazione che subentrerà alla guida dell'azienda.

Prima di entrare nel dettaglio delle parti che compongono il documento in esame è bene valutare alcuni aspetti di carattere più generale, facendo quindi riferimento alla fase preparatoria del Patto, ai tempi di redazione dello stesso, alla filosofia che dovrà animare il documento, alle condizioni per la sua applicabilità ed infine alle modalità con cui potrà avvenire la sua modifica ${ }^{8}$.

Per quanto attiene la fase preparatoria del Patto di famiglia, occorre dire che, come visto in precedenza, è necessario l'intervento di persone competenti in materie tra loro molto diverse (diritto civile, ereditario, tributario, societario, finanza aziendale, ecc.), e non sempre attori con questo bagaglio culturale sono presenti all'interno dell'impresa familiare. Per questo

\footnotetext{
${ }^{7}$ Ciò s'intende in senso generale. In particolare poi si può dire che i soci coinvolti nell'amministrazione hanno tutti gli obblighi legati alla loro carica; inoltre possono esserci delle azioni assegnate ai dipendenti (Spa), quote con prestazioni accessorie (Srl). Fra gli obblighi dei soci va ricordato quello di 'liberare il capitale'.

${ }^{8}$ Cfr. Jovenitti, Strategie mobiliari, cit.
} 
motivo, nella stesura del Patto di famiglia, gli imprenditori si avvalgono spesso della consulenza di soggetti specializzati in materia successoria, che assistono e provvedono alla formulazione del testo del Patto di famiglia. Attraverso questa assistenza, l'imprenditore ottiene il vantaggio di evitare la discussione del problema con i propri familiari; di tale compito si farà infatti carico 'l'intermediario' specializzato, il quale, attingendo all'ampia casistica delle imprese familiari che si trovano nella medesima situazione, cercherà la soluzione ideale da applicare nell'azienda in questione.

I tempi di redazione del documento in esame sono, a questo proposito, fondamentali al fine del successo dello stesso e della sua ottimale applicazione. Come abbiamo visto precedentemente per quanto riguarda la pianificazione della successione imprenditoriale, anche per la stesura del Patto di famiglia è importante anticipare e programmare con cura il momento della sua redazione. Questo al fine di realizzare con successo e secondo le caratteristiche volute da tutti i membri della famiglia, il documento in esame, il quale diviene significativo, come vedremo tra poco, per la stessa programmazione del ricambio generazionale. Proprio per questo motivo, l'atto deve essere redatto con largo anticipo rispetto al momento nel quale si ipotizza avverrà il processo successorio, in modo tale che esso possa essere compilato senza quelle tensioni che animano i momenti immediatamente precedenti all'evento e che possono, di conseguenza, influenzarne negativamente il contenuto e, soprattutto, il successo.

Un altro elemento capace di influenzare totalmente il contenuto del Patto di famiglia riguarda la 'filosofia del documento'. Con questa espressione si vuole indicare la scelta tra due alternative tra loro antitetiche, che privilegiano di volta in volta in volta l'impresa rispetto alla famiglia o viceversa. L'imprenditore potrà, infatti, attuare una scelta con riguardo al fatto di privilegiare gli interessi propri dell'impresa e della sua continuità, oppure dare priorità ai valori ed ai benefici della compagine familiare. Non esiste a questo proposito una scelta migliore in generale, o una regola predefinita da applicare ai casi concreti, anche se nelle varie applicazioni di questo Patto, si assiste spesso, tra le aziende familiari, ad una predilezione per gli interessi dell'impresa rispetto a quelli della famiglia, la quale dovrà di conseguenza adeguarvisi.

Per quanto attiene poi le condizioni di applicabilità del documento in esame è importante che la sua validità sia «erga omnes», cioè nei confronti di tutti i componenti della famiglia, senza attuare così favoritismi o eccezioni, che possono, se attuate, comprometterne il successo. Oltre all'applicabilità incondizionata, occorre anche che esso abbia durata illimitata nel tempo, in modo tale da non venire considerato come frutto di una decisione temporanea dell'imprenditore, la quale come tale, avrebbe difficile credibilità tra gli eredi.

Da quanto finora detto non deriva che il Patto di famiglia sia immodificabile, anzi, specifici articoli presenti in esso prevedono solitamente le norme da 
considerare per la sua attuazione. Importante è però il fatto che i cambiamenti da attuarsi debbano essere applicati attraverso il consenso unanime dei membri della famiglia, non potendosi applicare il principio maggioritario che comporterebbe la creazione di una 'frangia' contraria, la quale non avrebbe altro effetto se non quello di procurare diverbi e difficoltà interne alla famiglia che potrebbero sfociare nell'impresa pregiudicandone i risultati e la continuità.

Le ragioni principali che portano quindi alla stesura del Patto di famiglia riguardano il problema della deriva generazionale e del rapporto famiglia-impresa.

Dal primo punto di vista occorre dire che, come già visto precedentemente, con lo scorrere delle generazioni si assiste ad un progressivo aumento dei membri della famiglia, con la conseguente difficoltà nello scegliere la persona più adatta a ricoprire il ruolo imprenditoriale. L'aumento del numero dei soci di un'impresa familiare introduce solitamente una maggiore complessità nella gestione della stessa e, di conseguenza, anche nella scelta del leader tra una pluralità di candidati ${ }^{9}$. Questo può essere risolto solo attraverso dei principi-guida e delle regole condivise che orientino le scelte. Queste regole e principi troveranno collocazione all'interno del documento che stiamo esaminando.

Per quanto attiene la seconda problematica in esame, va detto che il rapporto famiglia-impresa è, come visto, difficile da gestire sotto diversi profili. Uno di questi riguarda le finalità e le regole di gestione dell'impresa, le quali dovranno essere formulate seguendo quelli che sono i valori propri della famiglia, oppure i principi di economicità ed efficienza propri dell'azienda. L'imprenditore ha davanti la scelta per evitare un contrasto tra queste due fonti di valori. I principi attinenti alla famiglia sono infatti quelli di unità, rispetto dell'anzianità, mutua assistenza ecc.; quelli attinenti all'azienda sono invece l'economicità, l'efficienza e le produttività. Questi fondamenti possono diventare tra loro antitetici e produrre contrasti gravi sia per l'impresa familiare, sia per l'insieme di soggetti addetti alla sua gestione. Si pensi, infatti, all'esempio di un figlio disoccupato dell'imprenditore che venga assunto nell'azienda con ruoli manageriali. Questo sarebbe giusto secondo il principio 'familiare' della mutua assistenza, ma sarebbe invece sbagliato secondo quello aziendale dell'economicità, il quale riterrebbe opportuna l'assunzione solo di soggetti motivati e professionalmente adatti al ruolo. Come si vede da questo semplice esempio, fissare delle regole adatte ad ogni caso concreto diviene imprescindibile al fine di evitare contrasti e difficoltà future. Per questo motivo, la stesura del Patto di famiglia costringe i familiari a riflettere sul rapporto famiglia-impresa ed a prenderne coscienza al fine di dotarsi di regole che prendano in considerazione le esigenze di ambedue le istituzioni.

${ }^{9}$ Cfr. ivi. 
Il Patto di famiglia costituisce inoltre un passaggio importante verso una maggiore trasparenza nei comportamenti e nelle linee di condotta aziendali. Infatti, fin quando l'impresa non si doti del documento in esame, ciascun familiare potrebbe prendere decisioni sulla base di convinzioni proprie, mutabili anche giornalmente; invece quando l'impresa codifichi principi e regole, questo non potrà più avvenire ed ogni azione dovrà essere giustificata dalle norme precedenti.

Naturalmente, il Patto di famiglia, pur avendo valore legale ${ }^{10}$, non garantisce pienamente che tutti i familiari rispettino i principi contenuti nello stesso, ma fa sì che i comportamenti che spazino al di fuori delle regole codificate in esso risultino evidenti a tutti. Esso assolve quindi alla funzione di strumento di pressione morale nei confronti di quei familiari che vogliano tenere comportamenti contrari alle regole formulate. Qualora poi, il numero di familiari che contravvengono ai principi stabiliti divenga ampio, questo vorrà significare che è giunto il momento per una sua modifica radicale.

Il Patto non serve però soltanto come strumento per mantenere l'unità familiare, ma anche come mezzo per separare due realtà diverse quali l'impresa e la famiglia. Infatti, fino ad ora abbiamo avuto riguardo a come mantenere l'unità interna, ma occorre vedere anche come mantenere quella esterna tra due realtà diverse, ma complementari quali sono l'impresa e la famiglia che la gestisce.

Il Patto assolve alla funzione di preservare da confusione i due istituti. Se è vero infatti che i principi propri dell'impresa non devono intaccare l'unità familiare, è vero anche il contrario, cioè che la famiglia non deve utilizzare l'azienda come una fonte da sfruttare, senza preoccuparsi della sua continuità. Questo è il risultato che si ottiene, solitamente, in un regime di assenza di regole, regime questo che non sussisterà se è presente un documento con compiti appositamente riguardanti tale contesto.

Questo insieme di principi sarà poi utile anche alle generazioni future, che saranno in grado di comprendere le ragioni del successo o dell'insuccesso dell'impresa familiare, sulla base delle norme che hanno guidato, fino a quel momento, la sua attività.

Gli svantaggi che può portare il Patto di famiglia non riguardano tanto il documento in sé, ma l'uso che ne viene fatto e i principi che esso con-

\footnotetext{
${ }^{10}$ La formula iniziale della maggior parte dei Patti di famiglia recita infatti: «I firmatori del presente Regolamento si impegnano sul proprio onore al rispetto delle norme in esso contenute». Si mette, in questo caso, l'accento sull'onore dei familiari, oltre che sulla legge o norme codificate. Tuttavia la validità legale del Patto di famiglia dipende dal tenore delle pattuizioni e la formula dell'onore, di cui sopra, non esime i firmatari dal rispetto delle regole, non escludendo altresì la possibilità, per i firmatari, di chiamare o esser chiamati ai danni in caso di mancata osservanza del patto sottoscritto che generi danno economico. Propenderemmo quindi, in caso di sottoscrizione di regole puntuali, a riconoscere decisamente il valore legale del Patto di famiglia, seguendo il principio che qualsiasi accordo lecito e sottoscritto ha forza di legge fra le parti.
} 
tiene. Questi ultimi, infatti, potrebbero non essere adatti all'impresa presa a riferimento e pregiudicarne, di conseguenza, la funzionalità duratura. Proprio per questi motivi è importante analizzare nel dettaglio il contenuto del documento.

Le principali aree trattate all'interno di un Patto di famiglia riguardano ${ }^{11}$ :

1. i principi e i valori di riferimento;

2. le regole per entrare nell'impresa familiare;

3 . le regole per permanervi;

4. le regole per il trasferimento dei titoli sociali;

5. le possibilità di uscita e di rientro nella compagine dell'impresa familiare;

6. le norme sui parenti acquisiti e sui discendenti;

7. le norme sui genitori.

Al fine del nostro lavoro, tratteremo soltanto le parti più afferenti la successione d'impresa e quelle ad essa collegate, senza addentrarci nelle complesse problematiche attinenti la redazione complessiva di un documento così vasto. Il primo punto del Patto di famiglia ha, quindi, riguardo ai principi di riferimento che dovranno animare l'intero documento in questione. A questo proposito, saranno in questa parte contenuti:

- la dichiarazione che la famiglia attua nei confronti dell'impresa, volta a garantirne la continuità nel tempo e nelle generazioni future;

- i valori di base che animano la famiglia e su cui viene costruito il rapporto con l'impresa (unità, tradizione, ecc.);

- l'impegno, da parte dei familiari, di rispettare e di far rispettare ai propri eredi il contenuto del Patto di famiglia, con un obbligo morale nei confronti degli altri sottoscrittori.

In alcuni casi, in questa parte del documento, anche a vantaggio delle generazioni future, viene fatto un breve riepilogo della storia dell'impresa e dei principali traguardi da essa raggiunti nel corso della sua attività, grazie all'impegno costante di tutti i familiari che ne hanno garantito la continuità.

Per quanto attiene le regole per entrare nell'impresa familiare, queste si riferiscono ai requisiti che deve possedere, non solo il futuro imprenditore, ma anche qualsiasi altro membro della famiglia che voglia cimentarsi nella vita aziendale. Queste norme riguarderanno perciò:

${ }^{11}$ Cfr. Jovenitti, Strategie mobiliari, cit. 
- l'età: in molti Patti di famiglia è prevista una soglia di età minima che deve essere superata per entrare direttamente nella compagine $\mathrm{d}$ 'impresa. Alcune volte questa soglia è bassa e, così facendo, si vuole incentivare l'entrata immediata degli eredi in azienda perché questi possano dimostrare sul campo le loro capacità. Al contrario, una soglia d'età relativamente alta tenderà a privilegiare l'acquisizione, da parte della generazione emergente, di una serie di competenze scientifiche e gestionali che possano permettere di gestire l'impresa con un maggior supporto culturale. Infine, in alcuni casi, la soglia d'età non è fissata in termini quantitativi, ma è collegata ad un determinato avvenimento (l'ottenimento di un particolare titolo di studio, il completamento della fase di tirocinio, ecc.);

- eventuali esperienze esterne: anche in questo caso, ci possono essere soluzioni molto diverse e tra loro eterogenee. In alcuni casi, gli imprenditori preferiscono, infatti, formare internamente all'impresa i propri eredi, senza che questi subiscano 'contaminazioni' da altre realtà aziendali. In altri casi, invece, gli imprenditori, ritengono di fondamentale importanza lo svolgimento di un'attività esterna da parte dell'erede o degli eredi designati, che preceda il loro ingresso nell'azienda di famiglia. Questa esperienza può essere svolta secondo varie modalità che vanno dal semplice stage in altre imprese, all'attività duratura in aziende operanti in settori diversi rispetto a quello della famiglia o, infine, alla permanenza, anche qui duratura, in imprese concorrenti con l'impresa familiare. Come abbiamo già detto in precedenza, non sempre, però, la scelta può essere così vasta, in quanto, molto spesso, si incontrano delle barriere relative al fatto che molte imprese, soprattutto le concorrenti, non sono ben disposte ad ospitare e formare un futuro imprenditore di un'azienda ad essa rivale, rendendolo partecipe di quelli che sono i suoi punti di forza e di debolezza. La scelta dell'esperienza esterna, può quindi restringersi di molto $\mathrm{e}$, in numerosi casi, dovrà limitarsi all'attività da svolgersi in aziende non facenti parte del settore nel quale opera la famiglia.

Qualunque sia la soluzione adottata, quello che si propone il Patto di famiglia è di fornire ai futuri eredi le competenze necessarie per amministrare l'impresa e per questo, molto spesso, la scelta dell'azienda nella quale affrontare l'esperienza esterna ricade su realtà di maggiori dimensioni rispetto a quelle nelle quali opera la famiglia, e ciò al fine di far acquisire alle generazioni entranti maggiori competenze che serviranno loro nei casi in cui l'azienda di famiglia tenda non soltanto a perseguire l'obiettivo della continuità, ma anche quello della crescita. Strettamente connesso al problema di dove affrontare l'esperienza esterna, è quello relativo al ruolo da ricoprire nell'impresa nella quale si andrà a formarsi. Anche qui le tesi 
sono discordanti: alcuni ritengono sia meglio svolgere mansioni tra loro differenziate, in modo da possedere un bagaglio culturale più vario; altri ritengono invece sia meglio specializzarsi nel ruolo che si andrà poi a svolgere nell'azienda di famiglia. Importante diventa, comunque, che questa esperienza esterna venga svolta in modo tale che l'erede possa inserirsi nel mondo del lavoro senza però condizionare l'azienda di famiglia con eventuali suoi errori dovuti, appunto, all'inesperienza. Un altro tema che si ricollega all'argomento in questione è quello relativo alla durata dell'apprendistato. In alcuni casi, i Patti di famiglia fanno riferimento a specifiche durate (di solito la soglia minima è di 3-5 anni), in altri, invece, fanno generico riferimento alla durata necessaria per raggiungere uno specifico traguardo (promozione, un determinato grado nella scala gerarchica, una rotazione completa dei ruoli aziendali). I vantaggi comuni a qualunque esperienza esterna riguardano comunque la possibilità da parte della futura generazione di scoprire il mondo del lavoro, comprenderne le problematiche ed i possibili vantaggi, verificare il possesso di eventuali doti imprenditoriali, fare la conoscenza di dirigenti che poi potranno risultare utili all'impresa di famiglia, ecc. Questi indubbi vantaggi vengono in parte ridotti, nel caso in cui l'esperienza venga a maturarsi internamente all'impresa di famiglia o in una sua filiale. In questi casi, infatti, ciò che è richiesto all'erede, è di maturare in fretta in modo da mettere in pratica il più presto possibile gli insegnamenti ricevuti, senza però possibilità di errori e quindi con maggiore tensione.

Con riferimento alle regole per permanere all'interno dell'impresa familiare una volta che l'erede abbia dimostrato di possederne i requisiti, attraverso esperienze esterne, andranno valutate le particolari mansioni da affidargli, le modalità per la sua remunerazione, l'eventuale necessità di affiancargli una particolare figura esterna (contract manager) ed altri punti importanti che vedremo qui di seguito.

Innanzitutto, sono da valutare le mansioni da affidare al giovane entrante. A questo proposito, molti imprenditori sono del parere di affidare a quest'ultimo una mansione di assistente, in modo tale che egli, stando continuamente accanto al capo dell'impresa, possa apprendere per imitazione attraverso l'osservazione. Questa diviene una soluzione comoda a molti imprenditori i quali, così facendo, evitano che i figli commettano errori significativi per l'azienda di famiglia, ma allo stesso tempo rendono possibile che vengano conosciuti dai lavoratori ed acquisiscano consenso e stima. Una critica al riguardo può essere quella che, operando in tal modo, si formeranno giovani del tutto simili alla generazione precedente e quindi non in grado di rispondere alle nuove esigenze di modernità che il mercato impone.

Diverso è invece il caso in cui, per favorire il nuovo entrato, venga istituita una nuova mansione da affidargli. In questa ipotesi si assiste alla totale inutilità all'ingresso dell'erede per il quale è stato necessario creare un'apposita area di attività precedentemente non esistente. Così facendo 
si dimostra come egli non sia in grado di ricoprire alcuna mansione precedente. Molto diverso però è il caso in cui vi fosse l'effettiva necessità a impegnarsi in un nuovo ramo di attività, nel quale, in questo caso, il neoimprenditore assumerà il ruolo di fondatore.

Ultimo caso afferente alle mansioni da affidare al futuro erede, riguarda la possibilità di inserire quest'ultimo all'interno di un organo di line della struttura organizzativa. In questa situazione, il futuro imprenditore dovrà salire tutta la scala gerarchica e meritarsi sul campo il ruolo in esame. I problemi riguarderanno principalmente l'accettazione del ruolo da parte dell'erede, nonché la sua stessa accettazione da parte dei futuri subordinati.

Al momento della sua entrata in impresa, l'erede può essere affiancato dalla figura di un tutor. Questi (da non confondere con il contract manager che esamineremo in seguito) è un soggetto vicino all'imprenditore, di cui gode la fiducia ed è apprezzato per le sue doti sia manageriali che umane. Solitamente, in passato, ha anch'egli svolto il ruolo imprenditoriale o manageriale, ma non all'interno dell'azienda di famiglia. L'erede, a sua volta, deve riporre la totale fiducia nei confronti del tutor ed affidarsi a quest'ultimo per apprendere i segreti della gestione d'impresa e la capacità di gestire i rapporti con i collaboratori. Anche in questo caso si pone il problema della durata di permanenza del tutor nell'impresa. Questa può essere fissata a priori o determinata autonomamente da ciascuno dei due soggetti in causa: il tutor potrebbe ritenere terminato il compito, quando vedrà risultati positivi nel futuro imprenditore; l'erede, a sua volta, si potrà ritenere soddisfatto nel momento in cui si accorge di avere competenze pari o superiori al suo assistente, il quale quindi ha completato il suo insegnamento.

Altro elemento di cui deve tener conto il Patto di famiglia, nelle regole per permanere all'interno dell'impresa, riguarda il volume d'impegno del futuro erede. In questo senso, l'aspetto maggiormente riscontrabile è riferibile ad un impegno costante ed intenso da parte del successore, che è chiamato a svolgere il ruolo assegnatogli con maggiore responsabilità e con un più assiduo impegno rispetto a qualunque altro soggetto presente nell'impresa, in quanto dovrà dimostrare di saper meritare il ruolo che assume e le mansioni che ne derivano.

Per quanto attiene le modalità di remunerazione, esistono differenze significative da Patto a Patto. In alcuni casi si fa riferimento al criterio dell'uguaglianza, in altri si predilige invece una remunerazione che si basi sul merito. Il principio di uguaglianza vuole che l'erede venga remunerato in misura uguale agli appartenenti al medesimo ruolo senza considerare quindi il cognome che porta. Questo metodo si contrappone a quello basato sul merito, che vuole invece una retribuzione che tenga conto delle maggiori prestazioni richieste all'erede rispetto agli altri dipendenti dell'impresa familiare. Il successore verrà quindi remunerato in relazione alle sue effettive capacità ed a ciò che sarà stato in grado di dimostrare. Rari, infine, sono i casi in cui manchi del tutto una retribuzione per l'erede, il 
quale, si presume, trovi fondi altrove. Questo comportamento, oltre a porre i colleghi in uno status d'imbarazzo, produce uno scarso impegno del successore nella sua attività, in questo caso, priva di frutti.

Le norme attinenti il trasferimento dei titoli sociali e la facoltà di uscita o di rientro dei soci familiari non riguardano direttamente il tema della successione d'impresa, ma fanno invece riferimento a principi volti a mantenere l'azienda nelle mani della famiglia del fondatore, in modo tale che la proprietà non vada dispersa con conseguenze negative sulla gestione. Per questi motivi, tali norme non verranno trattate in questa sede.

Molto più importanti per la tematica relativa alla successione imprenditoriale sono le parti attinenti i parenti acquisiti ed $i$ discendenti ed $i$ genitori. Le norme sui parenti acquisiti ed i discendenti sono spesso trascurate in molti Patti di famiglia, anche se comunque molto importanti dal punto di vista successorio. Per «parenti acquisiti» sono da intendersi soprattutto le nuore, i generi, i cognati e le cognate dell'imprenditore, mentre con il termine «discendenti» sono da intendersi i figli di figli, o i figli di fratelli. Queste norme tendono ad inibire l'ingresso in impresa di tali soggetti acquisiti, i quali, provenendo da ceppi diversi, tenderebbero a disarmonizzare i componenti della famiglia fondatrice ${ }^{12}$. Questo, però, è un principio destinato a cadere con il tempo e ad essere eliminato nelle future stesure del Patto di famiglia, in quanto, nel momento in cui, col passare di generazioni, i parenti acquisiti diventino di numero maggiore rispetto ai membri della famiglia fondatrice, diviene quasi impossibile lasciarli al di fuori dell'impresa.

Le motivazioni principali di questo atteggiamento restio nei confronti dei parenti acquisiti fanno riferimento al fatto che, spesso, questi, per le ridotte conoscenze dell'impresa o comunque le distorte informazioni che ad essi vengono fornite, possono creare attriti tra i familiari e minare così il futuro della gestione. Tutto ciò si risolve con appositi programmi (attuati da numerose imprese familiari) che tendono ad informare i discendenti ed i parenti acquisiti, sulle problematiche aziendali e sulla gestione in generale, promovendo riunioni periodiche a tal fine.

Ultimo punto da trattare nel Patto di famiglia è quello attinente alle «norme sui genitori». Questa regola, fortemente voluta dalla maggior parte degli imprenditori e solitamente avvallata da tutti i componenti della famiglia, riguarda le condizioni di sostentamento finanziario dell'imprenditore uscente all'indomani della successione, e l'eventuale ruolo ad esso affidato nell'impresa a successione avvenuta. In molti casi si assiste, infatti, all'attribuzione al genitore, di una posizione, pressoché formale, in azienda riguardante il ruolo di presidente onorario o di presidente del Consiglio di amministra-

\footnotetext{
${ }^{12}$ Ricordando proprio quanto detto in precedenza circa l'età (70 anni, almeno) con la quale l'imprenditore decide di ritirarsi, finiscono per giocare un ruolo importante i nipoti dell'imprenditore, intesi sia da parte di nonno che di zio. Ne è esempio attuale in Italia la famiglia Agnelli, aldilà delle disavventure occorse ai figli degli imprenditori in carica fino al 2003.
} 
zione senza poteri. In altri casi, le mansioni affidate all'imprenditore uscente possono essere di maggiore rilevanza e riguardare ruoli consultivi o formativi nei confronti delle nuove generazioni. Infine, si possono avere anche attribuzioni di rappresentanza, soprattutto in eventi mondani della società, per iniziative comunque non attinenti la gestione diretta degli affari aziendali.

Dalle osservazioni fin qui compiute si deduce come il Patto di famiglia sia un documento di fondamentale importanza all'interno di qualunque impresa familiare. Solitamente, però, la necessità di adottare questo atto viene compresa nel momento in cui scoppiano le prime tensioni e conflitti tra i familiari, relativamente alla scelta del successore. Questo meccanismo porta, però, ad una redazione molto difficoltosa del documento o, addirittura, all'impossibilità di metterlo in pratica. Per questi motivi, l'impresa familiare dovrebbe dotarsi con largo anticipo dell'atto in esame, in modo da affrontare con maggiore serenità tutte le vicende legate alla successione imprenditoriale. Le condizioni che permettono la migliore realizzazione del Patto di famiglia, riguardano ${ }^{13}$ : la presenza di un leader forte all'interno dell'impresa familiare, che guidi complessivamente l'intero processo che porta alla sua redazione; l'assunzione di un intermediario esterno alla famiglia che ascolti gli interessati, organizzi le riunioni e raccolga gli opportuni apporti nelle materie economiche, aziendali e giuridiche, necessari per la stesura del Patto, e che, infine, comunichi le conoscenze acquisite all'imprenditore, che sarà così in grado di guidare al meglio il processo; la volontà, da parte almeno della maggioranza dei soci, di pervenire alla stesura del Patto di famiglia; la non ostilità dei familiari che ricoprono un ruolo importante nella famiglia e nell'impresa; la disponibilità di tempo, da parte dei familiari, per partecipare agli incontri che precedono la redazione finale del documento, al fine di accordarsi sulle principali norme in esso contenute.

Come abbiamo detto in precedenza, il processo che porta alla stesura definitiva del Patto di famiglia deve essere preparato per tempo, anche perché non è un iter di breve durata. I familiari, infatti, prima di accettare le condizioni in esso contenute ed obbligarsi moralmente al loro rispetto, debbono essere in grado di comprenderle al meglio, valutando le soluzioni alternative ed, infine, decidendo quella più giusta per il bene della famiglia e la continuità dell'impresa. La redazione del Patto presuppone quindi una maggiore attenzione per quelli che sono i rapporti tra famiglia ed impresa e, di conseguenza, una maggiore attenzione al complesso processo di successione imprenditoriale. In Italia ed all'estero, infatti, solo le aziende che si sono date delle regole precise nei rapporti famiglia-impresa riescono a superare la terza generazione e questo dimostra la grande importanza da attribuire al documento in esame.

${ }^{13}$ Cfr. Corbetta, Le imprese familiari, cit. 


\section{II «contract manager»}

Una delle soluzioni non mobiliari di recente introduzione è rappresentata da una particolare figura di manager denominata «contract manager». $\grave{E}$ un soggetto che collabora con l'impresa familiare per un determinato arco di tempo ed è legato a quest'ultima da un rapporto contrattuale ${ }^{14}$. Supportato da conoscenza in materia di gestione aziendale, è solitamente chiamato a risolvere le problematiche attinenti la successione imprenditoriale.

La principale caratteristica del contract manager è quella di essere legato ad un duplice rapporto contrattuale, il primo con la società di temporary management a cui fa capo, la quale mette a disposizione delle imprese varie tipologie di manager per la risoluzione di specifici problemi di gestione; il secondo, con la società stessa che richiede il servizio e si avvale della collaborazione del contract manager, il quale stipula con essa un contratto di lavoro autonomo.

Altra caratteristica, che si evince dalla precedente, è la temporaneità dell'intervento. La funzione del manager in questione sarà infatti quella di gestire la specifica problematica successoria, lasciando all'imprenditore la guida di tutte le altre funzioni aziendali. Proprio per la temporaneità del suo intervento, il contract manager non trova difficoltà ad inserirsi nell'impresa, in quanto i familiari non vedono in quest'ultimo una figura in grado di 'usurpare il trono imprenditoriale', e perciò egli è solitamente circondato da un clima di collaborazione. La durata dell'intervento non è calcolata a priori e non lo può essere, in quanto non esistono tabelle specifiche, ma varierà da impresa a impresa, in relazione alla maggiore o minore complessità delle problematiche da risolvere.

Terza ed ultima caratteristica dell'intervento del contract manager è quella di 'specificità', nel senso che le competenze dell'intermediario in questione riguardano un problema specifico, nel nostro caso la successione imprenditoriale. Proprio per la specificità delle conoscenze, queste saranno naturalmente maggiori di quelle in possesso dal management aziendale preesistente.

L'ingresso del contract manager nell'impresa di famiglia, può essere richiesto sia in una fase di assoluta emergenza successoria, sia nella fase di programmazione del ricambio generazionale. L'ingresso nella fase di emergenza è dovuto, solitamente, all'improvvisa morte dell'imprenditore. In questi casi l'intervento del contract manager riguarderà la sostituzione degli eredi nella risoluzione delle problematiche gestionali dell'impresa, in un momento nel quale essi sono influenzati da un'alta emotività che potrebbe condizionarne le scelte. Il contact manager dovrà poi farsi capo del ruolo di coordinatore del management aziendale, il quale è ora privo di

\footnotetext{
${ }^{14}$ Jovenitti, Strategie mobiliari, cit.
} 
una guida. Il problema maggiore non riguarderà però l'entrata dell'intermediario nell'impresa, ma la sollecitazione del suo intervento da parte del management, di solito impegnato, in questi casi, in lotte intestine per l'acquisizione del potere imprenditoriale.

Se invece il contract manager è chiamato ad operare in vista del momento successorio con largo anticipo, da parte di un imprenditore lungimirante, le problematiche che dovrà risolvere saranno ben diverse. Innanzitutto non esiste più il problema di chi andrà a richiedere il suo intervento, in quanto sarà lo stesso imprenditore uscente a farsi carico della decisione in questione. In questi casi, il contract manager potrà essere chiamato a svolgere due diversi ruoli: il primo riguarderà l'assistenza all'imprenditore nella risoluzione delle problematiche successorie, nonché nella scelta dell'erede ottimale in grado di sostituirlo; il secondo sarà invece un compito di assistenza all'erede designato nella presa di conoscenza delle problematiche gestionali dell'impresa e nell'assunzione delle prime responsabilità. In questo caso, sarà il contract manager a gestire l'impresa familiare e l'erede avrà la funzione di suo assistente, fino al momento in cui, le sue competenze saranno tali da permettergli uno scambio di ruoli.

Come si vede da quanto fin qui detto, i ruoli nei quali può essere impegnato il contract manager sono molteplici e per questo egli deve essere una persona dotata della necessaria flessibilità per operare nelle situazioni più diverse. Potrà certe volte assumere la figura di 'allenatore' dell'erede, in altri casi quella di gestore della complessa realtà aziendale, ma deve comunque essere in grado di gestire al meglio qualsiasi problematica gli venga posta, in quanto è in gioco la continuità dell'impresa familiare. 



\section{Finanza straordinaria per la successione imprenditoriale}

Abbiamo finora visto che cosa si intenda per impresa familiare, la sua evoluzione nelle transizioni generazionali e abbiamo avvertito anche la necessità di sottolineare l'esigenza di aprire certe compagini sociali, individuando alcuni connotati tipici del capitalismo familiare. Ricordando quanto detto fino ad ora circa l'esigenza della pianificazione successoria, possiamo adesso affermare che la pianificazione della successione nell'impresa familiare riguarda sia l'impresa che la famiglia, proprio su due piani distinti: la parte aziendale si riferirà all'analisi dei motivi del successo aziendale, la verifica del presente e le condizioni per il futuro, al fine di raggiungere la missione aziendale; la componente familiare elencherà i valori ritenuti vitali per l'impresa, i modi di partecipare alla vita aziendale dei componenti e le soluzioni condivise.

Eseguiamo qui di seguito un'analisi delle principali operazioni che si possono utilizzare nella successione dell'impresa familiare, premettendo fin da subito che, con l'abolizione dell'imposta di successione, molte delle motivazioni di natura fiscale relative alla pianificazione successoria sono venute meno. Rimangono valide non solo le motivazioni di cui si è detto nel primo capitolo, ma anche le altre, fra cui ad esempio quella di salvaguardia del patrimonio immobiliare dalle vicende dell'impresa che non sarà più nelle mani dell'imprenditore che l'ha resa di successo, senza alcuna garanzia che gli eredi riescano allo stesso modo.

L'ordine di esposizione delle operazioni si informa a criteri di maggiore fattibilità per comprovata prassi, ma anche a criteri di complessità decrescenti, ricordando che la successione imprenditoriale è un'operazione alquanto articolata e necessita spesso di una combinazione di diverse operazioni che saranno affrontate in più fasi, secondo la programmazione prima pianificata. 


\section{La scissione}

La scissione è stata inserita nel sistema normativo italiano a seguito del recepimento della III e della IV Direttiva avvenuto con l'emanazione del D. Lgs 16 gennaio 1991 n. 22; essa costituisce una alternativa strategica per pianificare la successione dell'impresa familiare (e, più in generale, per assicurare la continuità all'impresa stessa), subordinatamente ad una serie di condizioni soprattutto di natura tributaria.

La normativa civilistica non fornisce una definizione dell'operazione, ma ne indica solo le modalità realizzative, precisandone l'ambito soggettivo: la scissione, infatti, può essere realizzata da tutti i tipi di società, lucrative (di persone e di capitali) e cooperative. I soggetti della scissione sono individuati nella società scissa, cioè la società che esegue la scissione tramite il «trasferimento» della azienda o di parte di essa ad una o più società beneficiarie, e nella società che ricevono il «trasferimento» dell'azienda o del ramo d'azienda.

Si distinguono due tipi di scissione:

- quella totale, in cui la società scissa trasferisce l'intera azienda a più società beneficiarie, di nuova costituzione o già esistenti, e si estingue. I soci della società scissa riceveranno in cambio delle azioni o quote della società scissa in numero proporzionale o meno ${ }^{1} \mathrm{di}$ azioni o quote delle società beneficiarie;

- quella parziale, in cui la società scissa trasferisce una parte della azienda a una o più società beneficiarie che possono essere di nuova costituzione ovvero già esistenti, e continua a sussistere con la residua parte di azienda non trasferita. Anche in questo caso i soci della società scissa riceveranno in cambio azioni/quote della/e società beneficiaria/e in misura proporzionale o meno.

Come già accennato nel primo capitolo a titolo di esempio, fra i molteplici scopi per i quali un'impresa può essere scissa, ci interessa quello inerente la successione dell'impresa di famiglia.

Innanzitutto la scissione parziale, mediante la costituzione di società beneficiarie separate, inizialmente facenti capo a tutti i soci della società scissa, ma immediatamente dopo trasferibili in capo ad un unico soggetto - erede destinato di quella porzione di azienda -, permette la successione di proprietà esclusive ai singoli eredi: in luogo di trasferire per successione una percentuale dell'impresa di famiglia che implica necessariamente la convivenza con gli altri eredi, si realizza il trasferimento del 100\% di una porzione dell'impresa di famiglia, elevata però al rango di società auto-

${ }^{1}$ Per approfondimenti tecnici sull'operazione di scissione cfr. Passeri, Valutazioni imprenditoriali in merito all'operazione di scissione, cit. 
noma ${ }^{2}$. Ciò produce la favorevole conseguenza della più facile gestibilità della società beneficiaria, nonché la sua alienabilità, totale o parziale. La realizzazione di questa soluzione esige tuttavia la verifica del presupposto della separabilità di parti aziendali, della loro sussistenza autonoma in condizioni di equilibrio economico-gestionale e perciò non è concessa ai casi di impresa familiare mono-business ${ }^{3}$.

Sempre nella logica successoria, la scissione si pone come una efficace soluzione per realizzare la differenziazione fra eredi, in quanto permette la separazione mirata degli asset della impresa di famiglia. In questo ambito trova posto anche una soluzione frequentemente adottata nelle pianificazioni successorie, soprattutto in presenza di una componente non interessata a continuare la gestione d'impresa, ma meritevole di una parte dell'eredità, sotto forma di patrimonio immobiliare e rendita connessa. L'obiettivo viene realizzato separando l'azienda produttiva dai cespiti immobiliari necessari al suo funzionamento (tipicamente i fabbricati industriali) che vengono mantenuti nella società scissa, mentre alla/e società beneficiaria/e viene trasferita l'attività operativa. Contestualmente si procede alla stipula di contratti di locazione fra la società scissa e la/e società beneficiaria/e con la conseguenza che le società produttive continuano indifferentemente la loro attività nei medesimi spazi utilizzati prima della scissione, ancorché disponibili in base ad un contratto di locazione, ma la società scissa percepisce periodicamente un canone che rappresenta il suo reddito caratteristico da cui deriveranno i frutti destinati ai soci.

Infine, ancora sul piano successorio, la scissione permette di prevenire il contenzioso fra eredi che dimostrino una difficile convivenza reciproca nel medesimo ambito societario, proprio grazie all'assegnazione mirata di porzioni dell'eredità separate ed autonome fra loro, sempre se divisibili.

\section{La fondazione e il trust}

La fondazione e il trust rappresentano strategie complesse di pianificazione della successione di impresa. In dette operazioni sono presenti molto frequentemente aspetti inerenti la problematica successoria familiare, anche perché trasferire un'impresa ad una fondazione o ad un trust significa anche ricorrere ad una soluzione che assicura la continuità dell'impresa trasferita dopo la morte del soggetto trasferente (fondatore o settlor). È assai raro assistere al ricorso alla fondazione o al trust da parte di un soggetto giovane che, pertanto, dispone ancora di un lungo orizzonte temporale di fronte a sé, in quanto le soluzioni qui esaminate sono

\footnotetext{
${ }^{2}$ Con l'osservanza della recente risoluzione n. 224/E del 9 luglio 2002 dell' Agenzia delle Entrate.

${ }^{3}$ Sui presupposti della scissione cfr. Passeri, Valutazioni imprenditoriali in merito all'operazione di scissione, cit.
} 
praticamente irreversibili, cioè «smontabili» solo a fronte di elevati oneri e di complesse procedure.

Oltre che per le immaginabili motivazioni mobiliari, giuridiche, fiscali e valutarie, il ricorso alla fondazione o al trust risulta più coerente con motivazioni psicologiche ed emotive legate alla successione, considerato che con esse l'imprenditore (fondatore o settlor) si propone di tramandare ai posteri i suoi valori ed il suo nome.

Ancorché le due alternative della fondazione e del trust debbano essere esaminate separatamente sotto il profilo tecnico-applicativo, si deve necessariamente far precedere a tale esame il richiamo ad alcuni aspetti comuni che riguardano l'obiettivo per cui sono promosse ed il relativo oggetto. Per quanto concerne il primo, sia mediante la fondazione, sia con il ricorso al trust, l'imprenditore (fondatore o settlor) si propone di tenere unito il suo patrimonio incentrato nell'impresa di famiglia per trasmetterlo in forma aggregata agli eredi e ai soggetti che vorrà indicare. Le motivazioni in base alle quali l'imprenditore fa ricorso a questa soluzione sono diverse e, come si è anticipato, vi sono confusi elementi economici ed extra economici. In ogni caso coincidono spesso con le principali motivazioni successorie a suo tempo evidenziate.

Più specificatamente, per le due singole soluzioni della fondazione e del trust si deve dire che entrambe sono ancora caratterizzate in Italia da un inquadramento normativo non precisamente definito e a ciò si deve sia il limitato ricorso ad esse da parte dell'imprenditore, sia l'atteggiamento non favorevole e spesso inquisitorio delle autorità di controllo.

Per quanto concerne la fondazione, che rappresenta la soluzione «italiana» più definita fra le due esaminate, si rileva che la sua disciplina civilistica è contenuta negli artt. 14-35 c.c. ${ }^{4}$. L'oggetto del trasferimento dal fondatore alla fondazione, come si è visto, non è una cessione o un conferimento - atti a titolo oneroso differenziati tra loro per la natura del corrispettivo, rispettivamente, denaro o titoli -, ma una donazione, cioè un atto a titolo gratuito

\footnotetext{
${ }^{4}$ La fondazione deve essere costituita per atto pubblico che può essere revocato dal fondatore prima del riconoscimento da parte dell'autorità governativa (che conferisce personalità giuridica all'ente), o prima dell'inizio della sua attività: altrimenti la fondazione si estinguerà quando sarà raggiunto il termine stabilito dal suo statuto, o quando avrà conseguito il suo scopo o esso sia divenuto impossibile, ferma restando la possibilità da parte dell'autorità governativa di prevedere la trasformazione della fondazione «allontanandosi il meno possibile dalla volontà del fondatore». In nessun caso, invece, l'atto di fondazione potrà essere revocato dagli eredi (cioè dai beneficiari).

La disciplina fiscale della fondazione è invece meno organica di quella civilistica e pone l'accento su un aspetto qualificante dell'ente in un momento determinato della sua storia. La norma rilevante a questi fini identifica tale «trasferimento» in una «donazione»e, di conseguenza, prevede il relativo trattamento fiscale nell'ambito dell'omonima imposta (recentemente modificata in senso migliorativo rispetto alla prossimità del vincolo di parentela). In tale ambito normativo sono previste differenti modalità ed onerosità a seconda che diverse classi di beni siano trasferite a persone fisiche o a persone giuridiche e, fra queste ultime, a società $\mathrm{o}$ a fondazioni.
} 
senza corrispettivo a favore del soggetto che trasferisce. Può essere rappresentato da una partecipazione rilevante o totalitaria nell'impresa di famiglia, integrata o meno da altri beni, frequentemente immobili.

Per quanto riguarda il trust ${ }^{5}$, che rappresenta la soluzione «estera» fra le due esaminate, si rileva che la sua disciplina in Italia è ancora in divenire, se si considera che tale istituto è stato bensì riconosciuto nel nostro ordinamento ${ }^{6}$, ma la ratifica non comporta l'introduzione dell'istituto del trust nell'ordinamento italiano, fermo il riconoscimento degli effetti dei trust costituiti dall'estero, pur in mancanza di norme regolamentari e applicative del regime fiscale del trust.

Il trust è un istituto di origine anglosassone, ampiamente sviluppato nei paesi di «common law», che non ha natura contrattuale, in quanto si basa su un rapporto trilaterale che realizza la separazione del godimento dei frutti di beni dalla proprietà e gestione degli stessi. Ciò ha permesso nei paesi di origine di perseguire diverse finalità economiche e sociali, quali la mera intestazione di beni, l'affidamento della amministrazione e gestione discrezionale di beni, l'investimento di somme raccolte presso il pubblico, l'affidamento di beni per scopi successori o per garanzia patrimoniale o per attività non profit ${ }^{7}$. Il trust pertanto si configura giuridicamente come un negozio unitario che compendia un negozio con effetto reale, inerente il trasferimento della proprietà del bene, e un negozio di carattere obbligatorio, che vincola un soggetto all'utilizzazione del bene secondo le indicazioni di chi glielo ha trasferito.

I soggetti del trust sono:

- il settlor (corrispondente al fondatore della fondazione) iniziale proprietario del bene o del patrimonio che intende trasferire per godimento dei relativi frutti o per utilizzazione a determinate condizioni. Nel costituire il trust, il settlor stabilisce la legge che lo regolerà, altrimenti si applicherà quella vigente nel luogo ove si è costituito;

- il protector con funzioni di controllore del trustee, a seguito della nomina effettuata dal settlor;

- il trustee (corrispondente all'amministratore della fondazione) con compiti di gestione del bene o del patrimonio trasferito dal settlor in proprietà al trust che costituisce un patrimonio separato da quello

\footnotetext{
${ }^{5} \mathrm{Si}$ veda la vasta letteratura in materia, ormai anche italiana, fra cui: M. Lupoi, Trusts, Giuffrè, Milano 20012; Id., L'atto istitutivo di trust, Giuffré, Milano 2005; L. Fumagalli, Il trust, in Gli enti non profit in Italia, Cedam, Padova 1994; L. Zitiello, Il trust e gli istituti corrispondenti nell'ordinamento italiano, «Le Società», 8, 1995.

${ }^{6}$ Con la Legge 16 ottobre 1989, n. 364, che ha ratificato la Convenzione dell'Aja del luglio 1985, entrata in vigore dal $1^{\circ}$ gennaio 1992, oltre che una più recente applicazione degli atti di disposizione successoria del patrimonio, contenuta nell'art. 2645-ter c.c., introdotto dall'art. 39-nonies, D.L. 30 dicembre 2005, n. 273, convertito, con modifiche, dalla L. 23 febbraio 2006, n. 51.

${ }^{7}$ Così Jovenitti, Strategie mobiliari, cit.
} 
del trustee (che può, infatti, amministrare e gestire contemporaneamente numerosi patrimoni). Questi ha l'obbligo di amministrare i beni trasferiti secondo quanto previsto nel contratto: con lui si costituisce il trust (trust agreement) e la sua attività può appunto essere controllata da un protector eventualmente nominato dal settlor;

- i beneficiari, fra i quali può esservi anche il settlor finché è in vita, che percepiranno i frutti dei beni amministrati dal trustee, secondo quanto disposto dal settlor nel trust agreement. Quest'ultimo regola anche la destinazione dei beni al termine del trust ${ }^{8}$.

Ai fini della successione dell'impresa familiare il ricorso al trust, pur dovendo superare una serie di dubbi interpretativi e applicativi, consente il raggiungimento di alcuni obiettivi non marginali, quali:

- la non aggredibilità del patrimonio del settlor da parte dei suoi creditori;

- la possibilità di realizzare la gestione del patrimonio del settlor secondo le istruzioni impartite al trustee (a meno di non aver fatto ricorso al trust discrezionale), compreso il trasferimento finale ai beneficiari;

- la aggregazione del patrimonio del settlor, sinonimo, come si è visto, di governabilità, accentramento decisionale, maggior valore, sinergie e non aggredibilità dall'esterno.

Pur ricordando quanto detto a proposito del Patto di famiglia relativamente alla nuova normativa che eccezionalmente lo regola, va ricordato che, peraltro, il ricorso al trust non consente di superare la normativa in materia di quota legittima dell'eredità, in quanto la struttura resta esposta al grave rischio dell'azione contro la riduzione della quota di legittima, proponibile dagli eredi o dai creditori degli eredi e presenta controindicazioni per la eventuale quotazione dell'impresa di famiglia e per l'applicabilità della legge sull'OPA? .

\section{II «Family Buy-Out»}

Nel caso in cui i soci non siano più interessati a partecipare alla gestione, oppure non siano più disposti a permanere nella società neppure come

\footnotetext{
${ }^{8}$ Si distinguono due diversi tipi di trust che presentano differente rilevanza ai fini fiscali, cioè: il trust irrevocabile nel quale il settlor non può revocare il trasferimento dei beni al trustee e ciò dimostra il definitivo spossessamento dei beni con conseguente trasferimento della loro proprietà; il trust discrezionale nel quale il settlor si riserva di orientare le scelte gestionali del trustee (con letters of wishes peraltro non vincolanti), il quale però è libero di distribuire o meno i frutti dei beni gestiti ai beneficiari, determinandone la misura.

${ }_{9}^{9}$ Così, sostanzialmente, Jovenitti, Strategie mobiliari, cit.
} 
finanziatori, o siano in disaccordo con le linee gestionali in atto o per la specifica operazione in esame, l'uscita di categorie di soci con simili intenti contribuisce ad assicurare la continuità dell'impresa di famiglia e facilita la successione dei soci/eredi interessati alla continuazione della gestione della stessa.

L'operazione che va sotto il nome di Family Buy-Out (FBO) rappresenta una variante della più nota e diffusa operazione societaria denominata Leveraged Buy-Out (LBO), con cui presenta numerosi aspetti comuni e un solo rilevante aspetto differenziale. Esso ha natura soggettiva e consiste nel fatto che il promotore del FBO è costituito dai membri della famiglia imprenditoriale interessati a continuare la gestione dell'impresa. Ricordiamo che il LBO è costituito da un'impresa che si prefigge di realizzare una particolare operazione di crescita esterna a ben determinate condizioni finanziarie e tributarie. In merito occorre ricordare anche l'altra diffusa variante del LBO rappresentata dal Management Buy-Out $(\mathrm{MBO})$, in cui il soggetto promotore è rappresentato da alcuni manager dell'impresa che, da soli o in collaborazione con investitori istituzionali, acquisiscono l'impresa da loro diretta, facendo leva su determinate condizioni di natura finanziaria e tributaria.

Come anticipato, il principale aspetto differenziale fra il LBO testé illustrato e il FBO consiste nell'identità del soggetto promotore dell'operazione: nel FBO vi è il gruppo di soci/membri familiari interessati a continuare la gestione dell'impresa di famiglia, che dà vita a una new company alla quale vengono trasferite le azioni/quote dell'impresa di famiglia, sia dei soci interessati a continuare la gestione, sia dei soci uscenti, a condizione - generalmente - di aggregare il controllo dell'impresa di famiglia.

Se viene realizzata l'operazione di FBO, ne consegue quasi certamente che nel breve o nel medio termine l'impresa di famiglia necessiterà di una ricapitalizzazione che potrà essere effettuata sia grazie all'intervento dei soci, sia, in presenza delle richieste condizioni, accedendo alla quotazione in Borsa e aprendo parte del capitale al finanziamento di soci esterni.

Va in ogni caso rilevato che l'operazione in esame dimostra la presenza di soggetti nell'ambito dell'impresa di famiglia particolarmente evoluti in materia di finanza aziendale, considerata la complessità dei problemi sollevati dal FBO di natura finanziaria, fiscale e giuridica.

\section{L'affitto e l'usufrutto d'azienda}

Nell'affrontare l'affitto e l'usufrutto di azienda come soluzioni alternative per preparare/realizzare la successione dell'impresa di famiglia, si evidenzia subito che i due istituti presentano una medesima disciplina civilistica e tributaria. A questa singolarità della disciplina si aggiungono gli esigui riferimenti normativi ai due istituti in esame, ancorché la prassi aziendale ne faccia ampio ricorso. 
La disciplina civilistica è contenuta negli articoli 2561 e 2562 del Codice civile, in base ai quali l'affittuario dell'azienda «deve esercitarla sotto la ditta che la contraddistingue», «deve gestire l'azienda senza modificarne la destinazione, in modo da conservare l'efficienza dell'organizzazione e degli impianti e le normali dotazioni di scorte». All'affitto d'azienda si applica anche la normativa in materia di trasferimento d'azienda (art. 2112 c.c.) che assicura la continuità dei rapporti contrattuali in essere, compresi i contratti di lavoro.

Anche la disciplina tributaria è comune per i due istituti, risolvendosi nell'obbligo di registrazione dei relativi contratti (art. 3 DPR 26 aprile 1986, n. 131) e nella previsione che le quote d'ammortamento siano deducibili nella determinazione del reddito dell'affittuario (art. 67, nono comma, DPR 22 dicembre 1986, n. 917).

Gli unici aspetti differenziali rilevanti sul piano normativo e procedurale fra i due istituti consistono nella cessione dei crediti (solo per l'azienda in usufrutto, ai sensi dell'art. 2559 c.c.) e nella circostanza che l'azienda concessa in usufrutto è destinata a riunirsi alla relativa nuda proprietà al termine del contratto, mentre l'azienda affittata - come si vedrà in seguito - viene più spesso ceduta o riscattata dall'affittuario (come si può facilmente immaginare).

Il ridotto spazio attribuito dalla normativa ai due istituti in esame ha dato spesso luogo ad abusi e a contenzioso di natura interpretativa in merito alla applicazione dei relativi contratti: si consideri, ad esempio, il totale silenzio normativo in tema di potere decisionale sulla stipula di tali contratti. Nessuna norma, infatti, prescrive quale sia l'organo sociale abilitato a concedere in affitto l'azienda, con la conseguenza di realizzare tale operazione con una semplice delibera consiliare, senza transitare dall'assemblea, luogo dove alcuni soci potrebbero essere contrari allo svuotamento della società o potrebbero eccepire in merito alla congruità del canone e/o del prezzo di riscatto ${ }^{10}$.

Ricordiamo che i soggetti del contratto di affitto d'azienda sono:

- la società a cui si riferisce l'azienda oggetto del contratto d'affitto che, ai presenti fini, viene identificata nell'impresa di famiglia. Per essa vige il divieto di concorrenza per la durata del contratto d'affitto (ai sensi dell'art. 2557 c.c.). La società in esame assume pertanto il ruolo di affittante;

- la società che prende in affitto l'azienda. Può trattarsi di una società all'uopo costituita da parte dei membri della famiglia nei confronti dei quali si intende realizzare la successione tramite la soluzione in esame. Può alternativamente trattarsi di una società di un altro im-

\footnotetext{
${ }^{10}$ In genere l'attribuzione di questa competenza viene definita in sede di statuto o all'atto della nomina degli amministratori, nella definizione dei loro poteri (se consentito dallo statuto).
} 
prenditore, anche concorrente, che si riserva di acquistare l'azienda affittata alla scadenza del contratto.

L'oggetto del contratto d'affitto d'azienda (o di usufrutto) consiste generalmente nell'intera azienda, ma nella pianificazione successoria è frequente identificare l'oggetto del contratto in un ramo aziendale: ciò si verifica soprattutto quando l'impresa di famiglia non sia mono-business, o quando, oltre alla azienda operativa, si trovino nell'impresa di famiglia anche altre attività facenti capo direttamente ai soci, come accade spesso con gli immobili. In generale, però, il ricorso al contratto d'affitto d'azienda presenta massima efficacia quando ha per oggetto una azienda in equilibrio economico, in grado perciò di far emergere un positivo risultato della gestione caratteristica.

Ai fini della pianificazione della successione, il ricorso al contratto d'affitto d'azienda viene generalmente effettuato con l'obiettivo di trasferire la gestione operativa dell'azienda contenuta nell'impresa di famiglia a quei soggetti/eredi che hanno dichiarato o dimostrato l'intenzione e la capacità di gestire, a differenza di altri soggetti/eredi non interessati/non capaci ai quali comunque deve essere riservata una parte della eredità. La parità di trattamento fra gli eredi viene realizzata ponendo inizialmente tutti sullo stesso piano: perciò, se gli eredi interessati a gestire disporranno dell'azienda che genera determinati risultati, i soci dell'impresa di famiglia non interessati a gestire l'azienda percepiranno un canone pari a quei risultati. Si verifica perciò che, almeno al tempo «zero», tutti gli eredi percepiscono il medesimo frutto. Peraltro i gestori, che hanno accettato il rischio imprenditoriale e si sono dichiarati disposti a «rischiare» i frutti dell'azienda, pagando un canone per poterla gestire, saranno ulteriormente remunerati appunto in relazione alla loro capacità di gestire l'azienda in affitto, in quanto i migliori/peggiori risultati economici oltre il canone saranno di loro esclusiva competenza. Gli altri eredi, invece, percepiranno una sorta di rendita, coincidente con il canone. Se poi nell'impresa di famiglia saranno stati trattenuti i cespiti (frequentemente di natura immobiliare) non strumentali all'esercizio dell'azienda concessa in affitto (o in usufrutto), gli eredi/redditieri percepiranno anche il frutto di tali cespiti.

Anche in merito alla determinazione della dimensione del canone, si rileva il più sopra citato silenzio normativo, nel senso che nessuna norma, né civile, né fiscale, stabilisce le modalità di calcolo del canone, né sistemi di controllo. Pertanto il canone viene determinato su basi contrattuali o su basi meramente convenzionali. Tuttavia può identificarsi un canone equo, che risponda alla logica economica su cui si fonda il contratto d'affitto d'azienda. Esso può riconoscersi nel citato risultato della gestione caratteristica dell'azienda, in quanto è indifferente, anche fiscalmente, gestire direttamente l'azienda, ovvero concederla in affitto per un canone corrispondente alla sua redditività gestionale. Quest'ultima viene rilevata 
a livello di gestione caratteristica in quanto generalmente i crediti/debiti rimangono nella società affittante e le poste straordinarie hanno carattere di aleatorietà. Tuttavia sono frequenti i casi in cui l'affittuario si fa carico anche del capitale circolante e della struttura finanziaria dell'azienda presa in affitto: in questo caso il canone viene più correttamente correlato al risultato lordo.

Per quanto riguarda la durata del contratto d'affitto d'azienda, essa è generalmente breve (pochi anni), con correlazione o meno al ciclo produttivo dell'azienda affittata (o in usufrutto). Nella problematica successoria, invece, si assiste a durate anche più lunghe, ovvero a durate di medio termine con clausola di tacito rinnovo.

Anche se la normativa in materia non ne fa alcun accenno, è frequentemente prevista nei contratti d'affitto d'azienda, qui a differenza dell'usufrutto destinato a «riunirsi» alla nuda proprietà, una clausola di riscatto che consente all'affittuario, ad una scadenza predeterminata e contro un corrispettivo pattuito, di riscattare l'azienda fino ad allora condotta in affitto.

\section{L’acquisto di azioni proprie}

L'operazione di acquisto di azioni proprie consiste nella cessione, da parte di uno o più soci, delle azioni sociali alla medesima società emittente: essa può essere realizzata secondo le modalità previste dall'art. 2357 c.c., che definiscono le caratteristiche procedurali dell'operazione.

La previsione di questa operazione di acquisto di azioni proprie nell'ambito del tema delle successioni va inquadrata come una delle possibili soluzioni di mobilità dei titoli dell'impresa di famiglia in preparazione (e per la pianificazione) dell'evento successorio, allo scopo di anticipare le movimentazioni di titoli sociali, ormai obbligatorie in quella sede, o di evitare destinazioni dei titoli sociali non funzionali alla continuità dell'impresa di famiglia.

Infatti, mediante le vendita da parte dei soci di azioni sociali alla medesima società emittente, è consentito all'imprenditore di trasferire, alla successione, i titoli dell'impresa appartenenti alla famiglia. Allo stesso tempo è permesso ai soci disporre della liquidità proveniente dalla vendita dei titoli sociali alla società, da destinarsi a distribuzioni dirette e non onerose fra gli eredi. Per i soci/eredi è consentito inoltre disporre di una sorta di «stanza di compensazione» dei titoli sociali in relazione alle redistribuzioni pianificate per realizzare la successione, mentre per i soci che abbiano manifestato il loro disinteresse a permanere nella compagine sociale, è consentito «uscire» dalla società e monetizzare il loro investimento.

In ogni caso, con l'operazione in esame, la movimentazione dei titoli sociali produce il risultato di mantenerli entro l'ambito societario e perciò utilizzabili per eventuali successive operazioni mobiliari, senza coinvolgere terzi e senza l'annullamento dei titoli, come invece avviene nel recesso 
(qualora ne ricorrano i presupposti). In altre parole, sia le movimentazioni dei titoli sociali, sia l'uscita dei soci dalla società vengono finanziate dalla società stessa con risorse a sua disposizione, senza ricorrere a terzi esterni.

Si ricorda che fino a quando le azioni sociali restano in proprietà della società emittente che le ha acquisite dai soci, il diritto agli utili e il diritto di opzione sono attribuiti proporzionalmente alle altre azioni (cioè agli altri soci). Questa norma (art. 2357-ter, secondo comma, c.c.) rafforza l'affermazione precedente secondo la quale l'operazione in esame mantiene entro l'ambito sociale tutti i suoi effetti, senza impoverire la società e senza ricorrere a terzi.

Nel medesimo periodo, il diritto di voto è sospeso, ma le azioni proprie sono tuttavia computate ai fini dei calcoli dei quorum costitutivi e deliberativi delle assemblee.

Ai presenti fini è particolarmente rilevante esaminare, sotto il profilo mobiliare, il concreto contributo che le azioni sociali acquistate dalla società emittente possono dare alla continuità aziendale ${ }^{11}$. Esse infatti possono essere utilizzate sia per essere cedute in blocco a terzi che per essere permutate con titoli di un'altra società, nell'ottica di un'alleanza strategica; oppure per essere l'oggetto di una OPV, allo scopo di concorrere alla formazione del flottante; infine per fungere da titolo di compendio di obbligazioni convertibili, obbligazioni con warrant, o warrant, e realizzare così una doppia raccolta di nuove risorse finanziarie.

\section{L'usufrutto su valori mobiliari}

Con l'usufrutto si ha la costituzione di un diritto reale di godimento che consente di utilizzare beni altrui, traendone i frutti, con l'obbligo di rispettarne la destinazione economica. Qui viene esaminato come strumento di pianificazione della successione dell'impresa di famiglia dopo qualche cenno di inquadramento normativo.

Possono formare oggetto di usufrutto, sia beni reali (quali i fondi agrari, gli immobili, gli impianti ecc., ai sensi degli artt. 978 e ss. c.c.), sia l'azienda (ai sensi dell'art. 2561 c.c.), sia le azioni (ai sensi dell'art. 2352 c.c.) ${ }^{12}$. La du-

\footnotetext{
${ }^{11}$ Se le azioni proprie non vengono utilizzate per le finalità mobiliari, possono essere mantenute in portafoglio senza limiti di tempo, ovvero possono essere annullate, riducendo proporzionalmente il capitale sociale (e riserve). È evidente che in quest'ultimo caso si riformerà lo spazio per acquisire nuovamente azioni proprie, comunque sempre nel limite massimo del $10 \%$ del capitale sociale. Rimane dubbio, invece, se le azioni proprie possano essere utilizzate per rappresentare una garanzia in occasione della richiesta di un finanziamento da parte della medesima società emittente, visto il disposto dell'art. 2358 c.c..

${ }^{12}$ Può trattarsi sia di azioni emesse dalle società per azioni che da società in accomandita per azioni, mentre è controversa la possibilità di costituire usufrutto sulle quote delle società a responsabilità limitata, considerata l'assenza di una norma specifica. Di parere favorevole è chi vede una analogia fra usufrutto e pegno, considerato che quest'ultimo può essere costituito su quote di Srl. Sono rare le posizioni giurisprudenziali orientate, sia verso la non esclusione, che lo specifico riconoscimento.
} 
rata massima dell'usufrutto è correlata alla tipologia della persona titolare. Se usufruttuario è la persona fisica, la durata massima è la sua vita fisica residua (e, come tale, non è determinabile con precisione); se si tratta invece di persona giuridica, la durata massima dell'usufrutto è pari a trenta anni ${ }^{13}$. L'usufrutto si estingue o per scadenza del termine contrattuale, o per perimento dell'oggetto, o per la morte (fine) di una delle parti: in quest'ultimo caso si verifica la riunione dell'usufrutto alla nuda proprietà (altrimenti detta «consolidazione»).

I soggetti del contratto di usufrutto sono pertanto:

- il proprietario originario del bene reale che trasferisce pro tempore il godimento del bene stesso all'usufruttuario, senza corrispettivo, rimanendo titolare della nuda proprietà del bene. In caso di usufrutto di azioni, il nudo proprietario rimane socio della società emittente le azioni e mantiene il diritto di opzione (su eventuali futuri aumenti del capitale), oltre al diritto di voto, se contrattualmente stabilito (ma ciò accade raramente);

- l'usufruttuario che pro tempore vanta il diritto di usufruire dei frutti del bene e ne diviene creditore quando essi diventano disponibili. In caso di usufrutto di azioni, l'usufruttuario non è socio della società emittente le azioni, anche se del contratto si fa menzione nel libro soci. Egli è titolare del diritto di voto e dei diritti di controllo sulla gestione sociale (ispezione dei libri sociali, esame preventivo del bilancio, denuncia delle eventuali irregolarità agli amministratori e al Tribunale), oltre che del diritto di intervento in assemblea, sia in sede ordinaria, sia in sede straordinaria.

Sempre se ammesso dal contratto, l'usufrutto può essere ceduto (o donato, o permutato) previa notifica al nudo proprietario. I corrispettivi per la costituzione e per la cessione dell'usufrutto (così come della nuda proprietà) sono liberamente definiti nell'ambito contrattuale; tuttavia la normativa fiscale indica la misura rilevante ai fini impositivi (diretti e indiretti) con la conseguenza che corrispettivi contrattuali eventualmente difformi dal valore fiscale generano differenze fiscalmente rilevanti. Non costituisce invece operazione fiscalmente imponibile la riunione dell'usufrutto alla nuda proprietà.

In particolare il valore fiscale del diritto di usufrutto è pari al valore attuale di una rendita annua posticipata di un reddito a sua volta calcolato nella

\footnotetext{
${ }^{13}$ La durata dell'usufrutto assume particolare rilevanza ai fini del suo valore e delle conseguenze sul piano civile e fiscale, potendosi stipulare contratti di usufrutto di durata limitata in relazione alle specifiche esigenze delle parti. La durata della vita residua di un individuo adulto di 35-55 anni può essere stimata pari a trenta anni, e questo è un criterio medio al quale si è ispirato il legislatore per la durata massima in caso di persona giuridica.
} 
misura del 5\% del valore del bene, mentre il valore della nuda proprietà è calcolato come differenza fra il valore della piena proprietà e il valore dell'usufrutto determinato come sopra, in modo che valga sempre l'eguaglianza:

$($ valore nuda proprietà $)+($ valore usufrutto $)=($ valore piena proprietà $)$

Premesso il quadro normativo di riferimento dell'usufrutto, è ora possibile espletare un tentativo di esaminare le modalità della sua applicazione nell'ambito della pianificazione e della successione dell'impresa familiare e della sua continuità.

L'applicazione più concreta implica che l'imprenditore, generalmente titolare della totalità delle azioni dell'impresa di famiglia (eventualmente divisa con la moglie in misura paritetica o di minoranza, spesso simbolica), trasferisca la nuda proprietà della stessa ai figli (o, più raramente, agli eredi designati, in assenza o in alternativa ai figli). Ciò avviene spesso in età matura dell'imprenditore limitando così il valore della nuda proprietà e conseguentemente l'onere del trasferimento. Spesso esso avviene per donazione in quanto i figli (o gli eredi) non dispongono (o non possono dimostrare la disponibilità) del corrispettivo ${ }^{14}$. La soluzione, in sostanza, riduce l'imponibile di una semplice cessione di partecipazioni, assoggettandola ad una aliquota fissa, e in più mantiene una rendita in capo all'imprenditore, rilevante ai fini economici ed etici: infine la riunione dell'usufrutto alla nuda proprietà in capo al/ai nudo/i proprietario/i, alla morte dell'imprenditore, non sarà fiscalmente imponibile.

Le motivazioni economiche, che presentano notevoli connotazioni etiche $^{15}$, che spingono l'imprenditore a trattenere l'usufrutto sull'impresa di famiglia trasferendone la nuda proprietà ai figli/eredi, vanno ricercate nel desiderio per sé di un corrispettivo sempre meno inerente la gestione aziendale (che verosimilmente viene trasmessa i figli/eredi), simile ad una rendita vitalizia, libera da diritti patrimoniali quali il diritto di opzione, semplice sul piano applicativo, considerato che l'usufrutto è destinato a ricongiungersi automaticamente e gratuitamente alla nuda proprietà alla sua morte. In altre parole, l'usufrutto configura per l'imprenditore una sorta di compenso psicologico per una vita di lavoro, ma anche uno strumento che lo tiene ancora vivo e legato all'impresa di famiglia, dandogli potere di partecipare alle assemblee periodiche.

Si osserva comunque che la separazione della nuda proprietà dall'usufrutto per le azioni che formano il capitale sociale dell'impresa di famiglia

\footnotetext{
${ }^{14}$ In passato a ciò si poneva rimedio con la donazione ai figli (o agli eredi) di titoli di stato, esenti dall'imposta di donazione che, venduti dai donatari, fornivano il corrispettivo per l'acquisto della nuda proprietà dell'impresa di famiglia.

${ }^{15}$ Sull'argomento cfr. R. Passeri, Valutazioni imprenditoriali del processo di formazione dell'etica d'impresa, Cedam, Padova 2001.
} 
può costituire un ostacolo per la loro eventuale cessione a terzi; tuttavia solleva sicuramente un vincolo per la politica dei dividendi dell'impresa di famiglia. L'imprenditore-usufruttuario, infatti, attende solo la remunerazione della 'sua' impresa, ma la ridotta redditività, o l'opportunità finanziaria, o l'alto costo del denaro, potrebbero sconsigliare la distribuzione di dividendi ${ }^{16}$.

Inoltre, se le azioni che formano il capitale sociale dell'impresa di famiglia non sono detenute personalmente dall'imprenditore, ma da una sua società, trova applicazione quanto sopra precisato circa il valore fiscalmente rilevante del trasferimento della nuda proprietà (cessione e donazione).

Ulteriori applicazioni della separazione dell'usufrutto dalla nuda proprietà nelle azioni che formano il capitale sociale dell'impresa di famiglia sono preordinate a realizzare soluzioni di continuità aziendale, ad esempio attraverso la tutela del controllo societario, la stipulazione di alleanze, il contenimento dell'onerosità tributaria e la raccolta di risorse finanziarie a titolo di capitale proprio ${ }^{17}$. Sono tutte situazioni ove il controllo sull'impresa di famiglia rimane sempre in capo all'imprenditore per la disponibilità dei diritti di voto, per la sterilizzazione dei diritti di voto su azioni proprie, mentre essa ha beneficiato di un apporto di capitale di rischio in una fase in cui le sue esigenze finanziarie potevano non essere soddisfatte dall'imprenditore e/o altri canali di finanziamento erano preclusi.

\section{II recesso indotto}

Il recesso da una società consente ai soci di ottenere dalla società medesima il rimborso dei propri titoli, se si verificano alcuni presupposti tassativamente previsti dalla legge (art. 2437 e 2473 c.c. e art. 13 Legge 18 febbraio 1992, n. 149). La previsione del recesso nell'ambito della successione d'impresa va inquadrata come una ulteriore possibile soluzione di mobilità dei titoli dell'impresa di famiglia in preparazione dell'evento successorio, evitando destinazioni di titoli sociali non funzionali alla continuità dell'impresa di famiglia. Chiaramente per i nostri fini, tale recesso deve essere 'provocato', cioè indotto dalla maggioranza, utilizzando i casi espressamente previsti.

Per quanto riguarda il prezzo è previsto un inderogabile livello del corrispettivo che la società dovrà versare ai soci dissenzienti, che risulta essere:

- «il prezzo medio dell'ultimo semestre» se le azioni «sono quotate in Borsa»;

\footnotetext{
${ }^{16}$ In qualche caso si è fatto ricorso alle azioni privilegiate (naturalmente nella misura massima del $50 \%$ del capitale sociale, come prescritto dall'art. 2351 c.c.) che hanno permesso la distribuzione di un dividendo significativo, ancorché limitato a quella categoria di azioni.

${ }^{17}$ Jovenitti, Strategie mobiliari, cit.
} 
- «in base alla consistenza patrimoniale» se non si tratta di titoli quotati.

Questa previsione dovrebbe perciò trovare applicazione, sia per le quote delle Srl, sia per le azioni di società quotate per le quali però non sia stata chiesta la quotazione.

L'art. 2437-ter c.c. stabilisce che il valore di liquidazione delle azioni è comunque determinato dagli amministratori, sentito il Collegio Sindacale e l'organo Revisore. Anche questa norma solleva problemi interpretativi in relazione alla data della sua applicazione rispetto ai termini di «consistenza patrimoniale e/o di ultimo esercizio», nel senso che il documento contabile di riferimento potrebbe risultare obsoleto. Inoltre non è fornita la nozione di «patrimonio sociale» e anche ciò lascia spazio a dubbi interpretativi: infatti, se in questa sede non sono rilevanti gli «utili distribuibili» e le «riserve disponibili» che, anzi, concorrono certamente a formare il «patrimonio sociale», non è sicuro se si debba tenere conto dei dividendi da prelevare dall'utile di esercizio per la distribuzione. Sembra invece certo che non si debba far ricorso né ad un documento contabile diverso dal bilancio di esercizio, ancorché redatto in base ai medesimi criteri, come la relazione semestrale, né al bilancio consolidato, in caso di recesso da una holding.

Il ricorso alla nozione di «consistenza patrimoniale» sembra escludere perciò il riferimento al patrimonio netto rettificato, al reddito, all'avviamento e al risultato di esercizio in corso di formazione, evidenziando una disparità di trattamento rispetto al titoli quotati.

E importante ricordare che non si tratta di una cessione di titoli dai soci dissenzienti alla società, ma di un recesso che dà perciò luogo ad un rimborso. Questo viene effettuato ad un corrispettivo che non ha natura di prezzo, con la conseguenza che non trova applicazione nella fattispecie la disciplina fiscale in materia di tassazione delle plusvalenze (capital gain), ma l'operazione è fiscalmente neutra ${ }^{18}$.

Rimane un problema di fondo del recesso provocato, che risiede nella sua credibilità e nel rischio di essere considerata una operazione potenzialmente elusiva sotto il profilo tributario. Per questi motivi, si assiste generalmente all'adozione delle due delibere sopra indicate non in modo isolato, ma in concomitanza con altre delibere assembleari finalizzate a realizzare una più ampia modificazione aziendale, e al supporto di analitiche e circostanziate relazioni accompagnatorie del Consiglio di amministrazione.

\footnotetext{
${ }^{18}$ Occorre fare attenzione che, in realtà, la neutralità fiscale è parziale quando il rimborso del capitale sociale e delle riserve non si riferisca anche a riserve in sospensione d'imposta: in quest'ultimo caso l'utilizzo delle riserve esige il preliminare pagamento delle imposte in sospensione.
} 


\section{La donazione}

Un aspetto particolare della successione imprenditoriale in azienda riguarda la possibilità che quest'ultima possa essere donata dal disponente-imprenditore ai propri eredi naturali o anche ad altri. Da un punto di vista civilistico, occorre ricordarsi che le donazioni sono revocabili da chi vi abbia diritto, come ad esempio i figli naturali (artt. 803-804 c.c.). Da un punto di vista fiscale, solo di recente la questione si è chiarita, accertando che l'azienda che 'transiti' da un soggetto ad un altro a titolo gratuito non genera plusvalenze tassabili ${ }^{19}$.

Infatti, se analizziamo il primo comma dell'art. 58 del TUIR, si evidenzia che il trasferimento di aziende, per causa di morte o per atto gratuito a familiari, non costituisce realizzo di plusvalenze dell'azienda stessa se l'azienda è assunta ai medesimi valori fiscalmente riconosciuti nei confronti del dante causa ${ }^{20}$.

Con la C.M. 137/1997 sono stati forniti chiarimenti in materia di imposte sui redditi, IVA, imposta di registro, Ici e in particolare si chiarisce che la norma agevolativa, per quanto riguarda i trasferimenti di azienda a familiari, si applica esclusivamente all'ipotesi di donazione e non di successione. In tale ultimo caso, la neutralità fiscale sussiste, infatti, anche qualora il trasferimento di azienda avvenga a favore di soggetti diversi dai familiari ${ }^{21}$.

Siamo arrivati poi all'art. 16, c. 2 L. 383/2001 che ha stabilito, come già detto, che, in caso di trasferimento a titolo di successione per causa di morte o di donazione dell'azienda o del ramo di azienda, con prosecuzione dell'attività d'impresa, i beni e le attività cedute sono assunti ai medesimi valori fiscalmente riconosciuti nei confronti del dante causa.

A tale riguardo poi la C.M. 91/E/2001 ha precisato che tale disposizione amplia la previsione normativa già contenuta nell'art. 58 c. 1 TUIR, al fine di stabilire il regime agevolativo delle plusvalenze patrimoniali in caso di trasferimento, a titolo di successione o per donazione dell'azienda, nell'ipotesi di prosecuzione dell'attività dell'impresa.

In questo caso, a prescindere dal grado di parentela con il beneficiario, è stabilito che il trasferimento, ancorché riferibile ad un atto di liberalità,

\footnotetext{
${ }^{19}$ Sull'argomento cfr. G. Gavelli, Più spazio alla neutralità fiscale nei passaggi gratuiti d'azienda, «Il Fisco», 42, 2002, pp. 6657 e ss.

${ }^{20} \mathrm{Si}$ noti che per effetto dell'art. 67 c.1 lett. h-bis TUIR, in caso di successiva cessione, anche parziale, delle aziende acquisite ai sensi del menzionato art. 58 c. 1 TUIR, è previsto che le plusvalenze realizzate costituiscano redditi diversi.

${ }^{21}$ La norma agevolativa trova applicazione anche in caso di una pluralità di familiari, considerato che nel testo legislativo non è posta alcuna limitazione in riferimento al numero dei beneficiari che, nel proseguire l'attività del donante, danno vita, tra loro, ad una società di fatto. Inoltre, con la stessa citata circolare è stato precisato che qualora i donatari intendano regolarizzare la società di fatto tra loro costituitasi, avente per oggetto attività commerciale, in una delle società tipiche regolate dal Codice civile, si rende applicabile la disposizione prevista dall'art. 122, concernente la trasformazione delle società.
} 
non abbia effetti realizzativi ed i beni si trasferiscano al beneficiario, che prosegue l'attività, in regime di neutralità fiscale ai fini delle imposte sui redditi, senza, quindi, emersione di plusvalenze o minusvalenze fiscalmente rilevanti.

Si precisa poi che se la donazione è effettuata nei riguardi di un soggetto diverso dai familiari, la disposizione agevolativa di cui all'art. 58 c. 1 TUIR si applica per effetto dell'art. 16 L. 383/2001, a condizione che il donatario continui nell'esercizio dell'attività economica.

Si osserva infine che il trasferimento è soggetto all'imposta di registro sulla parte di valore della quota spettante a ciascun beneficiario che supera l'importo di esenzione. Riteniamo pertanto che anche questo tipo di operazione possa rappresentare un valido strumento per la successione imprenditoriale. 



\section{Bibliografia}

Abate F., Dimundo A., Lambertini L., Panzani L., Patti A., Gruppi, trasformazione, fusione e scissione, scioglimento e liquidazione, società estere (artt. 2484-2510 c.c.), Giuffrè, Milano 2003.

Allegra A. et al., Continuità e ricambio generazionale nell'impresa, Giuffrè, Milano 1995.

Barca F., Allocazione e riallocazione della proprietà e del controllo delle imprese, «Banca d'Italia», 194, 1993.

Barca F. et al., Assetti proprietari e mercato delle imprese, I, Proprietà, modelli di controllo e riallocazione nelle imprese industriali italiane, Il Mulino, Bologna 1994.

Bauer M., Tra impresa e famiglia. Trasmissione e successione nelle piccole e medie imprese, NIS Roma 1997.

Bertella V., La pianificazione del ricambio generazionale nell'impresa familiare, Cedam, Padova 1995.

Camuffo A., Costa G., Strategia d'impresa e gestione delle risorse umane, Cedam, Padova 1990.

Ciambotti M., I processi di transizione imprenditoriale nelle imprese familiari di minore dimensione, «Piccola Impresa», 1, 1991.

Ciappei C., La governance nell'impresa familiare, in Neri A., Frangioni A. (a cura di), Successione imprenditoriale e continuità di impresa, ApiFinser, Livorno, 2001.

Coase R.H., The nature of firm, «Economica», 4, 1937.

Corbetta G., Gnan L., Montemerlo D., Indagine sulle piccole e medie imprese secondo il modello di indagine MassMutual, Rapporto di ricerca, SDA Bocconi, Milano 1997.

Corbetta G., Le imprese familiari: caratteri originali, varietà e condizioni di sviluppo, Egea, Milano 1995.

Corsi F., Le nuove società di capitali, Giuffrè, Milano 2003.

D'Alessio G., Diffusione della proprietà delle imprese fra le famiglie italiane e trasferimento intergenerazionale: alcune evidenze, «Banca d'Italia», 241, 1994. 
De Rosa L., Lo sviluppo economico dell'Italia dal dopoguerra a oggi, Laterza, Bari 1997.

Demattè C., Corbetta G. (a cura di), I processi di transizione delle imprese familiari, Mediocredito Lombardo, Milano 1993.

Dessy A., Vender J. (a cura di), Capitale di rischio e sviluppo dell'impresa, Egea, Milano 1996.

Di Vittorio A., Evoluzione e funzione dell'impresa familiare, Giappichelli, Torino 2000.

Fabbrini A., Micucci G., Le imprese italiane di fronte al ricambio generazionale, in atti della XXIII Conferenza Italiana di Scienze Regionali, AISRE (Reggio Calabria, ottobre 2002), cd-rom.

Favotto F., Gubitta P. et al., Imprese al bivio. Investire nella successione imprenditoriale come vantaggio competitivo, Rapporto di ricerca (Gruppo Giovani Imprenditori di Unindustria Padova e Facoltà di Economia di Padova), Padova 2002.

Fazzi R., Comportamenti imprenditoriali e modelli di decisione negli studi di tecnica economica, Le Monnier, Firenze 1960.

Fazzi R., Il governo d'impresa, vol. I, Giuffrè, Milano 1982.

Ferrero G., Impresa e Management, Giuffrè, Milano 1987.

Fumagalli L., Il trust, in Gli enti non profit in Italia, a cura di G. Ponzanelli, Cedam, Padova 1994.

Galgano F., Il nuovo diritto societario, Cedam, Padova 2003.

Guatri L., La teoria di creazione del valore. Una via europea, Egea, Milano 1991.

Guatri L., Massari M., La diffusione del valore, Egea, Milano 1992.

Guatri L., Vicari S., Sistemi d'impresa e capitalismi a confronto. Creazione di valore in diversi contesti, Egea, Milano 1994.

«L'imprenditore. Piccola Industria. Confindustria», speciale Passaggio generazionale per la continuità dell'impresa, settembre 2007.

Gavelli G., Più spazio alla neutralità fiscale nei passaggi gratuiti d'azienda, «Il Fisco», 42, 2002.

ISTUD, La successione imprenditoriale nelle PMI lombarde, Ricerca ADAPT, Milano 1998.

Jovenitti P., Strategie mobiliari per la continuità e la successione d'impresa, Egea, Milano 1998.

Lansberg S.L., La gestione delle risorse umane nelle imprese familiari: il problema della sovrapposizione istituzionale, «Problemi di gestione», XV, 1, 1984.

Lupoi M., Trusts, Giuffrè, Milano 2001².

Lupoi M., L'atto istitutivo di trust, Giuffrè, Milano 2005.

Manzone B., Trento S., Il trasferimento intergenerazionale delle Imprese, «Banca d'Italia», 205, 1993.

Mastroberardino P., Significato e ruolo dei clan familiari nel governo dell'impresa, Cedam, Padova 1996.

McGiven P., The dynamic of Management Decision, «Management Decision», 1, 1978. 
Montemerlo D., Il governo delle imprese familiari, Egea, Milano 2000.

Neri A., Frangioni A. (a cura di), Successione imprenditoriale e continuità di impresa, ApiFinser, Livorno, 2001.

Northington M.W., Gestire la vostra impresa familiare. Come conciliare legami di parentela e affari. Una guida per il successo, Franco Angeli, Milano 1995.

Paci A., Assetti proprietari e governo d'impresa: il management buy-out, Tipografia Pistoiese, Pistoia 1990

Passeri R., Valutazioni imprenditoriali in merito all'operazione di scissione con riferimento al caso italiano, Cedam, Padova 1995.

Passeri R., Valutazioni imprenditoriali del processo di formazione dell'etica d'impresa, Cedam, Padova 2001.

Peghin F., La successione imprenditoriale, in Imprese al bivio. Investire nella successione imprenditoriale come vantaggio competitivo, Rapporto di ricerca (Gruppo Giovani Imprenditori di Unindustria Padova e Facoltà di Economia di Padova), Padova 2002.

Perrini F., Capitale di rischio e mercati per PMI. Metodologie e canali di accesso al capitale per lo sviluppo, Egea, Milano 1998.

Piantoni G., La successione familiare in azienda. Continuità dell'impresa e ricambio generazionale, Etaslibri, Milano 1990.

Ragusa Maggiore G., Trattato delle società, 2 voll., Cedam, Padova 2000-2004.

Schillaci C.E., I processi di transizione del potere imprenditoriale nelle imprese familiari, Giappichelli, Torino 1990.

Stocchetti G., L'utilizzo del sistema di controllo di gestione nel processo di successione generazionale in azienda, «Piccola Impresa», 2, 1998.

Tomaselli S., Longevità e sviluppo delle imprese familiari. Problemi, strategie e strutture di governo, Giuffrè, Milano 1996.

Valente A., Passaggio del testimone: gestire con efficacia la successione, <URL: www. euromedfinanza.it/Servizi/Informazione/Schede/Passaggio_generazionale/ 01Gestire_la_successione.htm>.

Vallini C., Fondamenti di governo e di direzione d'impresa, Giappichelli, Torino 1990.

Zattoni A., Economia e governo dei gruppi aziendali, Egea, Milano 2000

Zitiello L., Il trust e gli istituti corrispondenti nell'ordinamento italiano, «Le Società», 8, 1995. 

In questo volume si affronta il tema della successione imprenditoriale nell'impresa familiare. Si tratta di un passaggio fondamentale, spesso decisivo per la sopravvivenza di questo particolare tipo di imprese, peraltro molto diffuso nel contesto economico italiano ed europeo. Emerge dunque con forza l'importanza di un'adeguata pianificazione e conoscenza delle alternative strategiche e operative ideali a realizzarla.

Dopo una ricognizione delle peculiarità delle imprese familiari, nel volume si affrontano problematiche tipiche dell'apertura della compagine sociale e della procedura successoria, in un'ottica imprenditoriale. Vengono quindi analizzati alcuni strumenti di pianificazione successoria e le principali operazioni ritenute utili al processo successorio-imprenditoriale.

RICCARDO PASSERI è professore straordinario di Economia e Gestione delle Imprese nella Facoltà di Economia dell'Università degli Studi di Firenze. Ė autore di pubblicazioni su vari temi inerenti il governo d'impresa. Con la Firenze University Press ha già pubblicato Procedure concorsuali e governo dellimpresa artigiana in Toscana (in collaborazione con L. Quagliotti e C. Simoni). 